\title{
AVALIAÇÃO DE AMBIENTES SERVIDORES PARA AGENTES MÓVEIS
}

STÊNIO FIRMINO PEREIRA FILHO

Orientador: Prof. Dr. Edson dos Santos Moreira

Dissertação apresentada ao Instituto de Ciências Matemáticas e de Computação -USP, como parte dos requisitos para a obtenção do título de Mestre em Ciências - Ârea de Ciências da Computação.

São Carlos - SP

2001 

Para Latife, Sérgio e Vitor, meus irmãos queridos! 



\section{Agradecimentos}

Este espaço é dedicado às pessoas que foram muito importantes para o desenvolvimento deste trabalho. Muitos contribuíram diretamente outros colaboraram da maneira que puderam. Neste período fiz muitos amigos e grande parte deles dificilmente reencontrarei. Então, fica aqui a minha homenagem a estas grandes pessoas, que sem elas, dificilmente eu finalizaria o trabalho.

Primeiramente gostaria de agradecer ao meu orientador prof. Edson Moreira, pela dedicação e paciência durantes estes longos 2 anos e 3 meses. Sempre pronto para atender. Seu incentivo nos momentos finais foi muito importante para mim. Ao invés de pressão, recebi palavras que me tranqüilizaram e me ajudaram a terminar o trabalho.

À minha grande família, os "Firmino Pereira" de Piumhi/MG e os "Braz Cota" de Formiga/MG. Vocês são e sempre serão as pessoas mais importantes em minha vida. Desculpem-me se não estive presente durante este meu período de mestrado, mas gostaria de lembrar-lhes que sempre estiveram em meus pensamentos.

Ao meu pai, o melhor do mundo, sempre presente, mesmo morando quase mil quilômetros de distância. Nunca conseguirei alcançar seu conhecimento e sua cultura. Você é o meu exemplo de vida. Sempre serei seu aluno.

À minha mãe, quando estávamos juntos, sempre cuidou bem de mim, com muito carinho e amor. Espero que aí no Céu você esteja tão feliz quanto eu estou aqui. Saudades...

Às minhas outras mães, Vó Dondoca, Tia Said, Silvania, este trabalho também é fruto do carinho que vocês têm me dado.

Ao Tio Paulo, meu padrinho. Iniciei minha carreira na informática com você no jornal. Espero poder retribuir tudo que fez por mim. 
À Gildete, minha noiva, seguiu meus caminhos e também se tornou uma analista de sistemas. Espero continuar sempre ao seu lado, ficando mais próximo de você. A sua compreensão e paciência tiveram um grande valor em minha jornada. Continue sendo esta companheira que você sempre foi.

Ao meu grande amigo Mauro. Você assumiu um papel importante durante o meu mestrado, foi o meu tutor. Nunca esperei isto de você. Sempre te achei um grande amigo, mas não tanto. Você sabe os problemas que eu tive e você me ajudou muito para superá-los. Sempre te agradecerei.

Ao Tomás, grande mano, moramos juntos durante estes dois anos. Nunca imaginei que aquele rapaz, que sentava no fundo da sala em Alfenas/MG, que ficava calado, que só percebia sua presença quando os professores falavam suas ótimas notas, fosse uma pessoa alegre e tão companheira.

Aos amigos do laboratório Intermídia, Tom, Chico, Dalton, Rudinas, Dani (espero que não goste da Alemanha e que volte para o Brasil), Bola, Taboca (cuidado com os earthquakes de Califórnia/USA), Gusfaria (meu levou para o mundo, e sem volta, dos Palms), Carbol, Richard e a muitos outros que fizeram dos momentos de tensão momentos descontraídos.

Aos amigos do laboratório Lasdpc, Edmilson, Omar, Márcio, Arion (olha o ônibus), pelos altos papos, dicas e pelas noites em claro no laboratório.

A Deus, pela minha vida, pelos meus amigos, pela minha família.

A todos os meus sinceros agradecimentos! 


\section{Sumário}

1. INTRODUÇÃO ................................................................................................................... 9

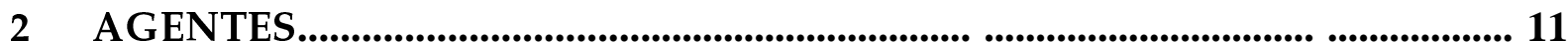

2.1 TAXONOMIA DOS AGENTES................................................................... 11

2.2 AGENTES MÓVEIS …………………………........................................ 14

2.3 SEGURANÇA DOS AGENTES.......................................................................... 16

2.3.1 Categorias de ameaças de segurança para agentes móveis.............................. 19

2.3.2 Taxonomia de Ataques............................................................................ 20

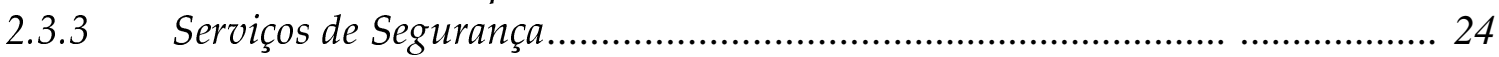

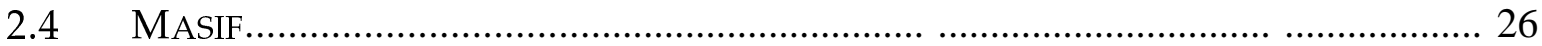

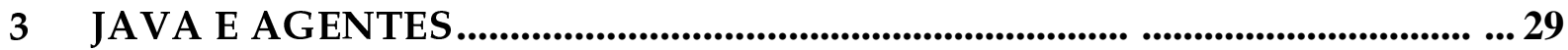

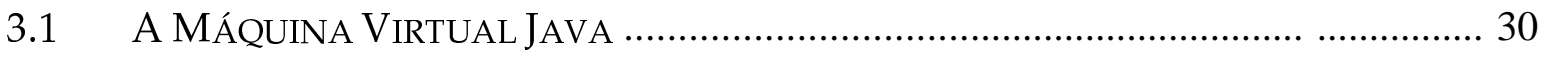

3.2 UM EXEMPLO DE PROGRAMA: HELLO WORLD! …………………..................... 31

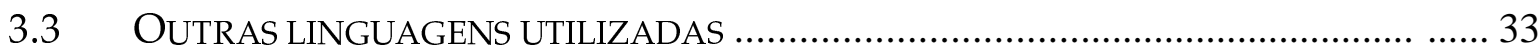

4 APLICAÇÕES DA TECNOLOGIA DE AGENTES MÓVEIS................................35

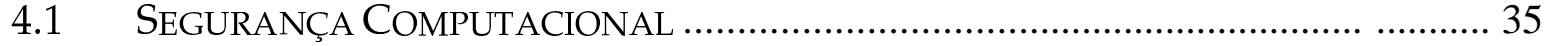

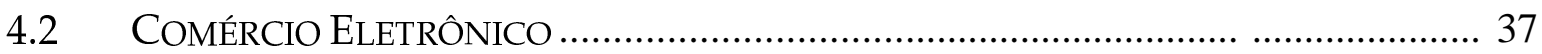

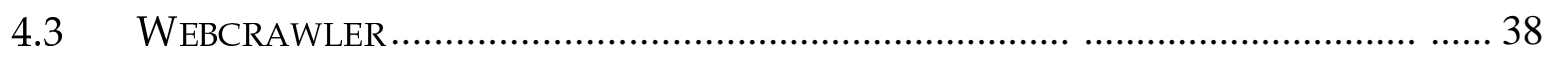

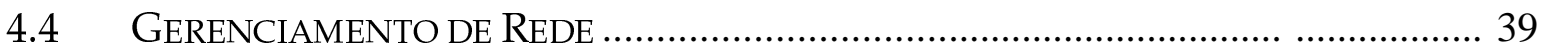

\section{SISTEMA DE DETECÇÃO DE INTRUSÃO BASEADO EM AGENTES} MÓVEIS ................................................................................................................................ 41

5.1 ARQUITETURA DO SISTEMA IMPLEMENTADO ................................................... 44

5.1.1 A Camada 1 - Agentes de Vigilância ........................................................... 46

5.1.2 A camada 2 - Agentes de Tomada de Decisão .............................................. 47

5.1.3 A camada 3 - Agentes de Notificação.......................................................... 49

5.1.4 A camada 4-Agentes de Reação ................................................................ . 50

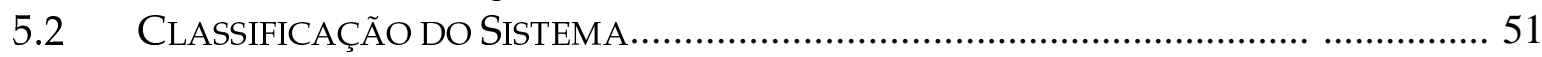

5.3 FALHAS DE SEGURANÇA …………………………………...................... 52

6 AMBIENTES SERVIDORES PARA AGENTES MÓVEIS.....................................57

6.1 Aglet Software DeVElopment Kit (IBM, 1998).......................................... 57

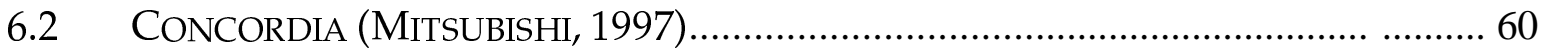

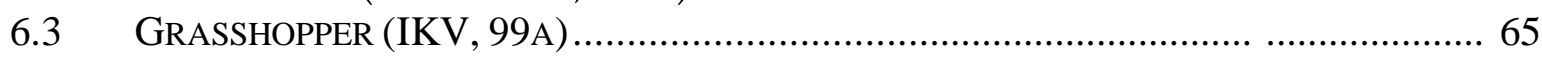

6.3.1 Sistema de Agentes (Agência) ................................................................... 67

6.3.2 Componente de Registro (Region Registry)............................................... 68

6.4 GOSSIP E TRYLLIAN AGENT TOOLKIT (TRYLLIAN, 99) .......................................... 68

6.5 CONSIDERAÇÕES FINAIS........................................................................... 71

7 ANÁLISES DE DESEMPENHO E SEGURANÇA.................................................... 73

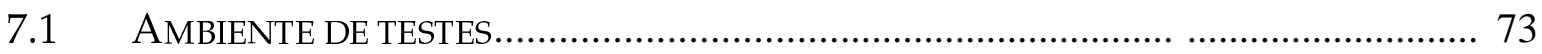

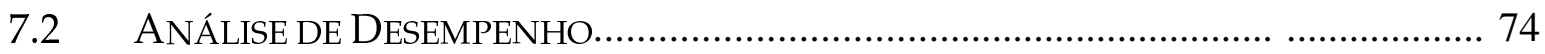

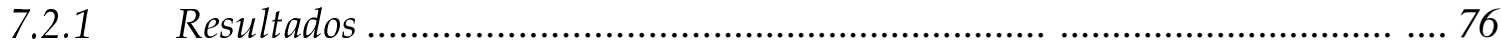

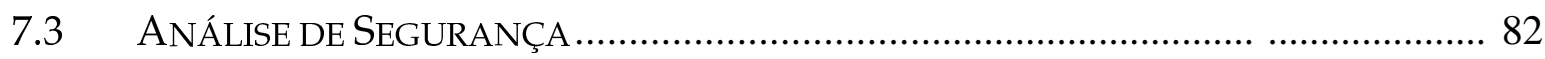

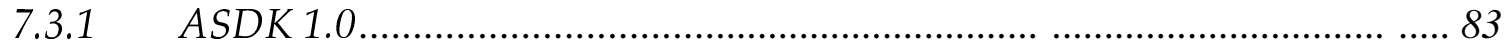

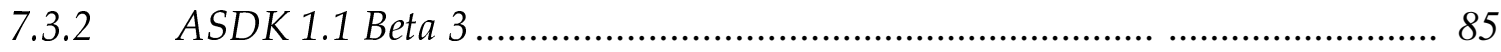

7.3.3 Concordia 1.1.6 Beta....................................................................... 86 


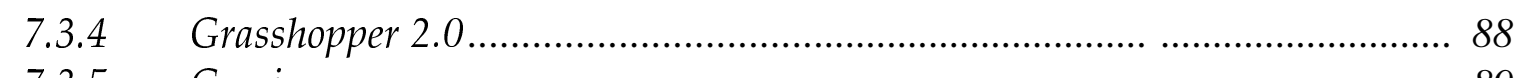

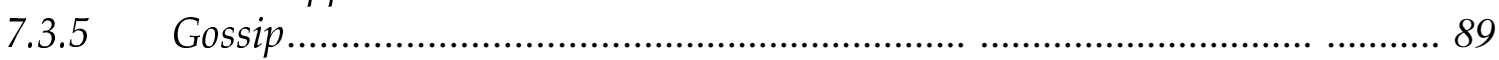

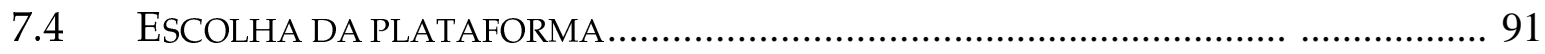

8 CONCLUSÕES E TRABALHOS FUTUROS............................................................ 95

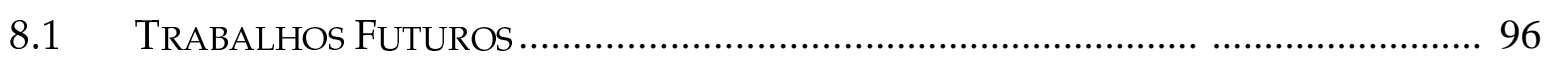

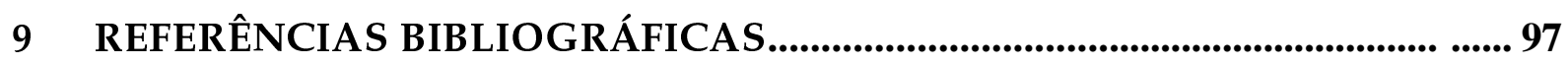




\section{Lista de figuras}

FIGURA 2.1 - ARQUITETURA DE UM SISTEMA DE AGENTES MÓVEIS ................................................. 17

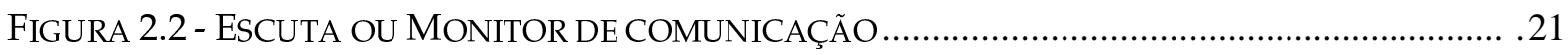

FIGURA 2.3 - DISFARCE DE AGENTE

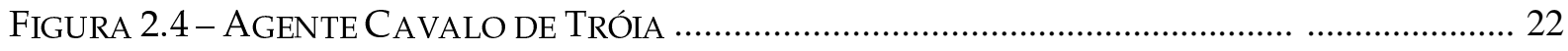

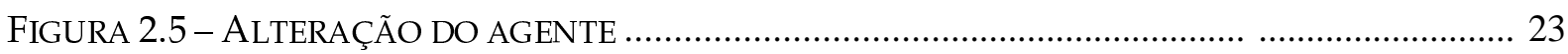

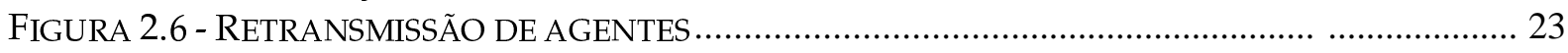

FIGURA 2.7 - REPRESENTAÇÃO DO OBJETIVO DO MASIF ......................................................... 27

FIGURA 3.1 - A MÁQUINA VIRTUAL JAVA SE SITUA ENTRE O SISTEMA OPERACIONAL E A APLICAÇÃO JAVA, PERMITINDO QUE UM SIMPLES EXECUTÁVEL RODE EM DIFERENTES

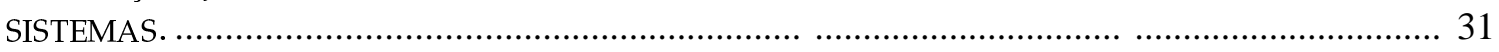

FIGURA 3.2 - RESULTADO DA EXECUÇÃO DO PROGRAMA HELLOWORLD. …................................. 32

FIGURA 4.1 - CENÁRIO DE COMÉRCIO ELETRÔNICO UTILIZANDO AGENTES MóvEIS ...................... 38

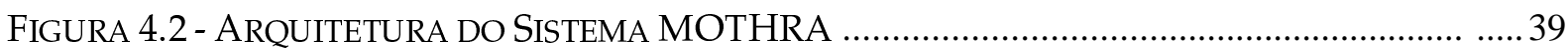

FIGURA 5.1 - MODELAGEM EM CAMAdAS PARA O SISTEMA PROPOSTO …................................. 45

FIGURA 5.2 - AGENTE COMPOSTO POR OBJETOS …................................................................. 53

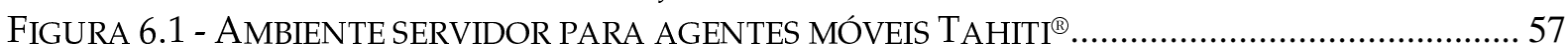

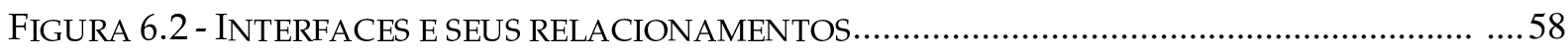

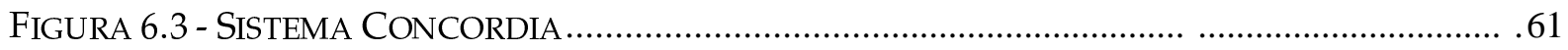

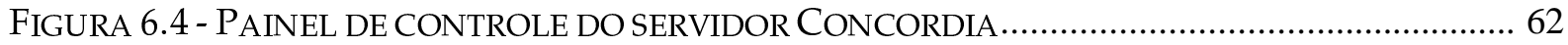

FIGURA 6.5 - INTERFACE GRÁFICA PARA GERENCIAMENTO DE AGENTES E AGÊNCIAS ...................66

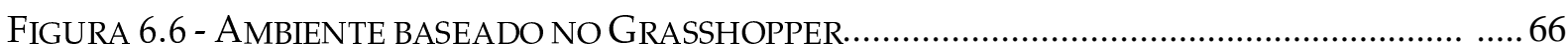

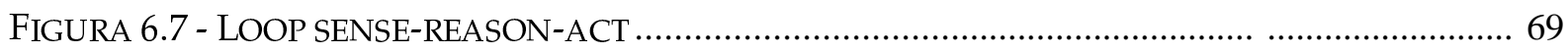

FIGURA 6.8 - ESTRUTURA EM CAMADAS DE UM AMBIENTE DE AGENTES …................................. 70

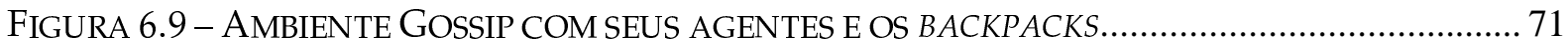

FIGURA 7.1 - DISPOSIÇÃO DAS MÁQUINAS UTILIZADAS NOS TESTES............................................. 74

FIGURA 7.2 - PROGRAMA UTILIZADO PARA CAPTURAR INFORMAÇÕES DE PROCESSAMENTO .........74

FIGURA 7.3 - CÓDIGO FONTE DA CLASSE DE MULTIPLICAÇÃO DE MATRIZES ................................75

FIGURA 7.4 - ALGORITMO BÁSICO DO AGENTE MULTIPLICADOR DE MATRIZES .............................76

FIGURA 7.5 - GRÁFICO DE UTILIZAÇÃO DO PROCESSADOR DO SERVIDOR TAHITI (ASDK 1.0).......78

FIGURA 7.6 - TEMPO, EM MILISEGUNDOS, DE 100 EXECUÇÕES DO AGENTE EM ASDK 1.0 .............78

FIGURA 7.7 - GRÁFICO DE UTILIZAÇÃO DO PROCESSADOR DO SERVIDOR TAHITI (ASDK 1.1) .......78

FIGURA 7.8 -TEMPO, EM MILISEGUNDOS, DE 100 EXECUÇÕES DO AGENTE EM ASDK 1.1 ...............79

FIGURA 7.9 - GRÁFICO DE UTILIZAÇÃO DO PROCESSADOR DO CONCORDIA SERVER......................79

FIGURA 7.10 -TEMPO, EM MILISEGUNDOS, DE 100 EXECUÇÕES DO AGENTE EM CONCORDIA..........79

FIGURA 7.11 - GRÁFICO DE UTILIZAÇÃO DO PROCESSADOR DO SERVIDOR GRASSHOPPER .............80

FIGURA 7.12 - TEMPO, EM MILISEGUNDOS, DE 100 EXECUÇÕES DO AGENTE EM GRASSHOPER........80

FIGURA 7.13 - GRÁFICO DE UTILIZAÇÃO DO PROCESSADOR DO SERVIDOR GOSSIP ........................81

FIGURA 7.14 - GRÁFICO GERAL DA TAXA DE UTILIZAÇÃO DE PROCESSAMENTO ….......................81

FIGURA 7.15 - GRÁFICO GERAL DOS RESULTADOS DE TESTE DE DESEMPENHO DOS AGENTES ........82

FIGURA 7.16 - FIGURA DEMONSTRATIVA DOS SERVIÇOS DE SEGURANÇA OFERECIDOS PELAS

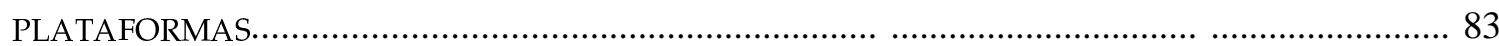


Agentes móveis são programas que podem ser disparados de um computador (cliente) e transmitidos através de uma rede de comunicação para uma outra maquina (servidor) com o objetivo de executar tarefas a eles designadas. Esta dissertação apresenta uma avaliação de plataformas de desenvolvimento e servidores para agentes móveis. A tecnologia de agentes móveis tem sido alvo de grandes pesquisas, inclusive nos setores de Segurança da Informação e Comércio Eletrônico. Foram executados testes e com as informações foi feita uma análise comparativa, levando-se em consideração questões como características de desempenho dos agentes, desempenho e segurança. Para efetuar os testes foram necessários o entendimento do funcionamento do servidor e o desenvolvimento de seus agentes. Os testes de desempenho serviram para definir quais agentes são mais ágeis e quais são os gastos de processamento dos servidores. Já o teste de segurança teve a finalidade de classificar os servidores quanto à segurança. Os resultados obtidos serviram para indicar qual a melhor plataforma a ser utilizada no desenvolvimento do Sistema de Detecção de Intrusão (SDI) do ICMC. As plataformas que obtiveram destaques nos testes foram o ASDK 1.1 e Grasshopper. A plataforma escolhida para o SDI foi o ASDK 1.1. 


\section{Abstract}

Mobile agents are programs able to migrate from a client computer to a server computer through communication networks. There are several mobile agent technologis application, includind Information Security and Eletronic Commerce. This work describes the valuation of mobile agent plataforms. A test environment was desired and 5 plataforms were compared in terms of the security and performance provided. To make the assessment it was necessary to understand the server functionality an the methodologies to develop the agents. The test of performace helped to define which agents are more agile and what are their processing needs while in the server. The security test aimed to classify the servers in them security. The results were used to determine which is better mobile agente plataform to be used in the on going ICMC's Intrusion Detection System (IDS). The best performance plataforms were the ASDK 1.1 and the Grasshopper. The chosen plataform for the IDS was the ASDK 1.1. 


\section{Introdução}

O impulso dado pela Internet para a disseminação de sistemas empresariais como Comércio Eletrônico e o seu alcance em proporções globalizadas, fez nascer a necessidade de tecnologias independentes de plataformas que viabilizem toda a infra-estrutura na transação entre usuário e empresa. Entre essas tecnologias, a que vem se destacando é a tecnologia de agentes móveis. Isso se deve principalmente ao fato de que ela apresenta características como reatividade, delegação de tarefas e execução assíncrona, além de minimizar o overhead na rede, possuir grande flexibilidade e tolerância à falhas.

Entretanto, a utilização da tecnologia de agentes móveis sem levar em consideração aspectos de segurança computacional pode acarretar em grandes catástrofes, o que poderia desmotivar sua utilização.

Agentes Móveis são programas que podem ser disparados de um computador (cliente) a fim de serem executados remotamente em outro (servidor). A tecnologia de agentes móveis tem sido alvo de diversas pesquisas, principalmente nos setores de Segurança Computacional (Reami, 1998) (Bernardes, 1999) (Bernardes \& Moreira, 2000a) (Bernardes \& Moreira, 2000b), Comércio Eletrônico (Rodriguez, 1998) e Gerenciamento de Redes (Rubinstein \& Duarte, 1999).

Desde 1990, diversos trabalhos nas áreas de gerenciamento e de segurança de redes foram realizados pelo Grupo de Segurança da Informação do Laboratório Intermídia do Instituto de Ciências Matemáticas e de Computação da USP de São Carlos, SP. Um dos trabalhos desenvolvidos constitui-se na especificação e implementação de agentes móveis específicos com habilidades de segurança computacional (Bernardes, 1999) (Bernardes \& Moreira, 2000a) (Bernardes \& Moreira, 2000b). Estes agentes foram desenvolvidos utilizando-se o Aglets Software Development Kit (ASDK), que é um conjunto de ferramentas empregadas na programação de agentes móveis em Java e um ambiente de hospedagem (servidor de agentes) denominado Tahiti, sendo ambos desenvolvidos pela IBM. 
No grupo ainda existem dois outros trabalhos em desenvolvimento que irão utilizarse do ambiente da IBM. As propostas de trabalho consistem em pesquisar alternativas de implementação de reconhecimento de padrões para agentes móveis em ambiente de segurança computacional e na criação de agentes móveis de captura de pacotes (sniffers) que poderão ser utilizados na implementação dos cenários propostos por Bernardes (Bernardes \& Moreira, 2000a).

Assim como o ASDK, existem diversos outros ambientes como: o Concordia da Mitsubishi; o Gossip da Tryllian; Grasshopper, IKV++, etc. Com destaque ao Grasshopper que é o primeiro ambiente comercial para desenvolvimento de aplicações baseado em agentes móveis seguindo a padronização MASIF (Mobile Agent System Interoperability Facility) apresentada pela OMG em 1998. Desta forma, uma avaliação de plataformas de agentes móveis torna-se necessária para que se consiga identificar quais podem oferecer melhores resultados no desenvolvimento e utilização dos sistemas baseados na tecnologia. A segurança e o desempenho são importantes para boa parte de sistemas onde a confidencialidade e o baixo tempo de resposta é necessário.

Esta dissertação está organizada da seguinte maneira: No Capítulo 2 tem-se uma revisão dos conceitos de agentes móveis, um resumo sobre a segurança dos agentes e sobre o padrão MASIF.

No Capítulo 3 são apresentadas características da linguagem Java que motivaram a sua utilização no desenvolvimento dos agentes e também são citadas outras linguagens utilizadas para o mesmo fim.

Já no Capítulo 4, têm-se alguns exemplos de aplicações que utilizam a tecnologia de agentes móveis. No Capítulo 5 é apresentado o SDI especificado por (Bernardes, 1999) e no Capítulo 6 são apresentados resumidamente alguns ambientes que serão avaliados e comparados no Capítulo 7. A conclusão e considerações finais, além dos trabalhos futuros, estarão no Capítulo 8. 


\section{Agentes}

Existem várias definições de agentes e este problema deve-se, em parte, à falta de coordenação entre as diversas pesquisas paralelas que foram feitas ao longo dos anos. Por outro lado, o termo agente não é propriedade dos pesquisadores da área, sendo usado diariamente no mundo real (agente de viagem, agente econômico, agente de seguros, etc.) (Bernardes, 1999).

Segundo o dicionário da língua portuguesa Silveira Bueno, o termo agente pode ser definido como "aquele que trata de negócios por conta alheia" (Bueno, 1987).

Em termos gerais, em computação, um agente pode ser definido como um software capaz de executar uma tarefa complexa em nome de um usuário.

Franklin e Graesser (Franklin \& Graesser, 1996) apresentam um conjunto de propriedades que auxiliam na classificação dos agentes. Segundo eles, agente reativo é aquele que responde conforme as mudanças no ambiente. $\mathrm{O}$ autônomo exerce controle sobre suas próprias ações, o orientado a metas ou com propósito pró-ativo é aquele que não age simplesmente em função do ambiente. Quando se tem um processo executado continuamente é classificado como contínuo. Comunicativo ou socialmente capaz são agentes capazes de comunicar-se com outros agentes e possivelmente com humanos. $\mathrm{O}$ agente inteligente ou adaptável muda seu

comportamento com base na sua experiência anterior. Agente móvel é o agente capaz de se mover de uma máquina para outra. Já o flexível é aquele que suas ações não são definidas através de scripts e os agentes que possuem caráter são aqueles que possuem personalidade e "estado emocional".

\subsection{Taxonomia dos Agentes}

Esta seção apresenta uma tentativa de classificar variados tipos de agentes existentes em diferentes classes, através de organização da taxonomia de agentes. Uma taxonomia refere-se ao estudo dos tipos de uma entidade. Nwana (Nwana, 1996) apresenta várias dimensões para classificar os agentes existentes. 
Primeiramente, agentes podem ser classificados por sua mobilidade, ou seja, por sua habilidade de se mover através da rede de computadores. Desta forma, os agentes podem ser estáticos ou móveis.

A segunda dimensão refere-se ao modo de funcionamento deliberativo ou reativo do agente. Um agente deliberativo possui um modelo de raciocínio simbólico interno, que permite que ele planeje e negocie tarefas com outros agentes de modo a coordenar a execução. Agentes reativos, por outro lado, apresentam um comportamento do tipo estímulo/resposta, ou seja, o agente responde ao estado atual do ambiente no qual ele está imerso, não possuindo o modelo de raciocínio simbólico.

A terceira dimensão envolve classificação de acordo com as diversas propriedades ideais e fundamentais que um agente deveria apresentar. Em seu trabalho, Nwana cita uma lista de três propriedades: autonomia, aprendizagem e cooperação.

A quarta dimensão é relacionada com o papel assumido pelo agente na aplicação, por exemplo, agentes de informação para WWW.

A quinta dimensão é a categoria dos agentes híbridos, que combinam duas ou mais das outras dimensões citadas em um único agente.

Em sua apresentação no mundo real e nas pesquisas, os agentes podem aparecer em várias das dimensões descritas anteriormente. Em seu trabalho, Nwana reduz a combinação dessas várias dimensões, que não seriam possíveis de representação gráfica simples, a uma lista arbitrária, mas que cobre a maioria dos tipos de agentes em investigação atualmente. Desta forma, Nwana identifica sete tipos de agentes:

- Agentes colaboradores - enfatizam autonomia e cooperação com outros agentes para executar tarefas para seus donos. Exemplos desses agentes, incluem agentes baseados no paradigma crenças-desejos-intenções sugerido por muitos autores da área de inteligência artificial distribuída; 
- Agentes de interface - enfatizam autonomia e aprendizagem e a metáfora chave que dá suporte a esses agentes é do assistente pessoal que colabora com o usuário em um mesmo ambiente de trabalho. O objetivo principal é migrar da manipulação direta da interface pelo usuário para a delegação de tarefas aos agentes de interface o que facilitaria a utilização por usuários novatos, uma vez que muitas tarefas são muito complexas ou trabalhosas e exigem treinamento intensivo para sua execução correta;

- Agentes móveis - são processos capazes de "vagar" através de redes de comunicação, interagindo com máquinas, coletando informações e retornando após executar os deveres ajustados pelo usuário. Apesar de mobilidade não ser uma condição, nem necessária, nem suficiente para o conceito de agente, os agentes móveis apresentam uma série de vantagens sobre os similares estáticos, por exemplo: redução dos custos de comunicação, independência da limitação imposta pelo uso de recursos locais, coordenação mais fácil, computação assíncrona, ambiente de desenvolvimento natural para serviços de comércio, arquitetura flexível para computação distribuída e fornecem uma nova abordagem atrativa e radicalmente diferente para o processo de projeto de aplicações (Bernardes, 1999);

- Agentes de informação - têm o papel de gerenciar, manipular e ordenar informações oriundas de várias fontes distribuídas. A necessidade para agentes deste tipo específico advém da quantidade enorme de informações disponíveis e que precisa ser pesquisada. Agentes deste tipo utilizam-se de outras tecnologias, tais como índices de busca on-line (Altavista, InfoSeek, Lycos, etc), para compilar informação sobre algum assunto requisitado pelo usuário e retornar o resultado ordenado para ele;

- Agentes reativos - representam uma categoria especial de agentes que não possuem nenhuma forma de representação simbólica interna dos seus ambientes e agem de acordo com o estado atual do ambiente em que estão imersos através de estímulos e respostas. Estes agentes normalmente são simples e se comunicam de maneiras básicas, no entanto, padrões de comportamento complexos emergem da interação entre os diversos agentes; são compostos por módulos autônomos com tarefas bem específicas e lidam 
com representações próximas do nível físico (dados de sensores) ao invés de representações simbólicas de alto nível. Algumas vantagens seriam robustez, flexibilidade e adaptação em contraposição à inflexibilidade, lentidão e fragilidade dos sistemas inteligentes baseados nas técnicas clássicas;

- Agentes híbridos - esses agentes baseiam-se na hipótese de que maiores benefícios resultam da utilização integrada das várias filosofias existentes. Por exemplo, um agente que implementa tanto o comportamento reativo, quanto o deliberativo, poderia apresentar respostas mais rápidas a mudanças no seu ambiente aplicando o comportamento reativo, enquanto outros problemas orientados a metas e que não exigem tal agilidade poderiam ser tratados pelo comportamento deliberativo;

- Agentes inteligentes - seriam agentes capazes de apresentar todas as características citadas possíveis de autonomia, aprendizagem e cooperação, mas que, na realidade, representam apenas aspiração dos pesquisadores atualmente.

É possível que se encontre sistemas que se utilizam dois ou mais desses tipos de agentes. Nwana refere-se a estas aplicações como sistemas de agentes heterogêneos.

\subsection{Agentes Móveis}

Agentes Móveis são agentes que possuem a capacidade de mover-se através da rede. Devem possuir habilidades para executar operações em qualquer máquina preparada para recebê-los dentro da rede, independente da plataforma utilizada, o que motiva a utilização da linguagem Java na implementação dos agentes móveis, no capítulo 3 são apresentadas as características da linguagem. Os agentes podem ser utilizados em redes heterogêneas.

Em modelos baseados em Agentes Móveis, um agente, que é enviado por um usuário, é responsável por realizar a tarefa desejada, sendo que o agente irá migrar para o servidor interagindo com ele localmente e em seguida retornar os resultados obtidos ao usuário (Oyamada \& Ito, 98). 
Um agente pode executar as tarefas a ele designadas mesmo com o host de origem desativado. Quando uma tarefa necessitar de um processamento pesado, o agente pode ser executado em outra máquina que tenha maior capacidade de processamento tornando-se uma ferramenta interessante para balanceamento de carga.

Os Agentes Móveis são constituídos de código, estado e atributos, onde o código de um agente móvel é o programa que define o seu comportamento, devendo, necessariamente, ser escrito em uma linguagem interpretada, independente de plataforma, permitindo assim, a mobilidade do agente. O estado do agente é utilizado para que ele possa retomar suas atividades a partir do ponto onde havia parado após se mover de um servidor para outro, pois o estado mantém guardado o ponto de execução e as variáveis necessárias para a realização das tarefas. Finalmente, os atributos que são utilizados para descrever o agente para os seus servidores, sendo que os eles incluem um identificador único de cada agente, um endereço para onde serão enviados resultados intermediários, mensagens de erro ou reclamações quanto ao mau comportamento de um agente, o tempo e a história do agente, além de impor limitações na mobilidade dos agentes, limites de domínios nos quais ele deve trafegar e limites de tempo de ação sob a forma de um prazo de expiração.

Os servidores de agentes têm que oferecer todo o suporte para os agentes realizarem suas tarefas, sendo que, para que isto ocorra, os agentes devem ser capazes de interagirem com os servidores, se comunicarem com outros agentes e mover-se através da rede. Uma outra função de extrema importância dos sistemas de agentes é a de garantir a segurança, tanto dos servidores quanto dos agentes neles hospedados.

Comunicação entre os agentes e servidores pode ser síncrona quando as partes envolvidas se encontram no tempo antes de iniciarem a transferência de dados propriamente dita. Este tipo de comunicação é adequado nas situações em que a transferência de dados necessita de confirmação urgente ou em diálogos interativos. 
Pode ser também assíncrona quando as diferentes partes não se encontram no tempo (Oyamada \& Ito, 98).

A segurança é um aspecto crítico no processo de execução de código móvel e em particular na execução de agentes móveis.

Em termos de organização, a arquitetura de um sistema de agentes (ou objetos) móveis é composta por quatro componentes:

- Host - um computador e sistema operacional, o ambiente computacional (AC);

- O sistema de execução (run-time system), sistemas de agentes (ou objetos) móveis;

- O conjunto de computações sendo executadas em um AC, e;

- A rede ou subsistema de comunicação que interliga os vários ACs rodando em hosts diferentes (Vitek et. al., 1997). A Figura 2.1 mostra a arquitetura de um sistema de agentes móveis.

Os componentes da arquitetura interagem uns com outros para implementar os comportamentos dos agentes e dependendo das permissões e restrições associadas a essas interações podem ocorrer problemas de segurança (Bernardes, 1999)

\subsection{Segurança dos agentes}

Um aspecto importante relacionado aos agentes e ao seu uso é a questão da segurança. Um vírus de computador pode ser caracterizado também como um agente, uma vez que ele possui pelo menos as quatro primeiras propriedades apresentadas no início deste capítulo e, principalmente, mobilidade. Pode ser correto dizer que se um agente é móvel, ele pode ser responsável por causar graves problemas de segurança.

Dessa forma, a questão da segurança relacionada aos agentes e, em especial, aos agentes móveis é de suma importância. 
Conforme observado em Reami (Reami, 1998) e em Bernardes (Bernardes, 1999) (Bernardes \& Moreira, 2000a), Sander e Tschudin (Sander \& Tschudin, 1998) fornecem um exemplo interessante do tipo de problema de segurança que pode ocorrer durante uma busca por preços de passagem feita por um agente de compras. Suponha que o objetivo programado pelo usuário seja visitar os servidores de várias empresas aéreas, encontrar um vôo disponível e, uma vez determinada a melhor oferta, agendar o vôo. Alguns ataques possíveis nesta situação são:

- Ao chegar em um servidor A (malicious host), o estado e código do agente são alterados de forma que ele esqueça os outros servidores já visitados e opte pela oferta do servidor A;

- Alterar o estado interno do agente e roubar toda moeda eletrônica que ele está levando;

- Agente resolve agendar o vôo e, portanto, precisa assinar digitalmente através de sua chave-privada: a chave-privada é roubada.

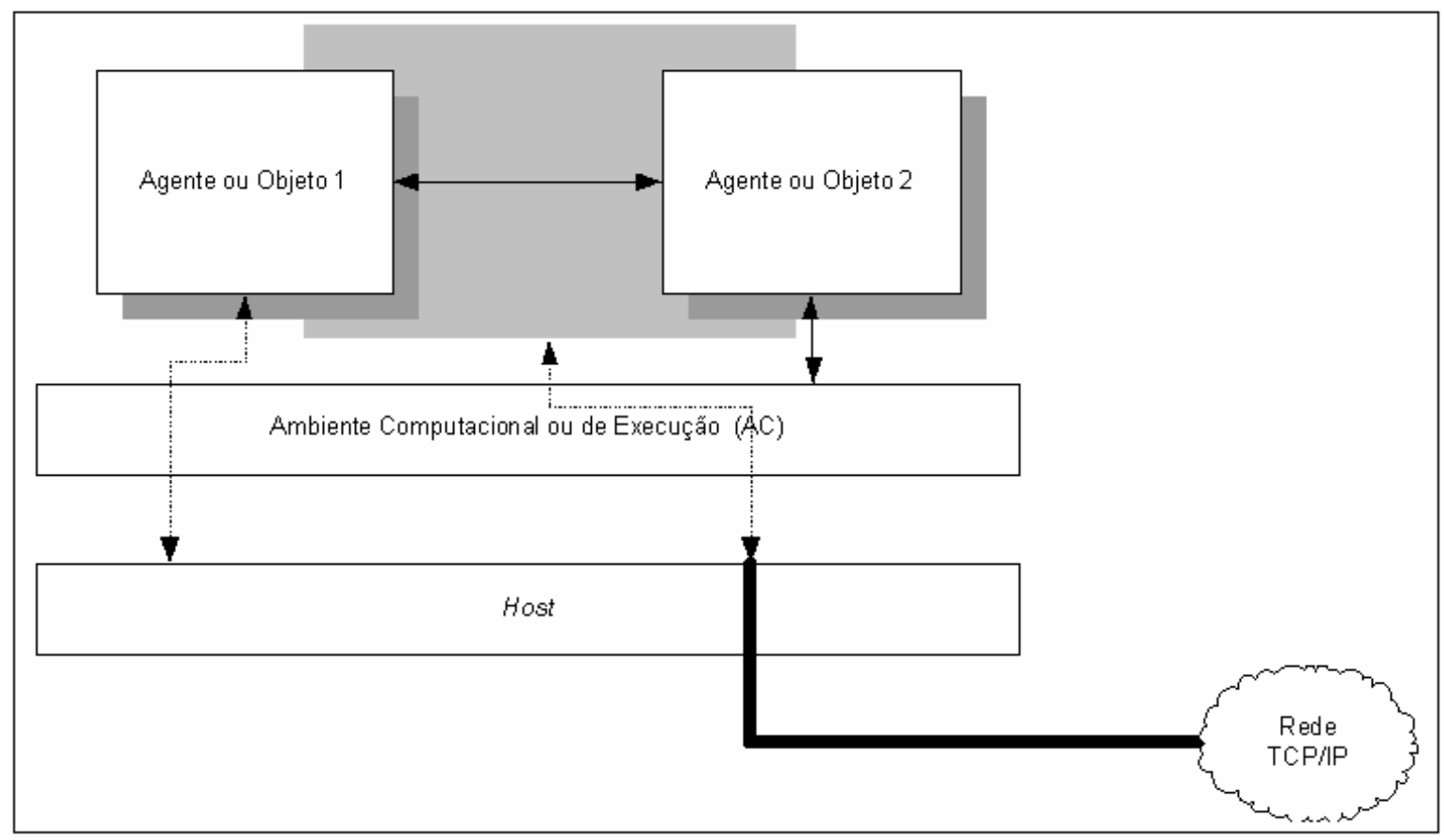

Figura 2.1 - Arquitetura de um sistema de agentes móveis

Observando a Figura 2.1, é possível verificar as diversas fronteiras em que ocorrem os problemas de segurança relacionados com os sistemas de agentes. Vitek, Serrano e Thanos (Vitek et. al, 1997) classificam aqueles problemas e propõe algumas soluções possíveis:

- Comunicação entre hosts e ACs precisa ser segura para prevenir a revelação de informações e a corrupção de dados e códigos; 
- Computações recebidas devem ser autenticadas e ter direitos de acesso garantidos, para que se saiba quem está executando a computação, quem deve ser cobrado, etc;

- Acesso aos recursos locais do host deve ser controlado;

- $\mathrm{O}$ AC deve ser protegido de computações possivelmente maliciosas (e viceversa), para se evitar que as computações passem por cima das regras de segurança do sistema;

- Os sistemas de objetos móveis devem ser protegidos uns dos outros, para prevenir a interrupção de uma computação por outra e para evitar que uma consiga informações privilegiadas da outra.

Os problemas mais preocupantes, no entanto, são: proteger um host de um agente mal intencionado e proteger um agente de um host mal intencionado. $\mathrm{O}$ primeiro problema pode ser tratado através de técnicas convencionais como listas de controle de acesso e autenticação. Por sua vez, é amplamente aceito que não existe uma solução que previna a ocorrência do segundo problema, a menos que haja hardware confiável e a prova de adulteração (Chess et. al., 1995). No entanto, vários autores estão trabalhando com a hipótese de que seja possível proteger agentes de hosts mal intencionados sem a necessidade daquele tipo de hardware (Bernardes, 1999).

Diversas pesquisas vêm sendo feitas com o intuito de criar ambientes de agentes que possam garantir um mínimo de segurança. No entanto, os maiores problemas localizam-se na tarefa de proteger os agentes da ação de máquinas mal-intencionadas (Vitek et. al, 1997).

Com a Internet, em particular a Web, se tornando cada vez mais popular e com o comércio eletrônico em ascensão, a segurança é sempre necessária. Com a segurança adequada estabelecida, as pessoas não se hesitarão em trocar informações confidenciais via Internet. De fato, a segurança é um dos fatores chave no progresso da tecnologia de agentes móveis (IBM, 1998). Como qualquer código executável, os agentes móveis são uma ameaça potencial ao sistema. Mas eles são também expostos às ameaças dos ambientes onde são hospedados. É uma situação atualmente não encontrada em sistemas de segurança tradicionais. Na ausência de um simples, mas 
compreensivo mecanismo de segurança de agentes, os usuários poderão não utilizar os agentes ou aceitá-los em seu computador.

\subsubsection{Categorias de ameaças de segurança para agentes móveis}

Suponha que é disparado um agente de reserva de passagens para uma agência. Quais são os riscos? Primeiro, o agente pode ser enganado. Como resultado, é possível que ele informe resultados inválidos; por exemplo, talvez o agente retorne que a reserva foi feita quando na realidade não foi. Um host hostil também pode roubar e utilizar as informações confidenciais do agente. Até mais repugnantes, alguns talvez enganam o agente ao ponto que ele chegue a danificar bases de dados do host remoto que está visitando. Nesse caso o agente "inocente" pode ser considerado responsável e barrado futuramente para utilizar os serviços no host.

Estes são precisamente alguns exemplos do que pode estar errado. Pode-se dividir as ameaças de segurança para agentes móveis nas seguintes categorias:

- Em relação à proteção do agente:

Hosts remotos hostis: Um agente está em um passeio e visita um host não confiável que pode tentar extrair suas informações privadas ou enganá-lo. Os tipos de ataques possíveis incluem falsificação, execução ilegal e acesso ilegal.

Agentes hostis: Um agente interage com outro agente na tentativa de extrair suas informações privadas e interromper sua execução. Um tipo de ataque possível é o acesso ilegal.

Fatores externos não autorizados: Uma entidade mal intencionada pode alterar mensagens enviadas entre hosts ou escutar a comunicação entre eles e desvendar o conteúdo do agente. Os tipos de ataque possíveis incluem alterações e a escuta de mensagens.

\section{- Em relação à proteção do host:}

Agentes hostis recebidos: Um agente visita um servidor tentando acessar ou corromper os arquivos do host ou interromper o servidor. Os tipos de ataque 
possíveis incluem acesso ilegal, disfarce, Cavalo de Tróia, recusa de serviços (DoS) e repudiação.

Fatores externos não autorizados: Uma entidade mal intencionada envia um grande número de agentes (spam) para o servidor para tirá-lo de serviço. Os tipos de ataque possíveis incluem recusa de serviços e retransmição.

- Em relação à proteção da rede:

Agentes hostis recebidos: Um agente se multiplica e se move intensivamente na tentativa de congestionar a rede com agentes. $\mathrm{O}$ ataque possível é a recusa de serviços.

Embora tais ameaças que envolvem relativamente novos assuntos de segurança, em se tratando de tecnologia de agentes móveis, utilizando-se da tecnologia de segurança existente pode-se resolver a maioria deles.

\subsubsection{Taxonomia de Ataques}

Nesta seção será introduzido alguns ataques possíveis a segurança relacionado à agentes móveis. Em geral, pode-se dividir os ataques aos agentes e seus hosts em duas categorias:

Ataques passivos que não modifica os agentes ou informações, e ataques ativos que atualmente fazem alguma coisa com os agentes. Nos ataques ativos pode-se detectar que alguma coisa aconteceu no agente, enquanto que não se pode dizer o mesmo nos ataques passivos.

\subsubsection{Ataques Passivos}

Os ataques passivos baseiam-se em ataques contra o sistema de comunicação dos agentes e na transferência de agentes em uma rede. Estes ataques são difíceis de serem detectados porque nenhuma mudança é feita no agente. Para se protegerem, os usuários de agentes poderiam utilizar uma criptografia. Os dois tipos de ataques passivos são: 
- Escuta. Este tipo de ataque normalmente usa um programa chamado de monitor de comunicação. Um monitor permanece observando as informações enviadas entre os sistemas de agentes, através da captura de agentes e mensagens que podem conter informações úteis (Figura 2.2). Geralmente, pode-se dizer que a informação é desvendada através da monitoração das comunicações.

- Análise do Tráfego. Pode parecer fácil prevenir escutas, basta utilizar agentes cifrados. Embora esta técnica possa, em muitos casos, ser suficiente, alguns ataques passivos ainda podem quebrá-la. Análise de Tráfego é uma variação do ataque de "Escuta" e permite ao agressor analisar os padrões dos agentes enviados entre os sistemas de agentes (como mudanças no fluxo do tráfego ou mudanças na freqüência de agentes enviados e recebidos), possivelmente permitindo-o fazer suposições baseadas nestes padrões, podendo, às vezes, ser eficaz mesmo se o conteúdo está cifrado.

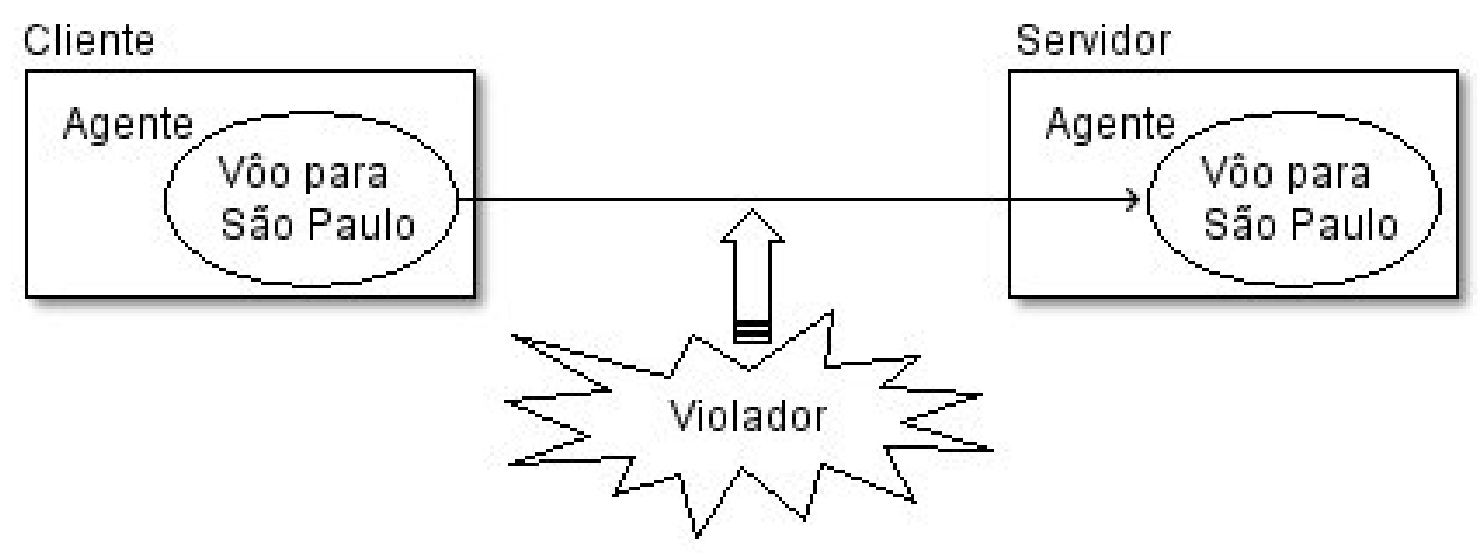

Figura 2.2 - Escuta ou Monitor de comunicação

\subsubsection{Ataques Ativos}

Os ataques ativos envolvem uma grande variedade de ameaças à segurança, abrangendo desde uma simples modificação dos dados dos agentes até a inserção de agentes mal intencionados dentro de servidor desconhecido. A seguir, alguns tipos de ataques ativos:

- Acesso Ilegal. Um agente acessa informações que não é permitido acessar. Isto pode acontecer quando o agente se disfarça como um usuário confiável ou é executado em um ambiente de execução sem segurança. Por exemplo, se um agente é escrito na linguagem $\mathrm{C}$, ele pode utilizar ponteiros aritméticos para 
acessar arbitrariamente localizações na memória. Não somente pode recuperar os dados privados do agente do host e outro agente do host, mas é capaz, também, de juntar aos dados. Utilizando Java no lugar de C, este problema será solucionado. No capítulo 3 serão apresentadas algumas características da linguagem Java.

- Disfarces. Uma entidade pretende ser uma outra entidade diferente (Figura 2.3). Em um exemplo típico, um agente entra em um servidor aparentemente representando uma pessoa confiável ou uma organização. Se há sucesso em enganar o host, o agente pode estar capacitado para utilizar um serviço livre ou roubar informações confidenciais reservadas para as entidades confiáveis.

\section{Cliente}

Figura 2.3 - Disfarce de agente

- Cavalo de Tróia. Um Cavalo de Tróia é um agente que é executado por um usuário legítimo mas executa alguma coisa diferente do que o usuário espera ou aprova (Figura 2.4). Um "violador" pode simplesmente criar e quem sabe executar um agente de busca inocente que na realidade causa danos para os usuários.

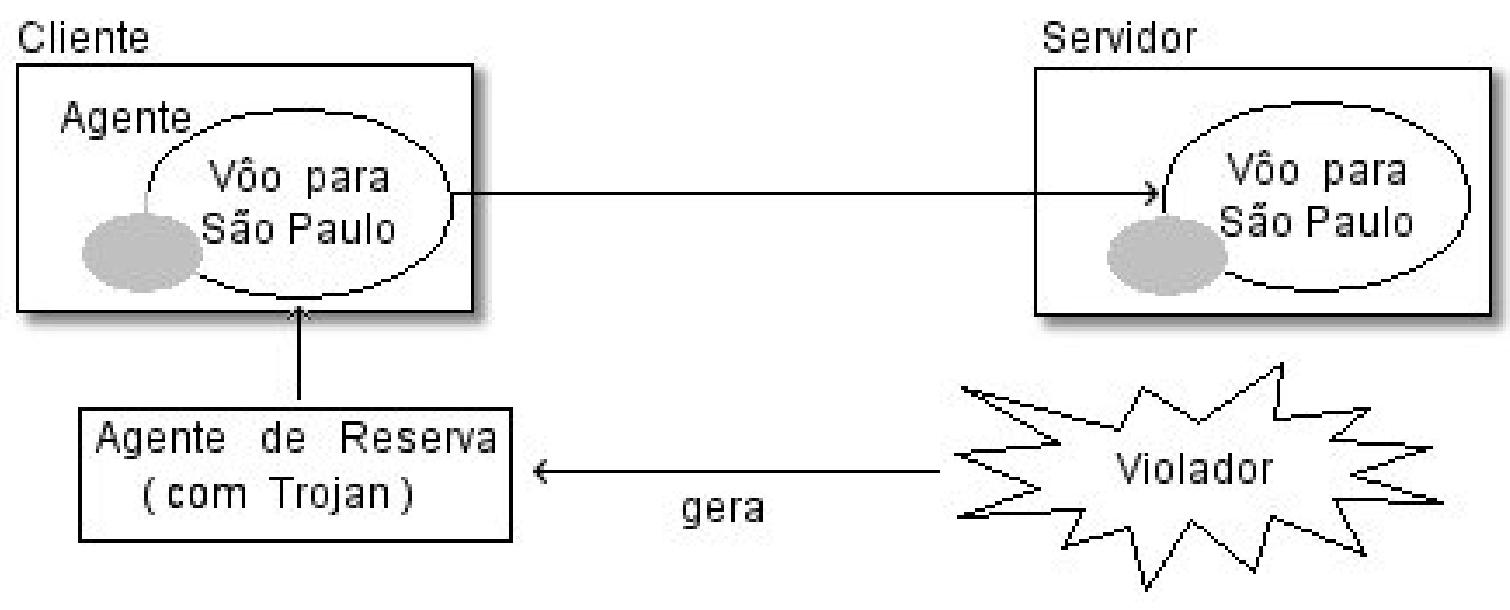

Figura 2.4 - Agente Cavalo de Tróia 
- Alteração. Um agente ou mensagem entre dois sistema de agentes é excluído ou alterado enquanto é transmitido (Figura 2.5). Em particular, qualquer host visitado no itinerário do agente pode remover dados adicionados pelo host anterior. Qualquer informação que é modificada de uma maneira inesperada pode transformar um agente legítimo em um outro agente mal intencionado ou pode simplesmente retornar resultados falsos.

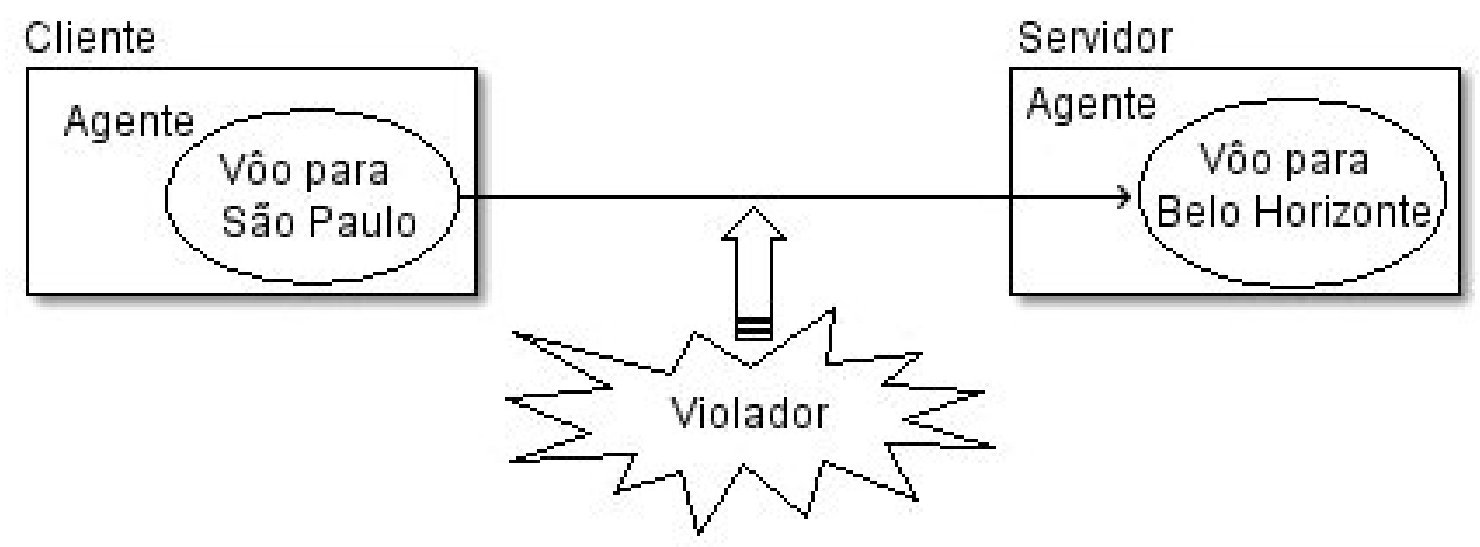

Figura 2.5 - Alteração do agente

- Retransmissão. Uma cópia capturada de um agente recentemente enviado é retransmitida para propósitos ilegítimos (Figura 2.6). Nesta maneira, o "violador" pode estar capacitado em obter resultados idênticos ou fatalmente atrapalhar o serviço. Mesmo se o agente está cifrado, o ataque ainda é possível, porque o agressor não precisa alterar o conteúdo do agente.

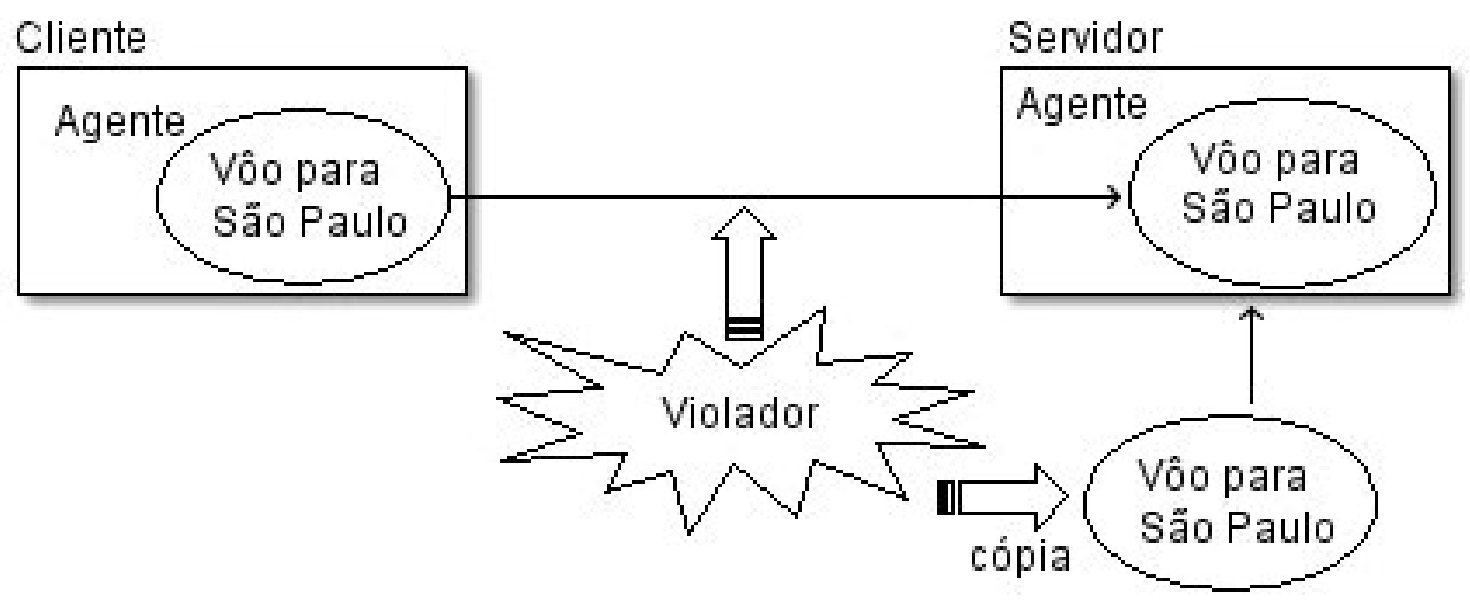

Figura 2.6 - Retransmissão de agentes 
- Exaustão de Recursos. Um recurso é deliberadamente utilizado exaustivamente chegando a ponto de atrapalhar o serviço aos outros usuários. Este ataque também é conhecido como uma recusa de serviço (denial of service). O recurso em questão pode ser uma largura de banda bem como a memória do servidor ou uma CPU. Por exemplo, se um agente mal intencionado permanece alocando memória, outros agentes ou possivelmente o servidor pode ficar incapaz de operar corretamente. Um outro exemplo é o uso de agentes que criam cópias. Em pouco tempo o servidor ou a rede estará cheio de agentes.

\subsubsection{Serviços de Segurança}

Os serviços de segurança são importantes, caso se deseja proteger os agentes e servidores contra ataques. Abaixo, segue a lista dos serviços de segurança mais comuns disponíveis para agentes:

- Autenticação. Antes de aceitar um agente em um sistema, deve-se conhecer quem o enviou. Neste caso, é necessária a autenticação do agente. Esse processo inclui a verificação da entidade que desenvolveu (programou) o agente e a entidade que instanciou e o enviou ao servidor. Antes de enviar um agente, pode haver a necessidade de verificar se o servidor de destino é sem dúvida o servidor que ele disse que é. Existem dois tipos de autenticação, são elas:

Autenticação do usuário: $\mathrm{O}$ usuário precisa se autenticar em um servidor qualquer. Uma criptografia com chave pública ou uma senha pode ser usada para este propósito.

Autenticação do host: Antes de um servidor iniciar uma comunicação com outro servidor ou cliente, é necessário que o servidor conheça com quem ele está comunicando. Isso é importante, porque não se pode assegurar a integridade e a confidencialidade sem conhecer de quem está recebendo os agentes ou enviando-os.

Autenticação de código: Antes de executar um agente recebido, o servidor precisa conhecer quem é responsável pela a implementação do agente. Assinaturas digitais são tipicamente utilizadas para esse propósito. 
Autenticação do agente: Antes de executar um agente recebido, o servidor precisa conhecer quem é responsável pelo agente.

- Integridade: Para confiar no agente, é necessário saber se o agente não foi alterado. Checar a integridade do agente é a técnica utilizada para verificar se alterações ilegítimas foram feitas no estado e no código de um agente.

- Confidencialidade: Um agente pode carregar uma informação confidencial mantendo-a ilegível de outros servidores ou agentes, podendo ser legível somente por servidores e agentes específicos. Um agente pode requisitar a um servidor para transportá-lo de uma maneira secreta, através do uso da criptografia, para enfrentar uma ameaça de escuta.

- Autorização: Um agente recebido deveria conceder direitos de acesso às informações de acordo com o seu gerenciador. A autorização, ou controle de acesso é a maneira de especificar e gerenciar as capacidades de acessar informações ou utilizar serviços oferecidos pelo servidor.

- Auditoria: Um serviço de auditoria grava atividades relacionadas a segurança de um agente para uma inspeção mais adiante.

É essencial estar prevenido de que há limites inerentes à segurança dos agentes.

A proteção dos agentes é confiada totalmente ao servidor que eles visitam, pois ele é responsável pela execução e transmissão entre hosts. A primeira ameaça que os agentes encontram é quando eles são transferidos pela rede. Há maneiras de "escutar" a transmissão na tentativa de obter as informações dos agentes. Fatores externos não confiáveis podem também alterar o conteúdo dos agentes, levando aos comportamentos indesejados dos agentes. Felizmente, este tipo de ataque é fácil de tratar e pode ser resolvido utilizando técnicas clássicas. Uma conexão segura normal, como SSL (Secure Sockets Layer) - que se baseia na criptografia dos dados e a checagem de suas integridade - pode ser utilizada para efetivamente prevenir este tipo de ataque (IBM, 1998).

A próxima ameaça é o servidor em que o agente está executando suas tarefas. Quando um agente é enviando este servidor, é esperado que ele trabalhe com o agente adequadamente e que sirva qualquer requisição válida. O agente está 
totalmente nas mãos do servidor remoto. Embora freqüentemente é afirmado que agentes são autônomos, eles não são processadores independentes que são capazes de executar seus próprios programas. O servidor é totalmente responsável pela execução do agente e também pode dar informações erradas ao agente para enganálo. Um servidor pode, também, proibir o agente de viajar para um servidor concorrente, e o enviando para um servidor conspirador.

Toda a informação necessária para o processamento de um agente deve ser legível ao servidor, o servidor tem potencial para roubar, alterar, ou revelar qualquer informação do agente. Por exemplo, se o agente carrega uma chave de acesso a um servidor específico e esta chave deve ser mantida em segredo dos outros servidores que o agente pode visitar, Para isto é necessária a criptografia da chave de acesso com a chave pública do servidor. Assim, somente o servidor que possui a chave pública poderá decodificar. A criptografia deve ser feita com a ajuda do servidor. Outros servidores não têm nenhuma maneira de ler o dado (IBM, 1998).

\subsection{Masif}

A interoperabilidade entre sistemas de diferentes fornecedores ou desenvolvedores é fundamental para satisfazer as necessidades de sistemas baseados em agentes móveis como comércio eletrônico. O básico exigido para a interoperabilidade é a padronização da tecnologia em relação à tecnologia de agentes móveis (IKV, 1999b).

Atualmente, os ambientes de desenvolvimento de agentes apresentam diferenças extremas de arquitetura e implementação, impedindo a interoperabilidade e rapidez no desenvolvimento da tecnologia de agentes móveis. As empresas Crystaliz, General Magic Inc, GMD Fokus, IBM Corporation e o The Open Group apresentaram juntas uma proposta para padronização de alguns aspectos da tecnologia de agentes móveis, na tentativa de promover a interoperabilidade entre sistemas. Essa iniciativa chamou a atenção da OMG (Object Management Group), resultando, em fevereiro de 1998, na criação do padrão chamado MASIF (Mobile Agent System Interoperability Facility). 
Interoperabilidade entre linguagem para objetos móveis é muito difícil e MASIF é direcionado para interoperabilidade entre sistemas de agentes escritos na mesma linguagem, mas potencialmente por vendedores diferentes, conforme pode ser observado na Figura 2.7. Além disso, MASIF não tenta padronizar operações locais de agentes como interpretação de agentes, serialização ou execução. Pode-se dizer que MASIF define a interface para o agente em nível de sistema e não em nível de agente.

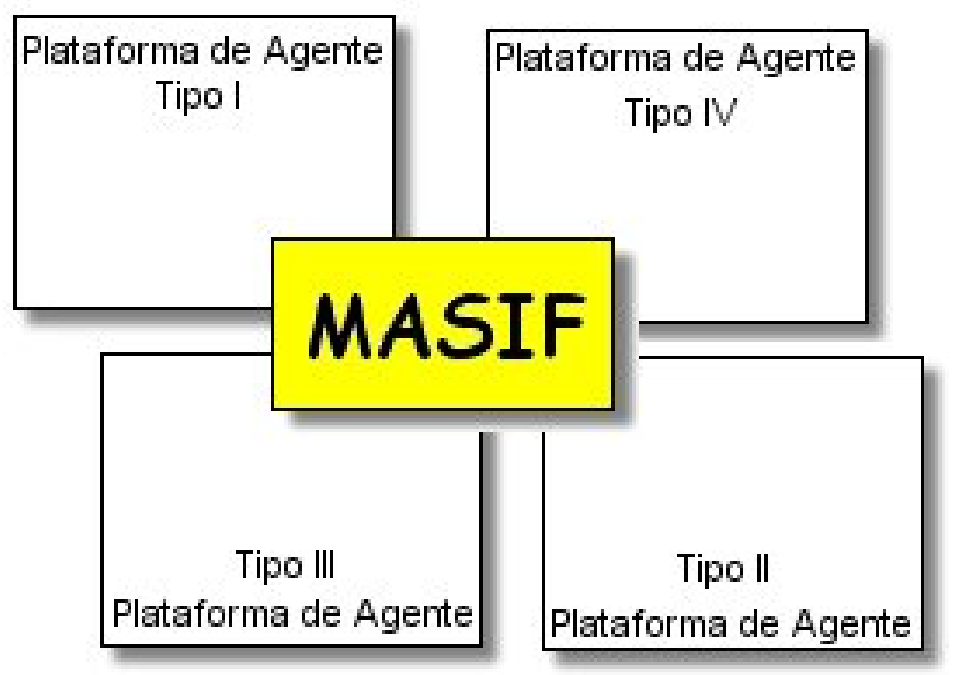

Figura 2.7 - Representação do objetivo do MASIF

O padrão MASIF é aplicável à seguintes áreas:

- Identificação de Agentes e de Sistemas de Agentes: Em adição à padronização de interoperabilidade entre sistemas de agentes, a sintaxe e semântica de vários parâmetros são padronizadas. Especialmente a identificação de agentes e de sistemas de agentes, permite aos sistemas de agentes e agentes identificaremse uns aos outros, além permitir às aplicações identificarem agentes e sistemas de agentes.

- Gerenciamento de Agentes: É desejável que o administrador de um sistema de agentes consiga operar um outro através de operações padrões. Isso possibilita encontrar um agente, criar um agente, suspender sua execução, concluir sua execução ou interrompê-la de uma forma padrão.

- Transferência de Agentes: É desejável que aplicações agentes possam disparar vários agentes para moverem-se livremente através de sistemas de agentes de diferentes tipos, resultando em uma infra-estrutura comum. 
- Sintaxe de Localização e Tipo de Sistema de Agentes: A sintaxe de localização é padronizada para permitir agentes acessarem informações sobre o tipo do sistema destino dos agentes. $\mathrm{O}$ agente poderá ser enviado somente se o sistema ao qual é destinado, se puder suportá-lo. Sintaxe de localização também é padronizada para que sistemas agentes possam localizar uns aos outros (Bernardes \& Moreira, 2000a). 


\section{Java e Agentes}

Um dos problemas encontrados, devido à utilização de agentes móveis na programação de aplicações distribuídas em um sistema distribuído heterogêneo, é a portabilidade dos agentes. Um agente em $\mathrm{C}++$ compilado para Solaris funcionará perfeitamente em um rede de computadores onde o sistema operacional é o próprio Solaris. As máquinas que possuem sistemas operacionais como Windows, MacOS ou até mesmo o OS/2 da IBM, conectadas à rede, não poderão ser acessadas por este agente. Para evitar esse problema, no desenvolvimento dos agentes, é necessária a utilização de uma linguagem cujo código gerado por ela seja portável. Dessa forma, o mais indicado é a utilização de uma linguagem interpretada.

Java pode ser a mais indicada. Uma vantagem é que ela disponibiliza uma biblioteca em tempo de execução que fornece uma independência de plataforma ${ }^{1}$, podendo utilizar o mesmo código em Windows 9x/2000, Solaris, MacOS, etc. Isto certamente é necessário para programação em sistemas distribuídos heterogêneos. Uma outra vantagem para muitos programadores é que Java possui uma sintaxe semelhante ao $\mathrm{C}++$. Java é totalmente orientada a objeto. Tudo em Java é objeto, exceto alguns tipos básicos como os números (Cornell \& Hostmann, 1997).

O compilador de Java gera um formato de arquivo-objeto ${ }^{2}$ com arquitetura neutra - o código compilado pode ser executado em muitos processadores, desde que o sistema local tenha o JIT (Just In Time) Compiler, que é o compilador em tempo de execução (Sun, 96). O compilador de Java faz isso gerando instruções em bytecodes que nada têm a ver com uma arquitetura de computador em particular. Eles são projetados para serem fáceis de interpretação em qualquer máquina e facilmente traduzidos em código de máquina nativo no momento da execução.

\footnotetext{
1 "Independência de plataforma" significa que o código binário que é gerado pelo compilador será executado em qualquer processador e sistema operacional. Em Java é gerado o chamado códigoobjeto.

2 Dependendo do autor, arquivo-objeto é encontrado como código-objeto.
} 
Ao contrário de $\mathrm{C}$ e $\mathrm{C}++$, não há aspectos da especificação "dependentes de implementação". Os tamanhos dos tipos de dados primitivos são especificados, assim como o comportamento da aritmética em relação a eles (Sun, 1996). Por exemplo, um int em Java é sempre um inteiro de 32 bits. Em $\mathrm{C} / \mathrm{C}++$, int pode significar um inteiro de 32 bits ou um inteiro de qualquer outro tamanho que o fornecedor do compilador queira utilizar. Os dados binários são armazenados em um formato fixo, eliminando a confusão do "big endian/little endian". As strings são salvas em um formato Unicode padrão.

Em Java, foi eliminada a alocação e a desalocação manual de memória. O lixo da memória é coletado automaticamente. Há verdadeiros arrays e foi eliminada a aritmética de ponteiros que tinha em $\mathrm{C}++$. Com isso, gerar códigos sem bugs é mais fácil de que em outras linguagens como C++ (Sun, 1996).

Java possui uma ampla biblioteca de rotinas para lidar facilmente com protocolos TCP/IP, como HTTP e FTP (Sun, 1996). Os aplicativos em Java podem abrir e acessar objetos através da rede usando URL's com a mesma facilidade com que os programadores acessam um sistema de arquivos local.

Java foi elaborada para ser usada em ambientes de redes/distribuídos. Por causa disso, muita ênfase foi dada a segurança. Java permite a construção de sistemas livres de falsificação através da utilização de assinaturas digitais (Sun, 1996), mas um grupo de experts em segurança na Universidade de Princeton encontrou um bug nos módulos de segurança do Java 1.0. O bug foi corrigido, mas nada impede de que alguém encontre outros. Mesmo assim Java oferece mais suporte à segurança do que outras linguagens como $\mathrm{C} / \mathrm{C}++$.

\subsection{A Máquina Virtual Java}

A Máquina Virtual Java (JVM) é implementada em uma camada de software acima da camada do sistema operacional nativo de uma máquina. É nela que são executadas as aplicações em Java que estão situadas em uma camada acima da JVM. A JVM isola a aplicação das diferenças entre o sistema operacional nativo e 
hardware, assegurando a compatibilidade das implementações da plataforma Java (Liden, 1997). Na Figura 3.1 é demonstrada a divisão de camadas do ambiente.

\section{Java Applications}

\section{Java Virtual Machine}

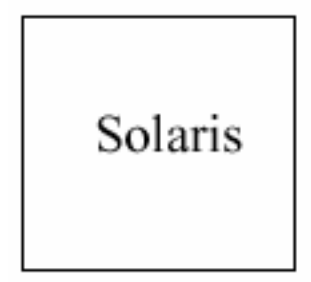

SPARC/Intel
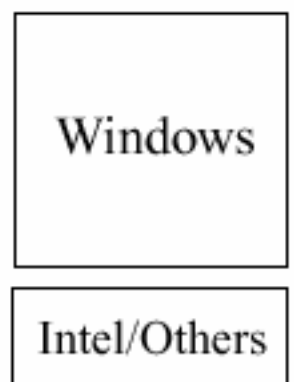

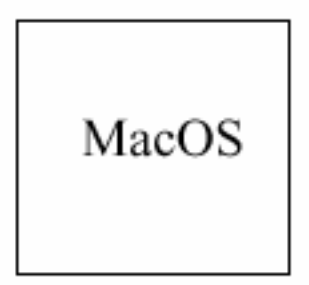

PowerPC

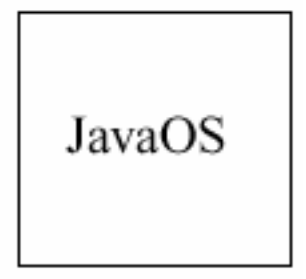

Thin Clients

Figura 3.1 - A Máquina Virtual Java se situa entre o sistema operacional e a aplicação Java, permitindo que um simples executável rode em diferentes sistemas.

A Máquina Virtual Java foi primeiramente disponibilizada em web browsers. Os browsers compatíveis com Java estão atualmente disponíveis para a maioria das versões de Unix, Windows 9x/NT/2000, MacOS e OS/2 Wrap. A JVM foi licenciada pela grande maioria dos fornecedores de sistemas operacionais, incluindo Apple, HP, IBM, Microsoft e SunSoft (Sun, 1996).

\subsection{Um exemplo de programa: Hello World!}

Uma maneira de exemplificar a portabilidade dos programas Java é criação de um programa bem simples com uma janela (Frame) e um botão (Button) que não faz nada. A idéia é mostrar que, sem fazer alterações no programa, é possível executá-lo em diferentes plataformas. 
O código-fonte do programa é o seguinte:

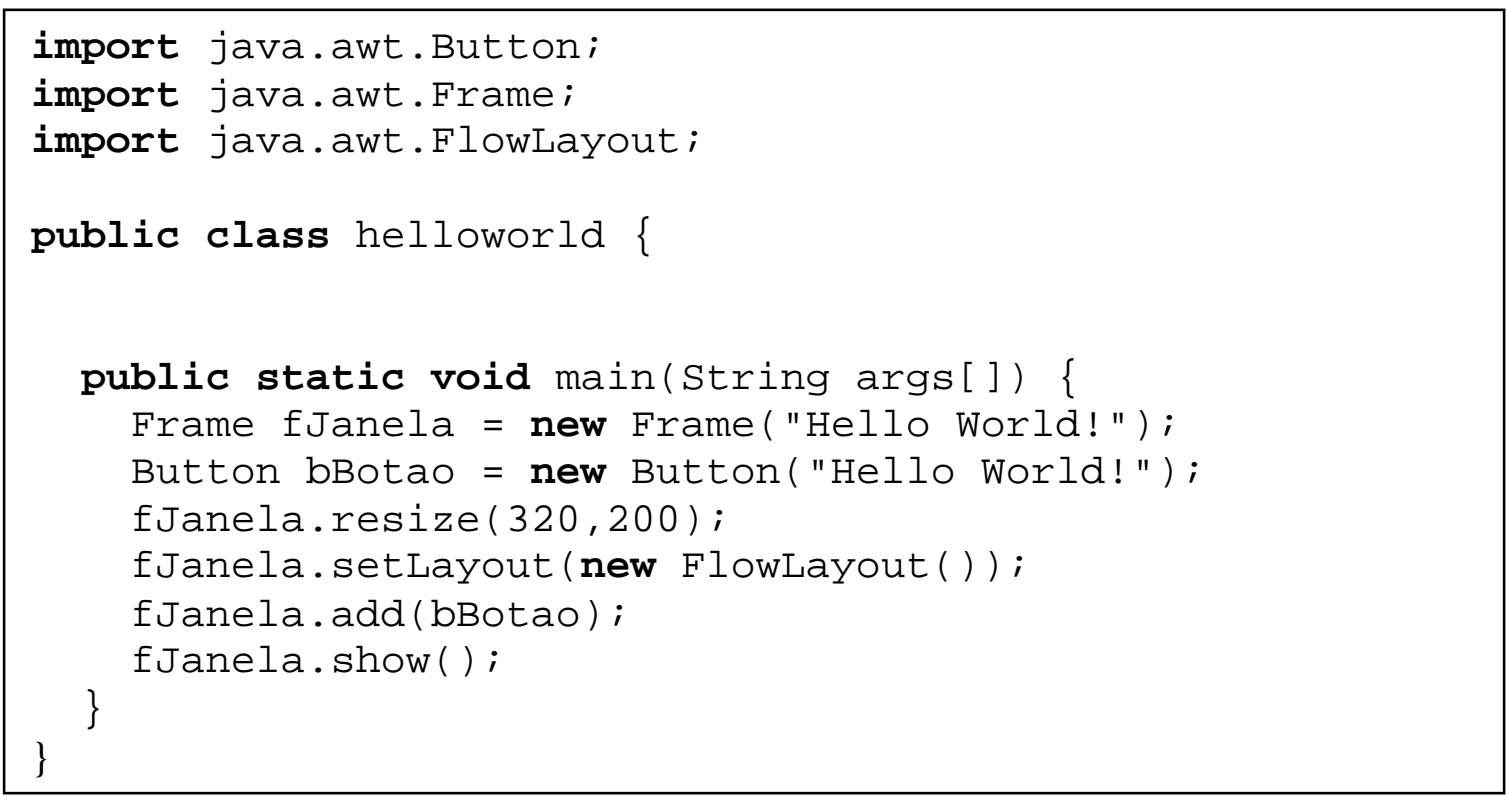

Este programa foi executado em 4 (quatro) sistemas operacionais diferentes, sem que houvesse qualquer alteração no código ou uma recompilação na plataforma testada. O programa HelloWorld foi compilado na plataforma Windows 2000 posteriormente executado. Durante a execução, foi copiada a tela resultante. A classe gerada pela compilação foi copiada para uma máquina com o Solaris, uma outra para um Mac e para uma máquina com o Linux. A Figura 3.2 demonstra o resultado obtido.

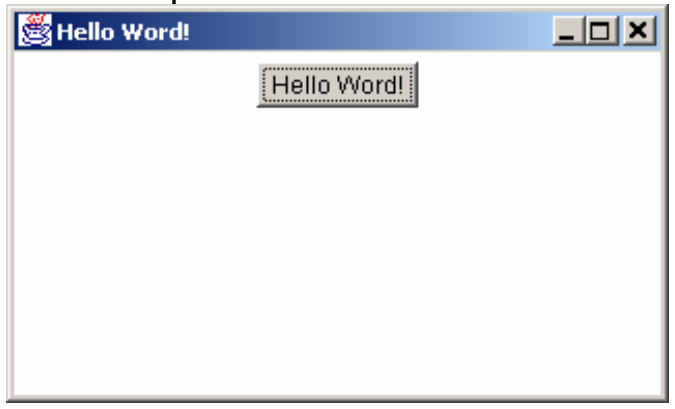

(a) HelloWorld no Windows 2000

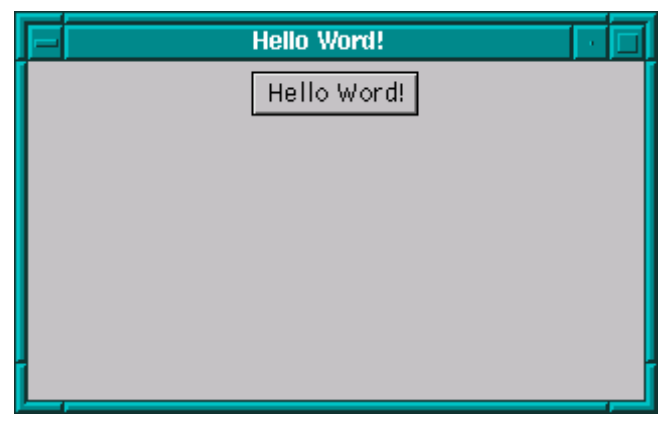

(c) HelloWorld no Solaris

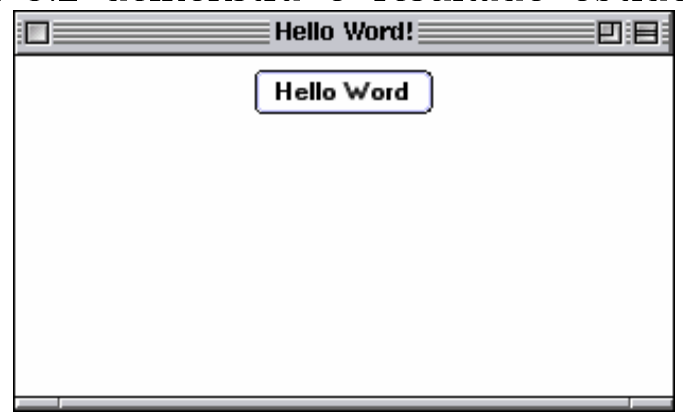

(b) HelloWorld no MacOS7

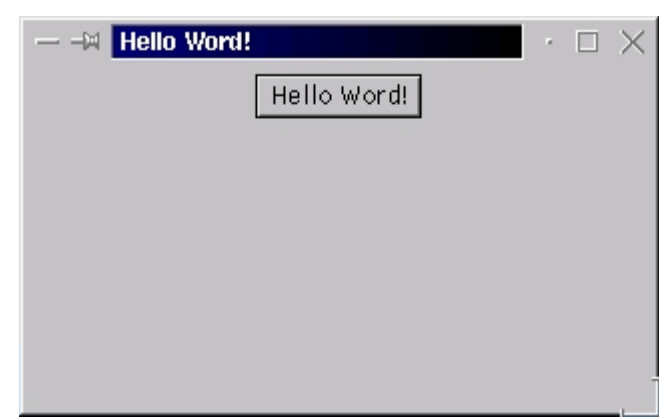

(d) HelloWorld no Linux (KDE)

Figura 3.2 - Resultado da execução do programa HelloWorld. 
Nota-se que as características, como posição e tamanho do objeto botão, permaneceram a mesma, excluído o seu formato. A versão do compilador utilizado para este exemplo é o JDK da Sun versão 1.1.8.

\subsection{Outras linguagens utilizadas}

Além de Java, existem outras linguagens que também são utilizadas na implementação de agentes. Embora a linguagem Java seja a mais utilizada, é possível encontrar diversos ambientes implementados em tais linguagens. Entre essas linguagens, duas têm sido utilizadas com freqüência:

- Perl: A Perl (Pratical Extraction and Report Language) é uma linguagem interpretada e portável (Jamsa et al, 1999), extremamente apropriada para muitas aplicações de processamento de texto. A Perl suporta as construções de programação estruturada encontradas na maioria das linguagens de alto nível e oferece fartos recursos reunidos. Geralmente, os programadores referem-se aos programas Perl como scripts, o que não deixa de ser uma verdade, pois a linguagem é muito utilizada para criação de scripts CGI. Perl oferece suporte para operações de arquivos e de banco de dados, o que a torna muito conveniente para armazenar e recuperar informações. Exemplo de um programa em Perl:

\section{\#! /usr/bin/perl}

print "Hello world!!"

- Tcl: Tcl (Tool Command Language) é uma linguagem de script que é executada na maioria das plataformas UNIX e WINDOWS NT. Tcl pode ser utilizada para gerar programas gráficos $\mathrm{X}$ Windows sem muitos códigos. Tcl foi feita para ser incorporada em programas C. A linguagem em si é extremamente simples e requer um interpretador muito pequeno. $\mathrm{O}$ interpretador $\mathrm{Tcl}$ lida apenas com comandos e argumentos. Cada linha distinta começa com um comando seguido pelos seus argumentos. Exemplo de um programa em Tcl:

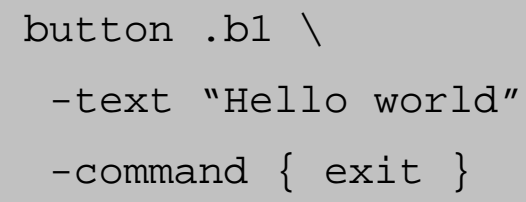




\section{Aplicações da tecnologia de Agentes Móveis}

No início da década de 90, as corporações voltaram os olhos para o novo paradigma de análise, projeto e programação orientados a objetos que veio facilitar o desenvolvimento de sistemas, melhorar as possibilidades de reutilização e aumentar a qualidade de software. Além disso, o desenvolvimento de aplicações distribuídas espalhou-se com a idéia de executar as tarefas nos locais mais adequados da rede; por exemplo, a interface com usuário é tratada no lado do cliente e o processamento de dados onde os dados estão (Bernardes \& Moreira, 2000b).

Com a consolidação da tendência de adoção das tecnologias orientadas a objetos, novos paradigmas vêm sendo criados para aumentar a flexibilidade dos sistemas computacionais envolvendo a mobilidade dos objetos implementados no sistema e a execução assíncrona de tarefas. Mais especificamente têm-se pesquisado muito sobre objetos móveis e sobre softwares denominados agentes móveis (Reami, 1998).

A tecnologia de agentes vem sendo aplicada academicamente nos mais diversos campos, principalmente em inteligência artificial, sistemas distribuídos e engenharia de software. Recentemente algumas aplicações comerciais e muitas pesquisas acadêmicas vêm sendo desenvolvidas com esta tecnologia. Nas seções seguintes são apresentadas algumas destas aplicações.

\subsection{Segurança Computacional}

As utilizações de agentes autônomos têm sido propostas por alguns autores como forma de construir sistemas de detecção de intrusão não-monolíticos. A capacidade dos agentes autônomos de manter informação específica do seu domínio de aplicação, nesse caso, aplicação de segurança, dá a estes agentes grandes flexibilidades.

Crosbie e Spafford especificaram um sistema deste tipo no qual as capacidades dos agentes são modificadas através do uso algoritmos genéticos. Os autores reconhecem, entre outras, as seguintes vantagens de sistemas baseados em agentes 
autônomos sobre sistemas monolíticos (Crosbie \& Spafford, 1995a) (Crosbie \& Spafford, 1995b):

- Fácil configuração: uma vez que é possível ter uma série de pequenos agentes especializados em tarefas específicas de detecção, o sistema de deteç̧ão pode ser configurado da forma mais adequada para cada caso; a adição e remoção de agentes do sistema são facilitadas;

- Eficiência: agentes podem ser treinados previamente e otimizados para que realize suas tarefas da maneira a gerar a menor sobrecarga do sistema possível;

- Capacidade de extensão: um sistema de agentes pode ser facilmente modificado para operar em rede e permitir migração para rastrear comportamentos anômalos através da rede, ou mover para máquinas onde eles podem ser mais úteis;

- Escalabilidade: para atuar em sistemas maiores, basta adicionar mais agentes e aumentar sua diversidade.

Recentemente, o COAST (Computer Operations, Audit and Security Technology, Computer Science Departament at Purdue University) liberou uma implementação de um ambiente que segue as idéias do sistema proposto por Crosbie e Spafford. Este ambiente denominado Autonomous Agents for Intrusion Detection (AAFID) foi implementado utilizando-se a linguagem de scripts Perl e diversos recursos de administração de sistemas e segurança comuns em ambiente UNIX. O ambiente AAFID possui duas entidades distintas que suportam a execução dos agentes do sistema: Transceivers e Monitors, sendo estes últimos entidades de mais alto nível, que podem detectar possíveis eventos intrusivos não notados por entidades mais simples como Transceivers. As informações preliminares sobre o sistema AAFID podem ser encontradas em Zamboni (Zamboni et al, 1998).

Outro trabalho recente na área de aplicação de agentes autônomos em sistemas de detecção de intrusão é apresentado por Barrus e Rowe (Barrus \& Rowe, 1998). A idéia dos autores é utilizar agentes autônomos estáticos que se comunicam através de um sistema de mensagens de alerta através de uma arquitetura distribuída. Algumas 
abordagens interessantes sugeridas são: a utilização de agentes especializados na deteçãa baseada em anomalia e na detecção baseada em uso indevido; e a criação de objetos específicos para tratar os diversos tipos de ataque.

Em sua dissertação de mestrado, Reami (Reami, 1998) apresentou a especificação e prototipagem de um ambiente de gerenciamento de segurança computacional apoiado por agentes móveis. $\mathrm{O}$ ambiente especificado e prototipado pode ser considerado um avanço importante, pois, além de fornecer recursos tecnológicos avançados e consoantes com o desenvolvimento da área, permite uma abordagem holística do problema do gerenciamento de segurança.

A implementação de agentes móveis específicos com habilidades de segurança computacional foi o trabalho de Bernardes (Bernardes, 1999). Os agentes foram desenvolvidos utilizando-se o Aglets Software Development Kit (ASDK 1.0), que é um ambiente para programação de agentes móveis em Java e utilizam um ambiente de hospedagem (servidor de agentes) denominado Tahiti, sendo ambos desenvolvidos pela IBM. No capítulo seguinte é apresentando com mais detalhes o sistema implementado.

\subsection{Comércio Eletrônico}

No trabalho de Rodeiguez (Rodriguez, 1998) é apresentado um modelo de aplicação de Comércio Eletrônico sobre a plataforma CORBA que consiste de um agente móvel que procura produtos numa rede em nome de um cliente. Uma das definições de Comércio Eletrônico encontradas no trabalho é que "qualquer tipo de transação de negócios na qual as partes interajam eletronicamente em lugar de fazê-lo através de intercâmbio físico ou com contato direto".

O Comércio Eletrônico é considerado o meio para permitir grandes mudanças, em escala global, das companhias, de uma forma que sejam mais eficientes e flexíveis (Rodriguez, 1998). 
O Comércio Eletrônico pode ser dividido em quatro categorias como Negócio Negócio, Negócio - Cliente, Negócio - Administração e Cliente - Administração.

O trabalho de Rodriguez apresentou uma implementação de agente móvel recolhendo informações sobre produtos ou serviços em um ambiente de comércio eletrônico, suportado pela plataforma CORBA, fornecendo facilidades aos clientes para que possam fazer negociações do produto encontrado. Na Figura 4.1 é apresentado o cenário proposto.

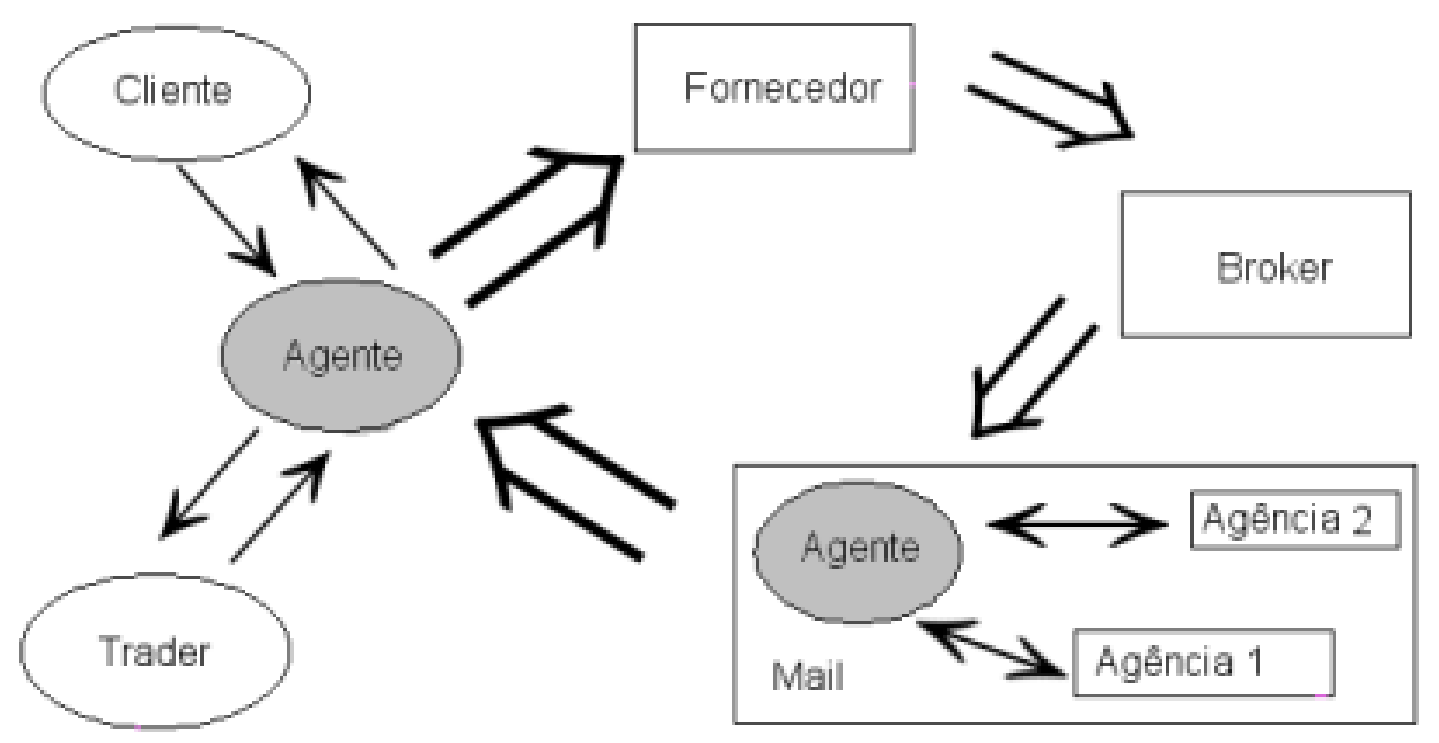

Figura 4.1 - Cenário de Comércio Eletrônico utilizando Agentes Móveis

\subsection{Webcrawler}

O objetivo de um webcrawler é a busca de informações em documentos HTML em uma base textual distribuída em diversas máquinas pela rede.

Radtke, em (Radtke et al, 1999), propôs um mecanismo baseado em pegadas que é a idéia de que os agentes deixam pegadas no ambiente por onde eles passam. Tais pegadas são elementos de informação sobre uma determinada tarefa, que se desfazem com o passar do tempo. Estas pegadas são utilizadas como um meio de identificar quais hosts já foram visitados pelos agentes evitando que outros realizem o mesmo serviço no mesmo local. Aplicando ao webcrawler, evitaria que agentes passassem por locais onde já foram efetuadas as buscas das informações. Ainda foi apresentada uma aplicação, MOTHRA (Figura 4.2), que tem por objetivo a busca de 
informações em uma rede de computadores através de uma sociedade de agentes de busca.

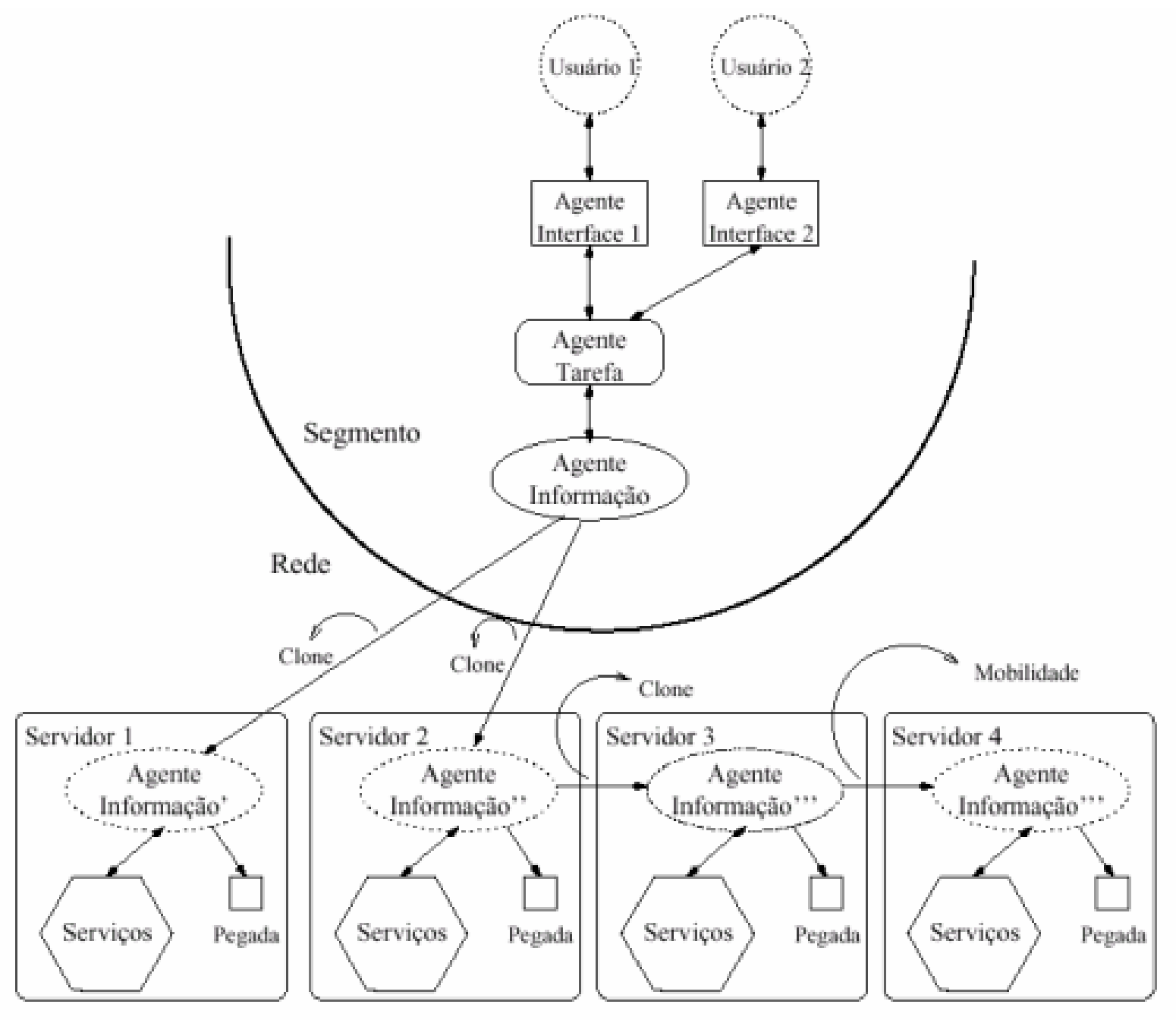

Figura 4.2 - Arquitetura do Sistema MOTHRA

O funcionamento da aplicação baseia-se em um agente que percorre a rede a partir de um ou mais documentos iniciais, procurando em seus links documentos que satisfaçam um critério de busca indicado pelo usuário. Em cada host visitado, o agente deixa uma marca (pegada) indicando que ele já passou por ali, evitando que agentes passem por ali executando a mesma busca.

\subsection{Gerenciamento de Rede}

O gerenciamento de redes é uma das aplicações que pode se beneficiar do uso de agentes móveis, por estar baseado de um modo geral em um paradigma centralizado. 
Alguns trabalhos utilizam agentes móveis no gerenciamento de redes. Alguns se baseiam na implementação de agentes autônomos integrados ao SNMP, com características de flexibilidade e adaptabilidade para um ambiente de gerencia mento de redes heterogêneas (Rubinstein \& Duarte, 1999).

Rubinstein \& Duarte apresentam as vantagens de se utilizar agentes móveis no gerenciamento de redes. São elas:

- Redução do custo: caso o gerenciamento exija um grande volume de informações a ser veiculado pela rede, pode ser mais econômico enviar um agente que execute a tarefa diretamente nos agentes de gerenciamento, onde estão localizadas estas informações. Desta forma, o agente pode filtrar e selecionar somente as informações relevantes e transferi-las para a estação de gerenciamento;

- Processamento assíncrono: um agente pode ser enviado através da rede, realizando suas tarefas em outros nós. Enquanto o agente se encontra fora de seu nó de origem, pode não ser necessário que este permaneça em operação;

- Divisão de processamento: computadores com pequena capacidade de processamento podem ser utilizados de maneira eficiente para realizar tarefas simples de gerenciamento, distribuindo o processamento antes concentrado na estação de gerenciamento;

- Flexibilidade: um novo comportamento dos agentes de gerenciamento pode ser introduzido pela estação de gerenciamento através do envio de um agente móvel com um código de execução diferente, substituindo em tempo real o código anterior.

Devido à centralização do processamento e do controle, o gerenciamento de redes no SNMP não é escalável quando o tamanho ou a complexidade da rede cresce. Para solucionar este problema, os agentes móveis podem ser utilizados, sendo importante descobrir quando estes aumentam a eficiência do gerenciamento. (Rubinstein \& Duarte, 1999) 


\section{Sistema de Deteç̧ão de Intrusão baseado em agentes móveis}

Esta seção é dedicada ao sistema de deteçãa de intrusão especificado por Bernardes (Bernardes, 1999) em seu trabalho de mestrado. De início, são apresentadas características do sistema, bem como sua arquitetura. Em seguida são apontadas falhas de segurança encontradas principalmente devido à plataforma de agentes móveis utilizada.

A arquitetura monolítica de Sistemas de Detecção de Intrusão (SDI), comumente utilizada em sistemas comerciais ou de pesquisa, apresenta um número de problemas que limitam sua capacidade de configuração, escalabilidade ou eficiência.

A abordagem monolítica apresenta alguns problemas práticos. Se uma nova forma de intrusão não prevista no sistema é descoberta, o SDI deve ser completamente reconstruído para conseguir tratá-la e isso, com certeza, não é uma ação trivial (Zamboni et al., 1998) (Crosbie \& Spafford, 1995a, 1995b).

Outra preocupação diz respeito à tolerância a falhas, uma vez que um sistema monolítico apresenta-se como um único ponto de falha $\mathrm{e}$ ataques. Conseqüentemente, metodologias de ataques bem conhecidas (como por exemplo, ataques Denial of Service), quando proferidas contra a máquina que hospeda o SDI, comprometem por completo a integridade do sistema (Bernardes, 1999) (Bernardes \& Moreira, 2000a) (Bernardes \& Moreira, 2000b).

A utilização de agentes autônomos tem sido proposta por alguns autores como uma forma de se construir sistemas de deteç̧ão de intrusão não-monolíticos (Crosbie \& Spafford, 1995a, 1995b) (Zamboni et al, 1998). A capacidade dos agentes autônomos de manter informação específica do seu domínio de aplicação, nesse caso, aplicação de segurança, dá aos agentes e conseqüentemente a todo o sistema, grande flexibilidade. 
Em vez de um grande módulo monolítico, o trabalho de Bernardes (Bernardes, 1999) apresenta a proposta de uma abordagem modular baseada em agentes autônomos e móveis para o desenvolvimento de um SDI. Este SDI consiste de um conjunto de pequenos processos (agentes) que podem agir independentemente no ambiente em construção. Os agentes foram desenvolvidos com a capacidade de se moverem pela rede executando rotinas de monitoração e análise dos resultados.

Cada agente observa somente um pequeno aspecto de todo o sistema. Um simples agente, sozinho, não pode formar um sistema de detecção de intrusão, uma vez que sua visão é limitada a uma pequena "fatia" do sistema. Entretanto, se muitos agentes operam em um sistema e cooperam uns com os outros, então um poderoso SDI pode ser desenvolvido. Uma vez que os agentes são independentes uns dos outros, eles podem ser adicionados e removidos do sistema dinamicamente, de forma que não é necessário reconstruir todo o SDI ou ainda, interromper suas atividades. Assim, qualquer identificação de uma nova forma de ataque, novos agentes especializados podem ser desenvolvidos, adicionados ao sistema e configurados para atender uma política de segurança específica (Bernardes, 1999) (Bernardes \& Moreira, 2000a) (Bernardes \& Moreira, 2000b).

Outra vantagem da abordagem descrita acima é a facilidade de configuração apresentada pelo sistema em atendimento às necessidades políticas do ambiente ao qual está inserido. Isso se torna uma característica importante uma vez que o que é considerado uma quebra de segurança para um ambiente pode não ser em outro, em função do tipo de informação que se quer proteger.

Sendo dividido em módulos contendo um conjunto de pequenos agentes especializados em uma única função e que apresentam uma menor complexidade lógica, o sistema procura minimizar o esforço gasto com a manutenibilidade. Isso se deve ao fato de que, desta forma, cada agente apresenta uma estrutura bem compreensível, facilitando o seu entendimento e conseqüente necessidade de manutenção. Isso é refletido diretamente em termos de:

- Tempo de reconhecimento do problema; 
- Tempo de análise do problema;

- Tempo de especificação das mudanças;

- Tempo de correção (ou modificação) ativa;

- Tempo de testes locais;

- Tempo de testes globais;

- Tempo de revisão de manutenção;

- Tempo de recuperação total.

Cada uma das métricas acima pode, de fato, ser registrada sem grandes dificuldades. Além dessas medidas orientadas para o tempo, a manutenibilidade pode ser medida indiretamente ao considerarmos as medidas da estrutura do projeto e as métricas da complexidade do sistema, que indicarão também um ganho significativo no momento da inserção de novas funções (novos agentes).

Além dessas vantagens, Crosbie e Spafford (Crosbie \& Spafford, 1995a; 1995b) especificam um sistema baseado em agentes autônomos no qual as capacidades dos agentes são modificadas através do uso algoritmos genéticos. Os autores reconhecem, entre outras, as seguintes vantagens de sistemas baseados em agentes autônomos sobre sistemas monolíticos:

- Fácil configuração: uma vez que é possível ter uma série de pequenos agentes especializados em tarefas específicas de detecção, o sistema de deteç̧ão pode ser configurado da forma mais adequada para cada caso; a adição e remoção de agentes do sistema são facilitadas;

- Eficiência: agentes podem ser treinados previamente e otimizados para que realizem suas tarefas de maneira a gerar a menor sobrecarga possível no sistema;

- Capacidade de extensão: um sistema de agentes pode ser facilmente modificado para operar em rede e permitir migração para rastrear comportamentos anômalos através da rede, ou mover para máquinas onde eles possam ser mais úteis;

- Resistência à subversão: caso um sistema de defesa seja subvertido, ele poderá dar a falsa sensação de segurança. Entretanto, isto se torna mais difícil, 
pois os conhecimentos adquiridos de um agente não dão o conhecimento das operações de outros, visto que eles desempenham funções diferentes.

- Escalabilidade: para atuar em sistemas maiores basta adicionar mais agentes e aumentar sua diversidade.

\subsection{Arquitetura do sistema implementado}

O conceito principal que envolve o SDI baseado em agentes autônomos e móveis é a simplicidade. Cada agente é uma entidade simples que irá desempenhar uma atividade específica e cooperar com outros agentes de forma mais eficiente possível. Quando uma atividade for considerada suspeita por um agente, ele irá comunicar aos demais agentes a suspeita de uma possível intrusão. Neste momento, será acionado um agente ou um conjunto de agentes com um maior grau de especialização naquele tipo de suspeita (Bernardes, 1999) (Bernardes \& Moreira, 2000a) (Bernardes \& Moreira, 2000b).

Naturalmente um agente poderá cometer um erro, que será identificado por um agente com um nível de especialização superior. Uma vez que um número maior de agentes suspeita de uma possível intrusão, uma mensagem pode ser enviada pedindo a intervenção de um operador humano (via alguns processos de monitoramento) e agentes de reação poderão ser acionados.

A Figura 5.1 apresenta uma arquitetura (modelo em camadas) para o SDI especificado por Bernardes (Bernardes, 1999). As camadas são numeradas a partir da camada de Vigilância (Camada 1), e cada uma delas representa um grupo de tarefas específicas desempenhas por agentes especializados nas funções desta camada. Através do mecanismo de troca de mensagens, um agente em uma camada aciona um ou mais agentes em uma camada superior. Em outras palavras, a camada $\mathrm{N}$ utiliza os serviços da camada N-1, desempenha suas funções e fornece serviços para a camada $\mathrm{N}+1$.

Com base em informações coletadas pelos Agentes de Vigilância, Agentes de Tomada de Decisão entram em ação, analisando e identificando possíveis intrusões. Caso uma ação seja considerada suspeita por estes agentes, Agentes de Notificação são acionados 
e cuidam de notificar o administrador da rede (via e-mail, pager, chamada telefônica, alarme, etc.) ou acionar os agentes de nível superior. Em último nível, encontram-se os Agentes de Reação. Estes agentes cuidam de contra-atacar automaticamente as possíveis intrusões, com base nas informações dos agentes de notificação ou ainda, serem acionados através de uma intervenção do administrador da rede.

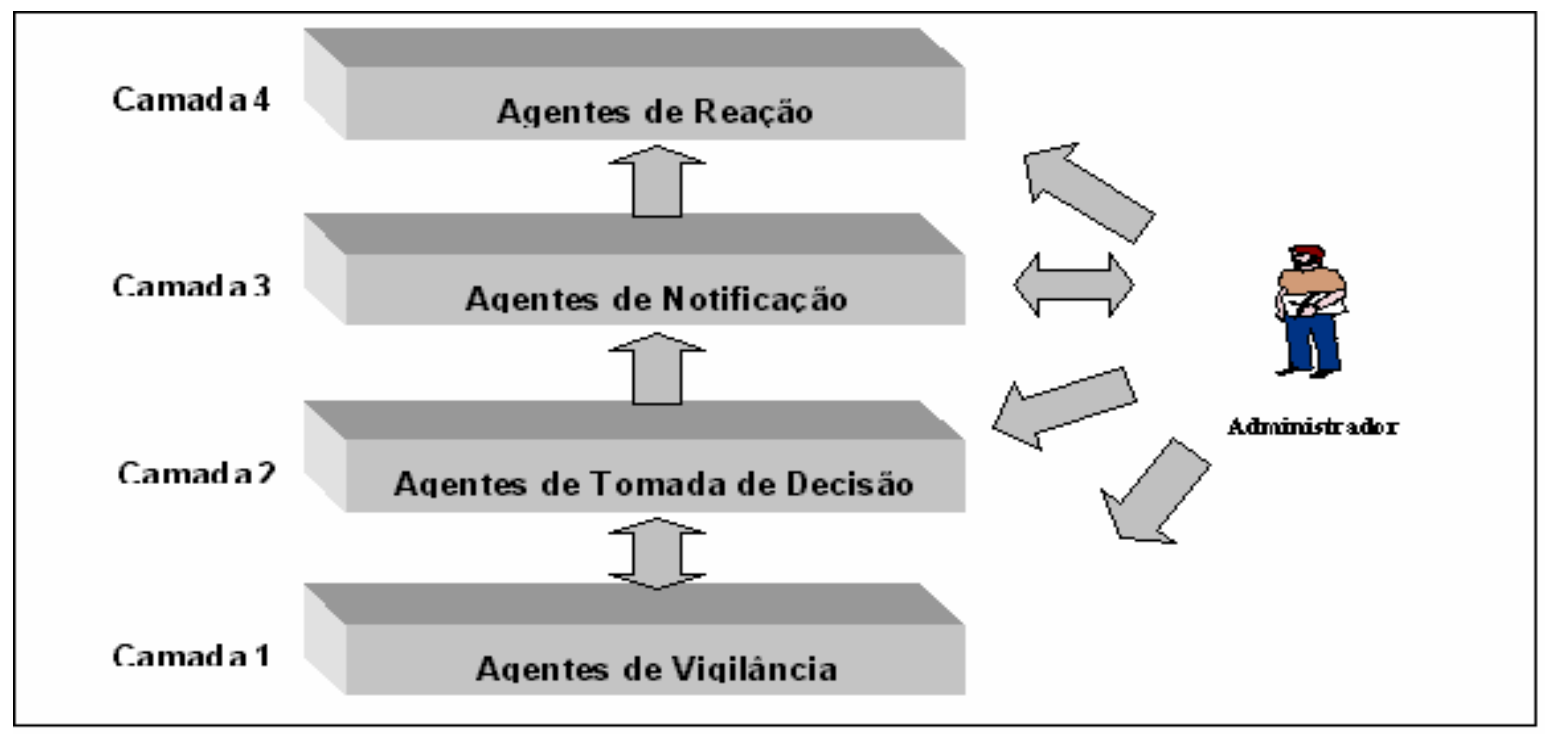

Figura 5.1 - Modelagem em Camadas para o Sistema Proposto

Apesar do cenário acima exemplificar uma comunicação bottom-up através das camadas da arquitetura proposta, há a possibilidade de uma comunicação top-down entre a camada de tomada de decisão e a camada de vigilância. Exemplificando, temos um cenário em que um agente de tomada de decisão, após receber uma mensagem ou um conjunto de dados dos agentes de vigilância, poderá no momento em que desempenhar uma análise, necessitar de mais informações. Neste caso, novos agentes de vigilância são acionados e mais informações são coletadas, na tentativa de se conseguir uma decisão com um maior grau de certeza.

A ampliação do SDI para atender uma nova configuração de ataque poderá envolver o desenvolvimento e conseqüente adição de novos agentes em uma única camada ou ainda, a criação de um novo cenário que envolverá a adição de agentes em todas as camadas. A seguir, serão apresentadas, com maiores detalhes, as funções de cada uma destas camadas. 


\subsubsection{A Camada 1 - Agentes de Vigilância}

Esta camada representa o primeiro nível de agentes do sistema proposto. Este conjunto de agentes será responsável pela monitoria, coleta de informações, testes de ambiente e ajustes de configuração a partir de arquivos de perfil de segurança que serão alocados estrategicamente no ambiente ao qual se quer proteger.

Uma analogia para os Agentes de Vigilância seria compará-los a guardas noturnos em uma empresa. Estes, ao invés de serem alocados estaticamente em pontos estratégicos do ambiente, seriam responsáveis em fazer a "ronda" pelo sistema em busca de portas abertas ou padrões que caracterizem possíveis intrusões. A seguir, são relacionados um conjunto de agentes de vigilância e suas respectivas funções:

- Agentes de verificação de usuários conectados ao sistema: Agente responsável pela obtenção de uma lista contendo os usuários conectados a um servidor, a hora de início e a origem destas conexões;

- Agente de verificação de hospedeiros: agente responsável pela verificação dos hospedeiros em execução no ambiente;

- Agente de captura de pacotes: agente que trabalha em modo promíscuo na rede ativando a captura de pacotes (sniffing);

- Agentes de scanning: conjunto de agentes que, através de tentativas de quebra de segurança, irão validar os serviços, processos e demais atividades que vão contra a política de segurança do ambiente;

- Agente de verificação de serviços: agente responsável pela verificação dos serviços em execução em máquinas servidoras;

- Agente de monitoria dos serviços: agente responsável por monitorar e filtrar as requisições de entrada dos serviços da rede, fornecendo informações para agentes da camada superior;

- Agente de verificação de utilização de recursos do sistema: agente responsável pela monitoria da utilização de recursos de sistema como CPU e Hard Disk, em momentos considerados estratégicos e não-críticos;

- Agente especializado em identificação de backdoors: agente que, com base nos padrões conhecidos e divulgados, irá rastrear o sistema em busca de backdoors. Este agente deverá apresentar uma grande facilidade em sua capacidade de reconfiguração com base em novos conhecimentos adquiridos, 
tendo em vista que constantemente são relatadas novas formas desse tipo de ataque;

- Agente de validação de serviços: agente responsável pela validação dos serviços em execução. Cabe a este agente a configuração do profile que autoriza a execução de um ou mais serviços em uma máquina/servidor do ambiente;

- Agentes de configuração de Profiles: com base na percepção de novas formas de intrusão ou variação do perfil de utilização dos usuários, proceder com as devidas (re)configurações dos profiles. Esses arquivos irão conter informações de padrões de normalidade de utilização do sistema, como: padrão dos horários de conexão de usuários; estatísticas de utilização de dispositivos do sistema; etc.

\subsubsection{A camada 2 - Agentes de Tomada de Decisão}

Nesta camada, encontram-se os agentes que exercem todas as funções de tomada de decisão no sistema, constituindo-se o "cérebro" do mesmo. Um agente desta camada irá receber uma mensagem ou um conjunto de dados dos agentes da camada inferior (a camada de Vigilância) e, com base em uma análise criteriosa destas informações, poderá identificar uma intrusão (ou tentativa), no momento de sua ocorrência, ou ainda, acionar novos Agentes de Vigilância para a coleta de informações complementares.

Em ações mais simples, estes agentes podem identificar uma anomalia, ou uso indevido, simplesmente comparando os dados obtidos com padrões de utilização do sistema (perfis de utilização). Entretanto, como esta camada representa o ponto de inteligência do sistema, deverão ser implementados agentes dotados de características de inteligência artificial para se alcançar um bom nível de reconhecimento de ações indevidas.

Entre essas características, é desejável que estes agentes sejam capazes de aprender coisas novas e se adaptarem a novas situações, em vez de simplesmente fazerem o que lhes foi atribuído. Entre os estímulos de ativação da aprendizagem, deve-se 
utilizar as ações tomadas pelo administrador ao ser notificado pelos agentes da camada de nível superior (a camada de notificação). Dessa forma, fica evidente a necessidade do desenvolvimento de agentes que exerçam funções de sistemas especialistas, o que poderá ser feito com a utilização das modernas técnicas de redes neurais e algoritmos genéticos, comumente referenciados em trabalhos relacionados à Inteligência Artificial.

A seguir são apresentados um conjunto de agentes de tomada de decisão e suas respectivas funções:

- Agente de controle: agente responsável pelo acionamento dos demais agentes. Constituindo-se o principal agente desta camada, este ficará em execução contínua à espera de uma mensagem de um agente da camada de vigilância. Ao receber e identificar a mensagem, este agente irá conseqüentemente acionar (ativar) o agente especializado em atender àquela chamada;

- Agente de verificação de usuários anômalos: agente que, baseado em um padrão de normalidade (perfis de usuário, como: horário de utilização, principais serviços utilizados, utilização de recursos do sistema, origem da conexão, etc), procura desvios do comportamento padrão, utilizando modelos estatísticos ou sistemas especialistas. Dessa forma, também será capaz de determinar possíveis personificações de usuários, baseando-se em uma análise do comportamento passado e na determinação de comportamentos que fujam ao padrão esperado de um comportamento aceitável;

- Agente de verificação de hospedeiros não autorizados: agente responsável pela verificação de existência de hospedeiros não autorizados na rede. Cabe a este agente a responsabilidade de validação dos ambientes servidores de agentes inseridos no sistema;

- Agente de Análise de pacotes: agente que recebe os pacotes do agente de captura (Camada de Vigilância) e procede com sua análise. As atividades desempenhadas por este agente representam um nível de complexidade elevado, uma vez que será dotado de algum mecanismo de tomada de decisão. Uma proposta inicial seria a conversão do módulo de análise do ambiente ACME! (Cansian, 1997) para o desempenho desta função; 
- Agente de identificação de pontos falhos: agente que irá identificar os pontos falhos no ambiente com base nas informações dos agentes de scanning;

- Agente de verificação de serviços: agente responsável pela verificação da integridade e autorização dos serviços em execução em máquinas servidoras;

- Agente de monitoria de logs: agente que ativa a captura de informações de logging adicional quando um nível de periculosidade mais elevado é notificado;

- Agente de monitoria de usuário indevido: com base na detecção de uma possível personificação, proceder com o acompanhamento deste usuário em busca de assinaturas de ataque;

- Agente de identificação de novos padrões de ataque: agentes inteligentes responsáveis pelo aprendizado e identificação de novos padrões de ataque.

\subsubsection{A camada 3 - Agentes de Notificação}

Esta é a camada menos populosa em quantidade de agentes. Os agentes desta camada são responsáveis, com base nas mensagens recebidas da camada 2 (Agentes de Tomada de Decisão), por notificar o administrador da rede e acionar os agentes da camada 4 (Agentes de Reação). Dessa forma, toda vez que os Agentes de Tomada de Decisão identificarem um nível de periculosidade acima do aceitável ou a necessidade de atualização de algum novo padrão identificado, Agentes de Notificação entrarão em ação.

A princípio, pode-se pensar que os agentes desta camada desempenham funções muito elementares, o que justificaria a agregação de suas funções à camada 4(ocasionando a eliminação da camada 3). Entretanto, uma decisão tomada na camada de nível 2 poderá necessitar de diversas formas de notificação, ocasionando a construção de um agente muito complexo, quer seja agregando suas funções a esta camada ou em uma camada de nível superior do modelo. Isso iria contra a proposta de pequenos agentes desempenhando funções específicas na tentativa de minimizar a degradação do ambiente.

- Agente de notificação de usuário indevido: agente que irá alarmar a suspeita de uma personificação utilizando o sistema; 
- Agente de notificação de hospedeiro não autorizado: agente que irá notificar a existência de hospedeiros não autorizados no ambiente;

- Agente de notificação de tentativas de ataque: agente que irá notificar as tentativas de conexão não autorizadas no ambiente;

- Agente de notificação de serviço não autorizado: agente que irá notificar a execução de algum serviço não-autorizado na rede;

- Agente de notificação de furos de segurança: Notificar furos de segurança provenientes de testes de scanning;

- Agente de notificação de utilização de recursos de sistema: agente que irá notificar a suspeita de utilização indevida de recursos do sistema;

- Agente de notificação de tentativas de intrusão: agente que irá notificar tentativas de intrusão por utilização de técnicas como quebra de senha por força bruta;

- Agentes de acionamento de contra ataque: Conjunto de agentes responsáveis por acionar cada ação de reação e contra-ataque;

- Agente de notificação de identificação de novos padrões: Agente que irá notificar a necessidade de reconfiguração ou desenvolvimento de novos agentes para atender um novo padrão de intrusão identificado.

\subsubsection{A camada 4 - Agentes de Reação}

Esta camada apresenta um conjunto de agentes que serão acionados pelos agentes da camada 3 (Agentes de Notificação) ou ainda, pela ação direta do administrador humano. Responsáveis por reagir (contra atacar), recuperar e reconfigurar o sistema, estes agentes representam a última instância de recursos do sistema modelado.

- Agentes de encerramento de conexão: agente responsável por cancelar e bloquear uma conexão para um possível usuário anômalo;

- Agentes de exclusão de hospedeiros: agente responsável pela remoção de hospedeiros não autorizados no ambiente;

- Agente de corte de conexão: agente responsável pelo acionamento do corte e/ou bloqueio da conexão de um possível intruso; 
- Agentes de eliminação de furos de segurança: conjunto de agentes responsáveis pela reconfiguração dos serviços na tentativa de eliminação de furos de segurança;

- Agente de bloqueio de serviço: agente responsável pelo bloqueio da execução de serviços não autorizados;

- Agente de recuperação de arquivos alterados: agente que cuida da recuperação do estado inicial, baseado em um repositório, caso seja efetuada uma alteração não validada em um arquivo;

- Agentes de reconfiguração: agente responsável pela recuperação do estado anterior de serviços autorizados;

- Agente de ativação de dispositivos auxiliares: agente responsável pela ativação de dispositivos auxiliares à captura de informações sobre o usuário interno. Um exemplo de um dispositivo auxiliar poderia ser uma câmera de vídeo.

\subsection{Classificação do Sistema}

As principais metodologias de classificação para os Sistemas de Detecção de Intrusão são expressas em termos da forma como o sistema aborda o problema de detectar a intrusão e em termos do tratamento dos dados (Bernardes, 1999) (Bernardes \& Moreira, 2000a) (Bernardes \& Moreira, 2000b).

Uma vez que a detecção de anomalia identifica atividades intrusivas como sendo um subconjunto que foge da atividade normal, o sistema proposto possui um conjunto de agentes que procuram quantificar o comportamento usual ou aceitável, armazenálo em profiles de usuário e posteriormente, identificar outros comportamentos irregulares como intrusivos. Entretanto, o sistema também possui agentes que procuram por ataques que podem ser precisamente identificados pela forma como acontecem, ou seja, intrusões que seguem um padrão bem definido de ataque (assinaturas de ataque), características estas do modelo de detecção de uso indevido (abuso).

Assim, em relação à forma com que aborda o problema de detectar a intrusão, o sistema proposto apresenta-se como um híbrido entre o modelo de detecção de 
anomalia e o modelo de detecção baseado em uso indevido. Isso também pode ser considerado uma vantagem significativa deste sistema, uma vez que sistemas híbridos monolíticos apresentam-se como sistemas complexos que implicam em severas penalidades de performance no ambiente a ser monitorado, o que não ocorre com a proposta modular.

Em termos de tratamento dos dados, o sistema apresenta-se como um híbrido entre um modelo baseado em host (host based) e um modelo baseado em redes (network based). Entre as características de um sistema baseado em host, o sistema apresenta um conjunto de agentes que, baseados em perfis de utilização de um equipamento, procuram por desvios de comportamento padrão, utilizando-se modelos estatísticos ou sistemas especialistas. Entretanto, também possui agentes que monitoram o tráfego da rede, capturam pacotes e procuram por "impressões digitais" do ataque, acontecendo em tempo real (Bernardes, 1999).

\subsection{Falhas de segurança}

Por se tratar de um sistema de detecção de intrusos, a sua segurança também se torna um ponto crucial para a proteção da rede. Um SDI inseguro acarretaria em mais uma alternativa de ataque para usuários maliciosos. $\mathrm{O}$ objetivo desta seção é apontar falhas de segurança no sistema especificado e implementado por Bernardes (Bernardes, 1999) que servirão como base para avaliação de segurança das plataformas apresentadas no capítulo 6.

As chances de um ataque bem sucedido à rede, através das falhas de segurança de um SDI são bem maiores do que através de outros furos, pois o sistema possui acesso irrestrito e privilégios de super usuário. O desenvolvimento do SDI utilizando-se de uma plataforma que oferece meios de evitar o sucesso de ataques diminui o risco aumentando a confiabilidade e eficiência do sistema. A seguir serão apresentadas as falhas de segurança detectadas no sistema:

- Problema $\mathbf{n}^{\mathbf{0}}$ 1: Autenticidade do código. O problema de autenticidade do código ocorre porque um agente é formado por um conjunto de classes que juntas executam as funções delegadas a eles. $\mathrm{O}$ risco se trata da possibilidade 
de que um agente execute funções indevidas no sistema mesmo ele sendo autentico. Na Figura 5.2 é demonstrado um agente composto por objetos válidos e inválidos. Em sistemas onde somente a autenticação do agente é feita este tipo de problema passa despercebido.

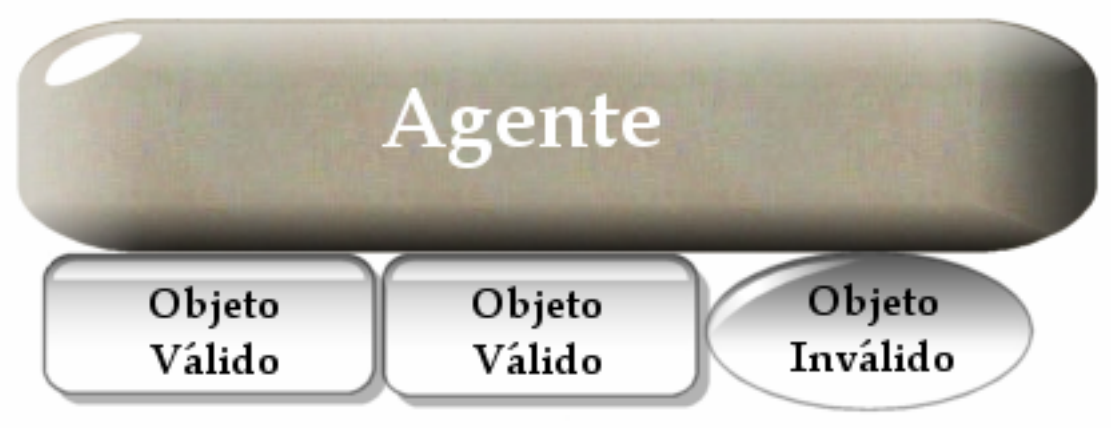

Figura 5.2 - Agente composto por objetos

- Problema no 2: Autenticidade do agente. Os agentes possuem privilégios de superusuários na rede. Se um desses agentes for um agente malicioso, a possibilidade de causar estragos é grande, pois o ele tem acesso irrestrito às informações sigilosas e a recursos do sistema.

- Problema $n^{0}$ 3: Autenticidade do usuário. No sistema não há uma autenticação do administrador permitindo que qualquer usuário acesse-o sem nenhum problema. O que pode acontecer é que um usuário, com más intenções, tente utilizar o sistema para danificar a rede ou use agentes para furar o próprio sistema de detecção de intrusão. Possivelmente, pode-se também autorizar a entrada de agentes maliciosos no sistema.

- Problema $n^{\circ}$ 4: Autenticidade do host. Os servidores de agentes utilizados na implementação do sistema não se autenticam a ponto de identificar se o servidor que irá receber o agente não irá fazer mal uso das informações nele contidas. Como exemplo, pode-se citar um cenário implementado que monitora os usuários da rede verificando horário de acesso, utilização do processador e serviços utilizados. $\mathrm{O}$ agente migra para as máquinas a serem monitoradas e caso um destes servidores for indevido, poderá alterar resultados do monitoramento encobrindo resultados importantes para a detecção da invasão. 
- Problema $\mathbf{n}^{\circ}$ 5: Integridade do agente. Os agentes não são protegidos durante a sua transmissão e execução. $\mathrm{O}$ que pode acontecer é que um agente pode ser capturado durante sua transmissão, alterado e enviado ao servidor de destino ou origem, não sendo possível identificar se realmente houve alguma alteração. $\mathrm{O}$ agente poderá retornar informações diferentes da esperada ou até mesmo executar ações diferentes das quais lhe foram delegadas.

- Problema $\mathbf{n}^{\circ}$ 6: Confidencialidade das informações. Há situações em que um agente precisa de se autenticar em algum serviço para que ele possa prosseguir na execução de suas tarefas. Am algumas vezes é necessário que o agente leve consigo senhas e usernames para logar em algum servidor. Atualmente, nenhuma proteção é fornecida para que se possa proteger e garantir a confidencialidade das informações carregadas com os agentes.

- Problema n ${ }^{\circ}$ 7: Autorização de acesso aos recursos do sistema. Como foi dito, para que se possa fazer a administração da segurança do sistema, os agentes possuem privilégios de superusuário e acesso irrestritos a todos os recursos. Mas nem sempre é necessário que todos os agentes possuam os mesmos privilégios e as mesmas autorizações de acesso sem que eles realmente precisem. Um agente que irá monitorar o processamento de um servidor não precisa necessariamente ter a capacidade e a autorização de abrir uma porta para conexão. O controle de autorização ajuda a prevenir que agentes maliciosos tenham acesso total aos recursos do sistema minimizando a possibilidade de sucesso de um ataque.

- Problema $\mathbf{n}^{\mathbf{0}}$ 8: Serviço de Auditoria insuficiente. Toda vez que os agentes executam alguma ação, sendo para monitorar ou para bloquear um ataque, é feito um arquivo de log contento algumas informações para que possa ser feita uma auditoria tanto nas informações capturadas quanto nos resultados das ações de bloqueio de ataques. As informações capturadas são somente das ações dos agentes e não informam o que o ataque estava realmente utilizando no sistema como arquivos e programas. O serviço de auditoria é importante também no servidor para que suas ações, e também as do administrador/usuário, sejam monitoradas a ponto de facilitar a identificação de problemas ajudando a sua solução. 
O objetivo da identificação desses problemas não é tirar os méritos do sistema apresentado neste capítulo e sim apresentar parâmetros que serão utilizados na avaliação dos ambientes. A seleção do ambiente ideal será importante para aumentar a confiabilidade do sistema. $\mathrm{O}$ ambiente ideal será aquele que apresentar os serviços necessários para a solução dos problemas de segurança apontados. 


\section{Ambientes Servidores para Agentes Móveis}

Neste capítulo, serão apresentados 5 (cinco) toolkits e ambientes servidores para agentes móveis disponíveis na web. Foram encontrados diversos ambientes servidores, comerciais e acadêmicos, implementados em C++, TCL, PERL, LISP e Java. Um dos critérios utilizados para a seleção do ambientes foi a linguagem utilizada na sua implementação. Todos os ambientes selecionados foram implementados utilizando Java, pois esta linguagem oferece uma série de vantagens que são discutidas no capítulo 3.

\subsection{Aglet Software Development Kit (IBM, 1998)}

Aglets são objetos Java que podem mover-se de um host para outro na rede. Em cada host deve haver o servidor de aglets denominado Tahiti ${ }^{\circledR}$ (Figura 6.1). O Tahiti é uma aplicação Java que permite ao usuário receber, gerenciar, e enviar Aglets para outros computadores que estão também executando o Tahiti.

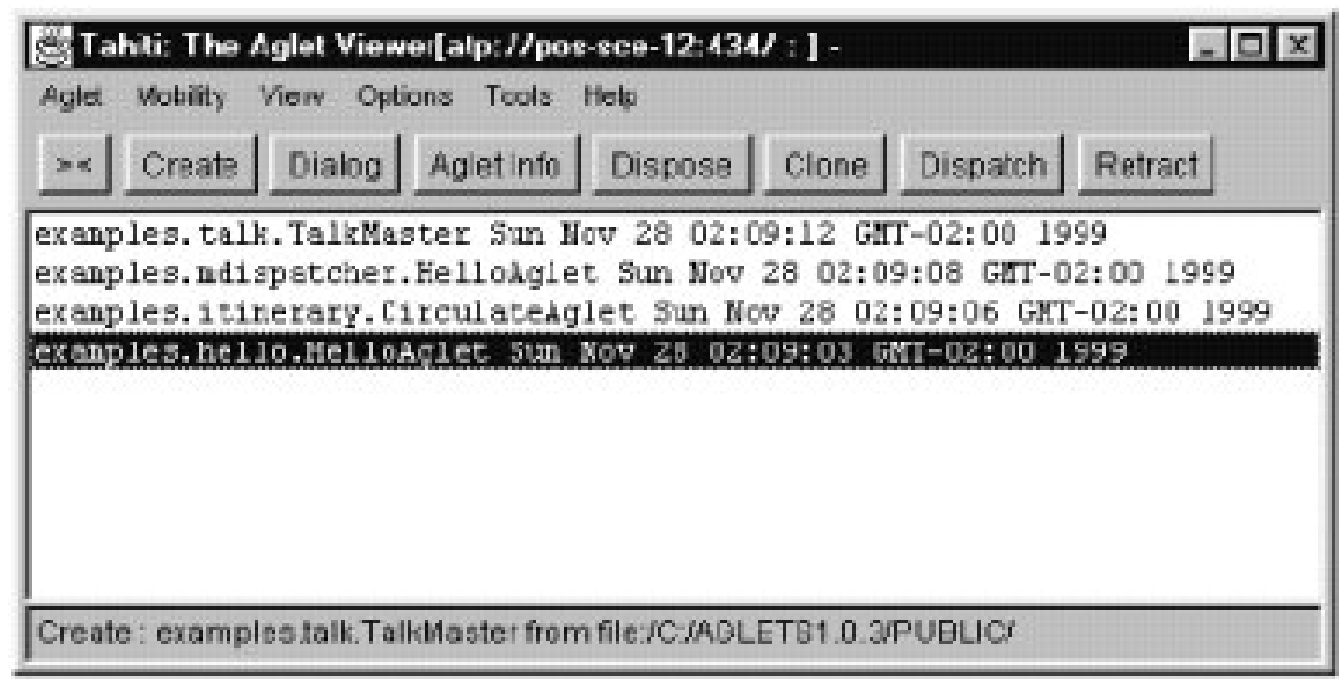

Figura 6.1 - Ambiente servidor para agentes móveis Tahiti ${ }^{\circledR}$

Quando o aglet se move, leva o seu próprio código, assim como os estados de todos os objetos que possui. Mecanismos de segurança embutidos podem ser utilizados para manter os aglets seguros contra hosts não-confiáveis.

Os objetivos do ambiente são fornecer um modelo fácil e compreensivo para a programação de agentes móveis sem necessitar de modificações na Máquina Virtual Java ou no código nativo, suporte dinâmico e comunicação poderosa que permite aos agentes comunicar com agentes desconhecidos assim como com agentes conhecidos, 
projetar arquiteturas reutilizáveis e extensíveis, projetar arquiteturas compatíveis com a tecnologia Web/Java existentes, fornecer mecanismos de segurança que são compreensivos e simples suficientes oferecer aos usuários agentes móveis confiáveis.

ASDK oferece uma Aglet API que define as funcionalidades fundamentais de agentes móveis. A figura a seguir (Figura 6.2) demonstra as interfaces principais e classes definidas na Aglet API e o relacionamento entre as interfaces.

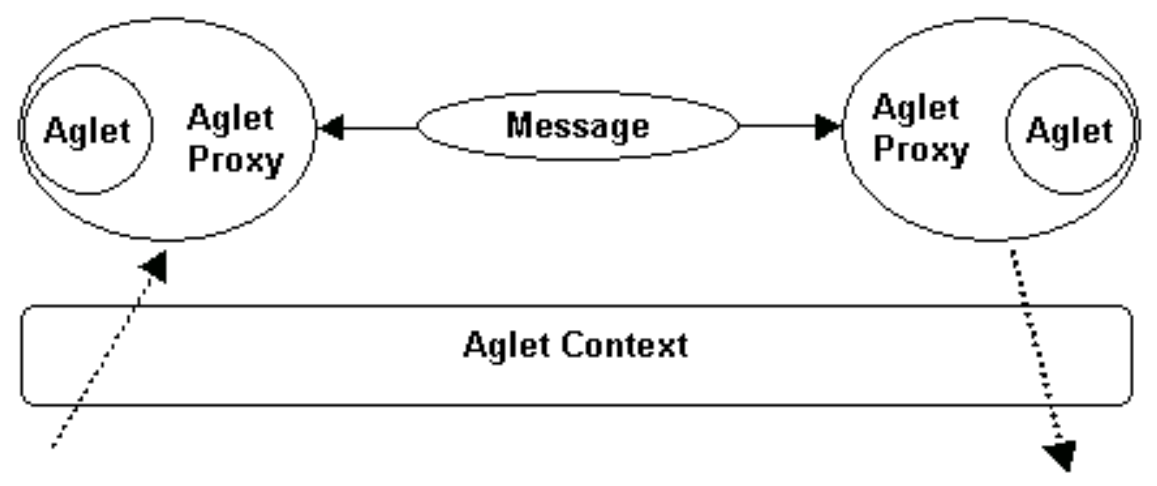

Figura 6.2 - Interfaces e seus relacionamentos

No modelo de objeto Aglet, um agente móvel é um objeto móvel que tem sua própria thread de controle, é orientado a evento e comunica por passagem de mensagem. Um modelo de objeto Aglet define um conjunto de abstrações e o comportamento necessário para a tecnologia de agentes móveis em redes de longa distância abertas, como a Internet. A abstração chave é composta por: Aglet, AgletProxy, AgletContext e AgletID, que são explicadas a seguir:

- Aglet: Um Aglet é um objeto Java móvel que visita hosts habilitados em uma rede de computadores.

- AgletProxy: Um proxy é uma representação de um Aglet. Ele serve como uma proteção para o Aglet contra acessos diretos a seus métodos públicos. O proxy também fornece transparência de localização para o Aglet; isto é, ele pode ocultar a localização real dos Aglets. Isso significa que um Aglet e seus proxies podem estar separados, de forma que um proxy local oculta à distância o Aglet. 
- AgletContext: O contexto é o lugar de trabalho do Aglet. Ele é um objeto estático que fornece um meio de manter e gerenciar Aglets rodando em um ambiente de execução uniforme onde o sistema host é protegido contra Aglets maliciosos. Um nó em uma rede de computadores pode rodar múltiplos processos servidores e cada servidor pode hospedar múltiplos contextos. Contextos são nomeados e assim podem ser localizados pela combinação do endereço do servidor e seu nome.

- AgletID: Um identificador é associado para cada Aglet. Esse identificador é único e imutável ao longo do ciclo de vida do Aglet.

A Aglet API possui diversas classes cada uma com funções específicas. As seguintes classes abaixo são as principais:

- com.ibm.aglet.Aglet: A classe abstrata Aglet define os métodos fundamentais utilizadas para controlar a mobilidade e o ciclo de vida dos agentes móveis. Todos agentes móveis definidos como Aglet são umas extensões a esta classe abstrata. Dentre os métodos existentes na classe, alguns podem ser destacados. A primitiva Aglet.dispacth(URL) é responsável em mover o aglet da máquina local para um destino especificado pelo argumento. A primitiva Aglet.deactivate(long time) permite que um aglet seja armazenado em uma memória secundária e a primitiva Aglet.clone() gera uma nova instancia do aglet que tem o mesmo estado do aglet original. Nota-se que o objeto retornado pela primitiva clone não é um objeto Aglet mas um objeto AgletProxy.

A classe Aglet é também utilizada para acessar atributos associados a um aglet. $\mathrm{O}$ objeto com.ibm.aglet.AgletInfo, contém todos os atributos do aglet, como a data de sua criação e a localização do seu código, assim como os atributos dinâmicos como o tempo de chegada e o endereço do contexto. 
- com.ibm.aglet.AgletID: Toda instancia aglet tem sua própria identidade que é única e imutável durante todo o ciclo de vida do aglet. Um a identidade pode possuir o ID do usuário e o tipo do sistema do agente.

- com.ibm.aglet.AgletProxy: A interface AgletProxy age como um handle de um aglet e fornece uma maneira comum de acessá-lo. Uma classe aglet possui diversos métodos públicos que não deveriam ser acessados diretamente por outros aglets devido às razões de segurança, por isso, qualquer aglet que deseja comunicar com outros aglets tem, primeiro, que obter o objeto proxy. Em outras palavras, o proxy do aglet age como um campo de força que protege um agente dos agentes maliciosos. Quando o proxy é chamado, o objeto consulta o Gerenciador de Segurança para determinar se a chamada é permitida. Um outro ponto importante da interface AgletProxy é a transparência de localização do aglet, podendo um proxy estar separado do aglet, mantendo-o oculto.

- com.ibm.aglet.AgletContext: A classe AgletContext fornece uma interface para a execução dos aglets. Qualquer aglet pode obter uma referencia para um objeto AgletContext. Um vez que o aglet tenha sido enviado a um servidor, o contexto no qual estava inserido é liberado e um contexto no servidor de destino é ativado no instante da chegada do aglet

- com.ibm.aglet.Message: Os objetos Aglets se comunicam através do objeto de troca de mensagens Message. O objeto de mensagens tem uma string especificando o tipo da mensagem e os argumentos. Uma mensagem pode ser enviada para o aglet através dos métodos sendMessage(Message msg), sendAsyncMessage(Message msg), sendOnewayMessage(Message msg) da interface AgletProxy, onde a mensagem é passada como um argumento.

\subsection{Concordia (Mitsubishi, 1997)}

Concordia é um framework para o desenvolvimento e gerenciamento de agentes móveis podendo ser utilizado em qualquer dispositivo que suporte Java. Concordia é 
escrito em Java e é portável para qualquer plataforma que possua suporte a Java. O Sistema Concordia, Figura 6.3, é composto de uma JVM (Máquina Virtual Java), o Concordia Server e pelo menos um agente e um nó da rede. Normalmente, o Sistema Concordia consiste em múltiplas máquinas em uma rede, cada uma com uma JVM, Concordia Server e agentes móveis.

O Concordia Server é um programa Java que é utilizado para "hospedar" os agentes móveis. O Concordia Server é responsável em fornecer todas as funcionalidades Concordia em uma máquina. O Concordia Server gerencia o ciclo de vida de um agente. Ele cuida da criação e destruição do agente e ainda fornece um ambiente no qual os agentes móveis são executados. O servidor possui um painel de configuração para tarefas básicas como localização do repositório dos agentes, iniciar e desligar o servidor, Figura 6.4 .

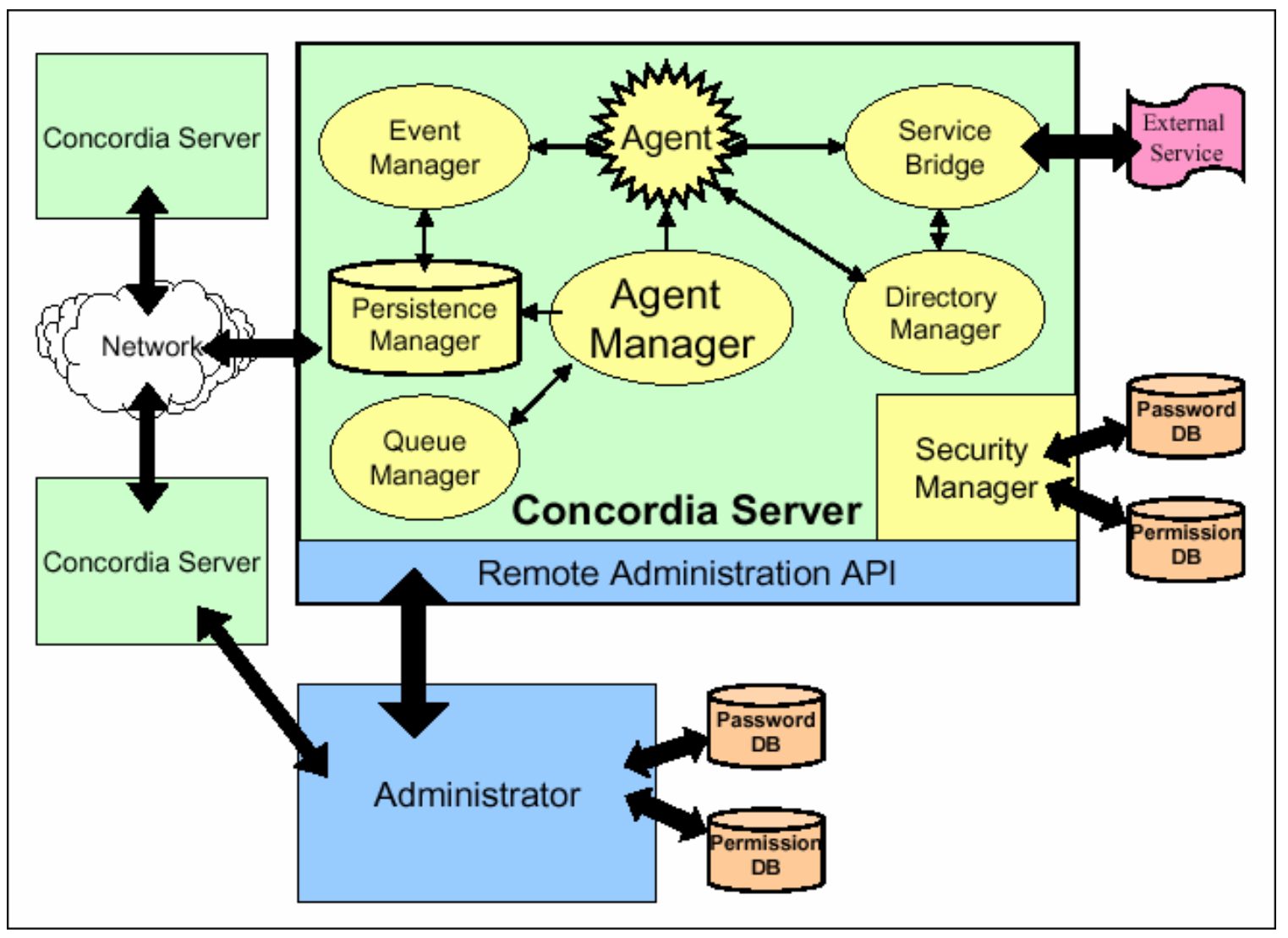

Figura 6.3 - Sistema Concordia

O Concordia Server gerencia os agentes móveis incluindo seus códigos, dados e movimentos. Os agentes móveis Concordia são objetos Java. Os agentes móveis Concordia são objetos Java. Os agentes móveis Concordia são importantes na criação 
de aplicações distribuídas. Os agentes móveis são inerentes as limitações da arquitetura cliente/servidor. O fluxo dos agentes móveis Concordia é em torno de uma rede; ao contrário da arquitetura request/response de cliente/servidor. De fato, cada nó da rede é um servidor e o agente (programa) move-se para a posição onde pode encontrar os serviços que ele necessita para sua execução. Por exemplo, um agente móvel pode viajar para múltiplas bases de dados localizadas em pontos diferentes, procura em cada base de dados em cada ponto e então retorna com os resultados e os entrega ao usuário.

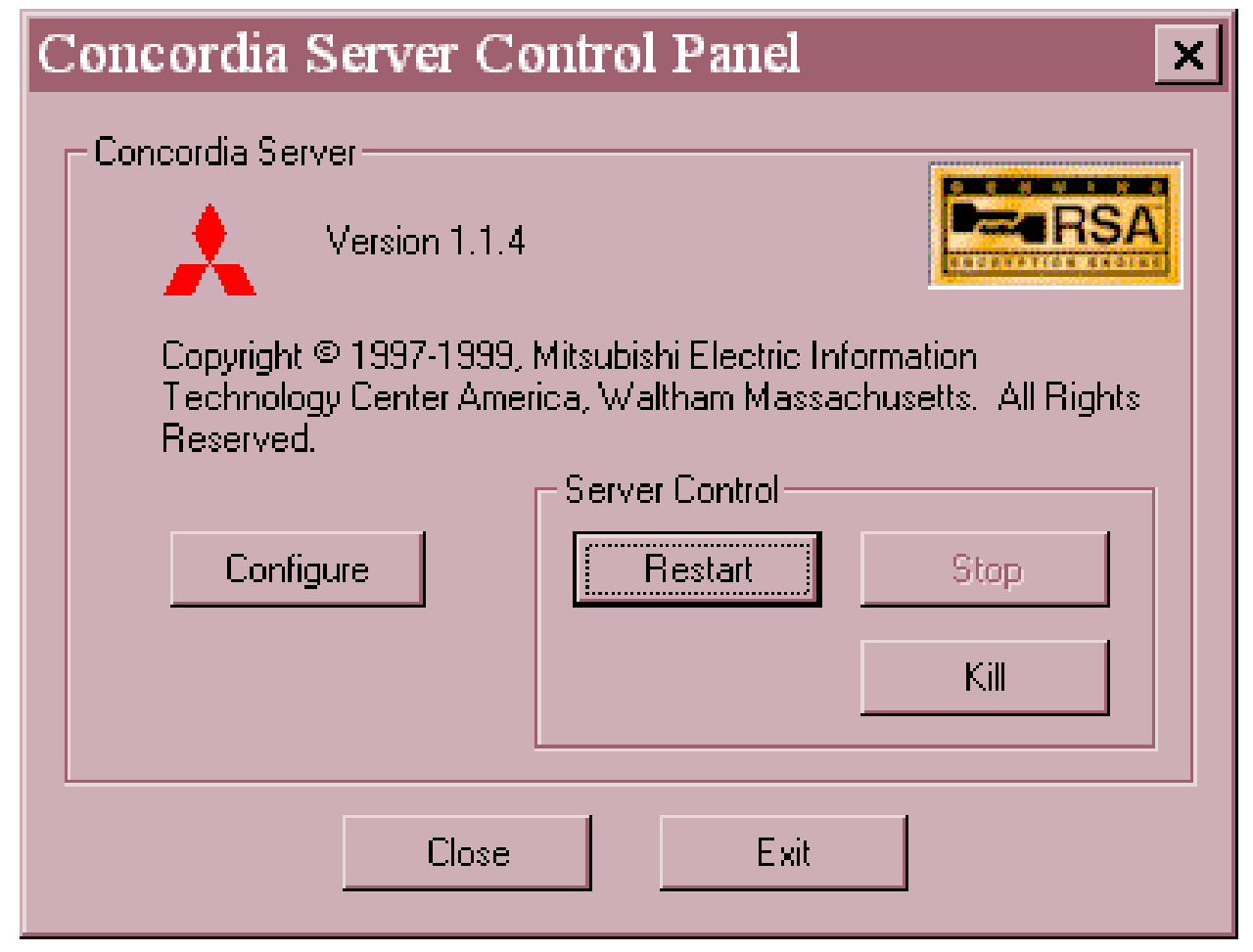

Figura 6.4 - Painel de controle do servidor Concordia

Os Concordia Servers se informam um a um para se conectarem de acordo com as exigências para se comunicarem de uma maneira segura e confiável. $\mathrm{O}$ agente inicia a transferência invocando os métodos do Concordia Server. Ao receber os sinais, o Concordia Server suspende a execução do agente e cria uma imagem dele para ser transferida. O Concordia Server analisa um objeto chamado de Itinerary, criado por cada agente, para determinar o destino. O servidor de destino é contatado e a imagem do agente é transmitida, onde é armazenado novamente antes de ser reconhecido.

Após a sua transferência, o agente é enfileirado para execução no nó receptor. A sua execução normalmente acontece quase que imediatamente, mas há a possibilidade de 
que se sujeite a certos obstáculos administrativos. Quando o agente inicia a sua execução, ele é reiniciado no novo nó de acordo com o método especificado no objeto itinerário. As credencias de segurança são automaticamente transferidas com o agente e seus acessos aos serviços está sobre o controle administrativo todo tempo.

A tarefa que o agente executa depende do código do qual ele foi programado para executar. Geralmente, os agentes têm vários componentes da mesma forma que programas "normais" possuem. Um agente inicia interativamente, por iniciativa do usuário que passas informações para que sejam encontradas, permitindo então que o agente viaje a um servidor para efetuar a consulta. Quando a tarefa é finalizada, o agente se move para outros Concordia Servers. Agentes com diferentes propósitos poderão ter diferentes itinerários.

O Sistema Concordia é formado de diversos componentes, cada qual se interagindo formando um framework para Agentes Móveis. O Concordia Server é formado por vários Concordia Managers, cada um sendo responsável por procedimentos diferentes.

Todo componente Concordia é codificado completamente em Java.

O Concordia Server é um componente que é instalado e é executado em uma máquina em uma rede. O Concordia Server é formado por componentes gerenciadores como o Agent Manager, Administrator Manager, Security Manager, Persistence Manager, Event Manager, Queue Manager, Directory Manager e Service Bridge.

O Agent Manager fornece toda a infra-estrutura de comunicação que permite que os agentes sejam transmitidos e recebidos pelos nós da rede. Tudo é feito transparentemente para o programador do agente, pois ele não precisa conhecer as especificações da rede e nem programar qualquer interface de rede. O Agent Manager também gerencia o ciclo de vida do agente. Ele é responsável pela criação e destruição e fornece um ambiente no qual o agente é executado. 
A Administração da rede Concordia é feita pelo Administrator Manager. O Administration Manager gerencia todos os serviços fornecidos pelo Concordia Server, incluindo o Agent Manager, Security Manager, Event Manager, etc. O Administration Manager suporta administração remota e pelo menos um é requerido em uma rede Concordia, podendo ser incluído outros mais. O Administration Manager tem um componente de interface com o usuário que é por onde o administrador executa suas tarefas de administração.

O Security Manager é responsável pela identificação dos usuários, autenticando seus agentes, protegendo os recursos do servidor e garantindo a integridade do agente e seus dados. O Security Manager é também responsável na autorização de classes Java dinamicamente carregadas para satisfazerem as necessidades do agente. O Security Manager tem uma interface com o usuário por onde ele configura e monitora os atributos de segurança de vários usuários e serviços. As funções da interface são integradas ao Administration Manager.

Para sistemas que utilizam redes públicas, torna-se necessária a criptografia e o uso de credenciais que possuem a identidade do usuário, como o seu nome e grupo. Para sistemas desenvolvidos para Internet, uma autenticação e segurança mais poderosa podem ser fornecidas por autoridades externas que fornecem assinaturas digitais. $\mathrm{O}$ Security Manager suporta todos esses níveis de segurança.

O Persistence Manager mantém o estado dos agentes em trânsito pela rede. A vantagem disso é que permite o uso de checkpoints e o reinicio dos agentes quando ocorrer uma falha do sistema.

O Persistence Manager é completamente transparente nas suas operações. Nem os agentes e nem o administrador precisa controlar ou monitorar a operação. Entretanto, se necessário, o acesso ao gerenciamento é permitido.

O Event Manager cuida da inscrição, postagem e notificação de eventos dos agentes. O Event Manager pode enviar notificações de eventos aos agentes em qualquer nó da 
rede. O Event Manager trabalha em conjunto como o Concordia Server na distribuição dos eventos.

O Queue Manager é responsável por escalonamento dos agentes no sistema Concordia. Entre suas características, inclui-se a manutenção de agentes a medida que eles esperam a oportunidade executar suas tarefas, mantendo-se no estado em que eles entraram e saíram de um sistema. O Queue Manager fornece mecanismos para priorizar e gerenciar execução de agentes.

O Directory Manager fornece o serviço de nomes em uma rede Concordia. O administrador pode configurar o serviço de nome de acordo com as necessidades do programador e serviços. O Directory Manager pode consultar um serviço de nomes local ou pode ser configurado para passar a requisição a outro servidor de nomes.

O Service Bridge fornece a interface dos agentes Concordia para os serviços disponíveis em várias máquinas na rede. Ele engloba um conjunto de extensões a programas fornecendo acesso às suas API's nativas.

Para o desenvolvimento dos agentes móveis, é fornecida uma biblioteca que fornece todas as classes necessárias, incluindo, é claro, a classe Agent e outras derivadas de classes básicas da linguagem Java. Estas ferramentas são conhecidas como ATL, Agent Tools Library.

\subsection{Grasshopper (IKV, 99a)}

O ambiente Grasshopper é o primeiro a ser desenvolvido seguindo os padrões MASIF. Grasshopper oferece um suporte a segurança e facilidades para gerenciamento. A proteção oferecida é aplicável aos agentes e ao ambiente (contra agentes maliciosos).

Outras capacidades essenciais do ambiente são a extensibilidade e integração das tecnologias existentes como Java e CORBA (Common Object Request Broker Architecture). Grasshopper é completamente implementado em Java. Desta forma, o ambiente pode ser instalado em qualquer computador que possui uma Máquina 
Virtual Java. Grasshopper pode se interagir com outras aplicações em Java e elas podem ser incorporadas aos seus agentes.

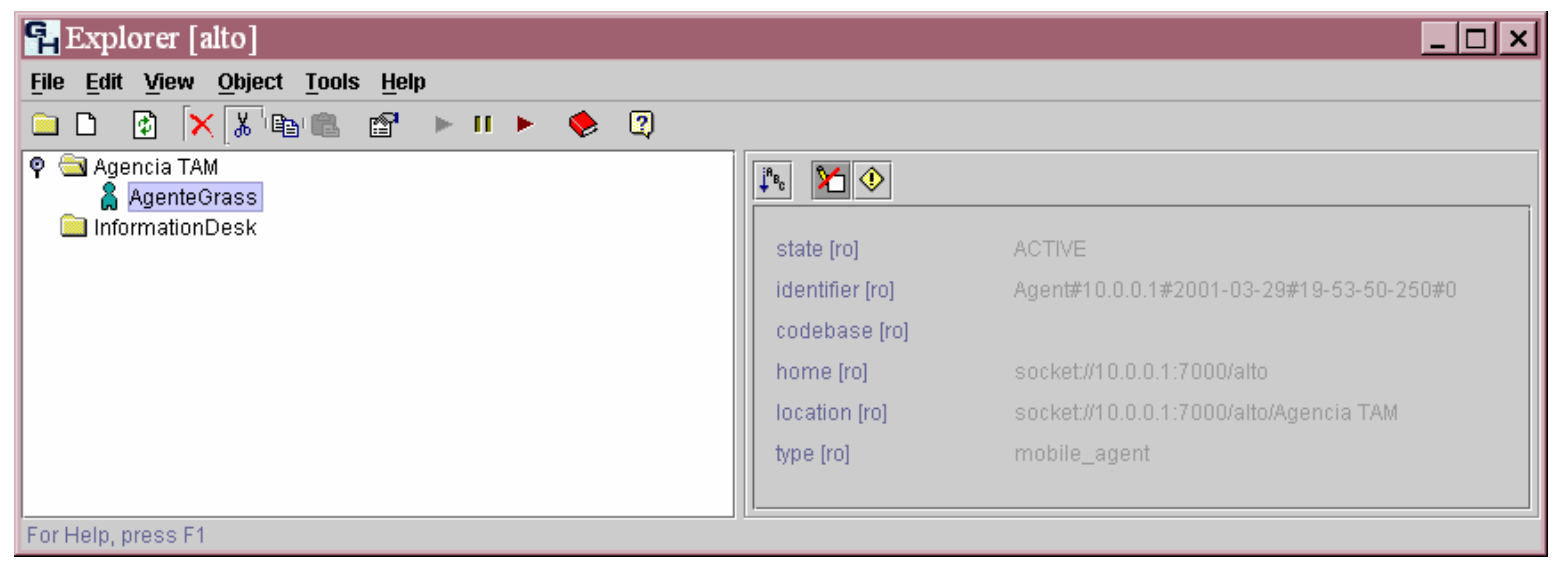

Figura 6.5 - Interface gráfica para gerenciamento de agentes e agências

A arquitetura do Grasshopper é aberta e suporta adaptações e extensões para satisfazer exigências de ambientes de execução específicos, como o Windows CE, ou para alterações no protocolo de comunicação, mecanismos de segurança, etc. A Figura 6.5 demonstra a interface de gerenciamento do Grasshopper.

A Figura 6.6 mostra a estrutura de um ambiente baseado em Grasshopper, formado por várias agências agrupadas em um domínio (região), como uma intranet.

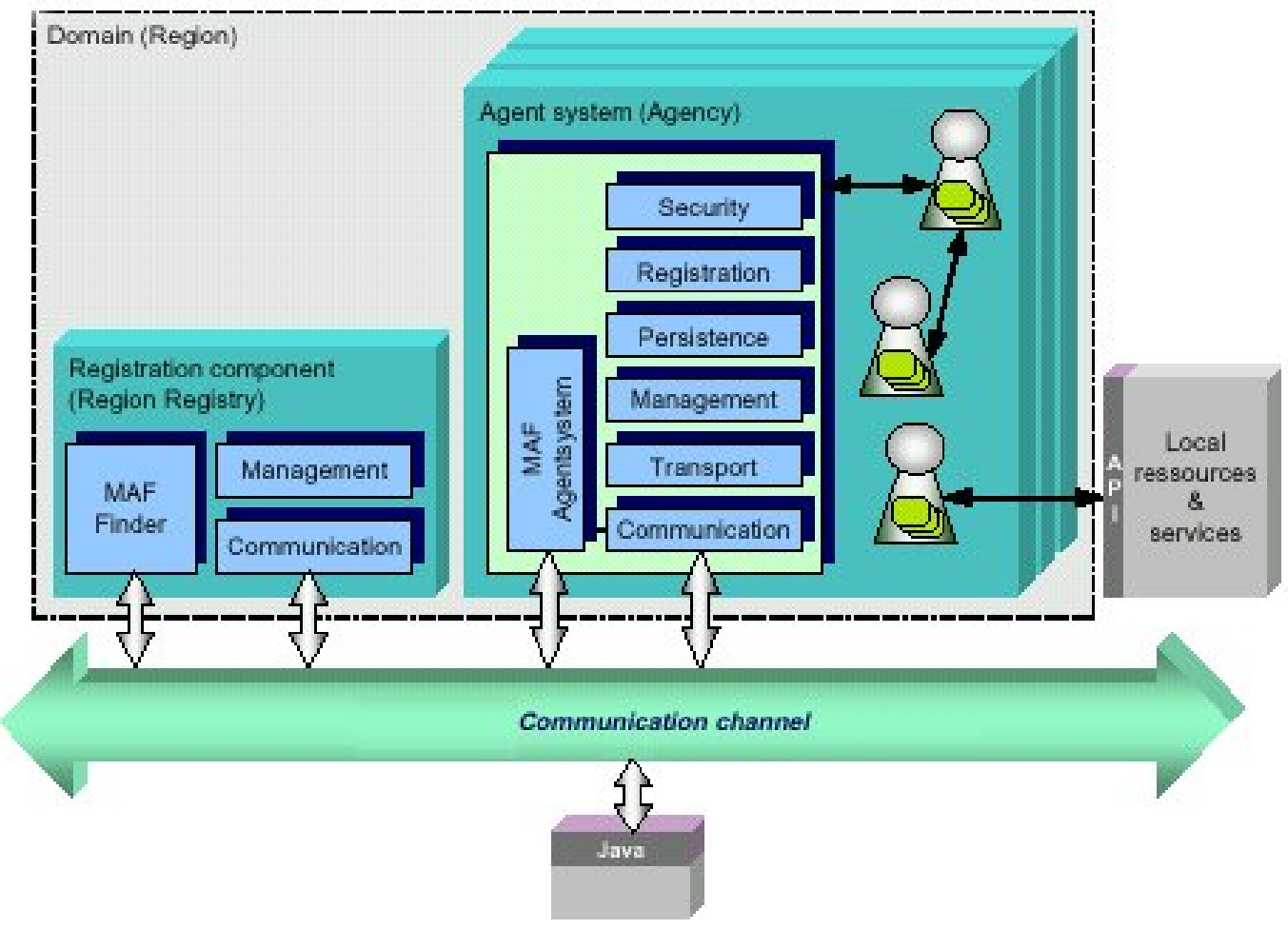

Figura 6.6 - Ambiente baseado no Grasshopper

Nas seções a seguir, tem-se a explicação das funções de cada componente e serviços. 


\subsubsection{Sistema de Agentes (Agência)}

Uma agência é um processo Java que controla a execução, gerenciamento, transporte, comunicação e outras funções dos agentes Grasshopper. Cada agência possui os seguintes serviços:

- Segurança (Security): Um agente móvel pode ser considerado um "elemento estranho" na visita a um host, uma tarefa fundamental de uma agência é proteger o host contra o acesso de agentes não-autorizados. Grasshopper oferece mecanismos de segurança externa que permite a criptografia dos agentes (código e estado) durante a transmissão, utilizando o protocolo SSL (Secure Socket Layer). Se necessário, as interações remotas entre entidades Grasshopper (agentes, agências, componentes) podem ser protegidas via SSL. Por meios de certificados, uma agência pode identificar e autenticar um agente.

- Registro (Registration): Cada agência registra todos os agentes que estão em execução localmente a fim de monitorar e controlar todos os seus processos internos e a fim de controlar a interação entre agentes.

- Persistência (Persistence): Utilizado para salvar as informações relacionadas aos agentes no caso de um crash no sistema. O serviço pode ser utilizado periodicamente para armazenar os estados internos e todos os agentes locais que estão em execução. Desta maneira, os agentes podem continuar a execução de suas tarefas após o reinicio da agência.

- Gerenciamento (Management): O serviço de gerenciamento é responsável em criar, remover, suspender e copiar os agentes. Os administradores podem interferir na execução dos agentes, via uma interface gráfica, sempre que for necessário, Figura 6.5 .

- Transporte (Transport): O serviço de transporte permite a serialização de um estado de um agente, transferência do agente a uma outra agência (através do serviço de comunicação), e o reinicio do agente no seu destino.

- Comunicação (Communication): O serviço de comunicação permite a transferência de agentes entre diferentes agências. $O$ serviço é também responsável em gerenciar as interações entre agentes remotos e entidades nãoagentes. Desta maneira, Grasshopper é capaz de integrar a tradicional arquitetura cliente/servidor com a tecnologia de agentes móveis. 
- MAF AgentSystem: Este componente realiza uma interface que é parte do padrão MASIF e ele permite que haja interoperabilidade entre o Grasshopper e qualquer outra plataforma de agentes.

\subsubsection{Componente de Registro (Region Registry)}

Uma agência pode se registrar em um componente de registro, registro de região. $\mathrm{O}$ registro de região é um serviço de informações centra que mantém informações sobre todas as agências registradas assim como todos os agentes em execução dentro destas agências. $\mathrm{O}$ grupo constituído por todas as agências registradas em uma única região de registro chama-se de região. $\mathrm{O}$ registro de agentes é automaticamente executado pela agência servidora e é completamente transparente para os agentes. Quando um agente se muda, as informações são automaticamente atualizadas dentro do registro. Desta maneira, um administrado ou agente é sempre pode adquirir informações atualizadas sobre a região ou a agentes específicos. $\mathrm{O}$ registro de região é formado pelos seguintes serviços/componentes:

- Gerenciamento (Management): O serviço de Gerenciamento é responsável por localizar os agentes dentro de uma região.

- Comunicação (Communication): Semelhante ao serviço de comunicação de uma agência, este serviço habilita interações entre o registro de região e entidades remotas (agências, agentes...). Através de uma interface textual, os administradores podem monitorar e controlar o processamento do registro.

- MAF Finder: Este componente realiza uma interface que é parte do padrão MASIF e ele permite que haja interoperabilidade entre o Grasshopper e qualquer outra plataforma de agentes.

Uma importante característica do Grasshopper é a possibilidade de adaptação da plataforma em sistemas diferentes, mantendo suas qualidades sem alteração no hardware ou no sistema.

\subsection{Gossip e Tryllian Agent Toolkit (Tryllian, 99)}

Na Tryllian, desenvolvedora do Gossip, a definição de um agente é "assistente inteligente móvel". Todas as informações do usuário, como interesses e preferências, são armazenadas em um profile do usuário. Um agente móvel é um agente capaz de 
mover-se de um computador para outro. Ele comporta-se como um objeto autônomo e é executado como um processo separado em um computador. Se o computado é conectado a uma rede, o agente pode decidir ele mesmo ou é instruído a mover-se para outro computador na rede e continuar a trabalhar lá.

Para serem autônomos os agentes devem ser inteligentes. Os agentes criados pela Tryllian demonstram um certo nível de inteligência. Eles utilizam um loop de sensereason-act. O loop sense-reason-act é um mecanismo que controla a interação entre uma entidade inteligente e um ambiente dinâmico ou desconhecido. O loop seguido pelo agente é demonstrado na Figura 6.7.

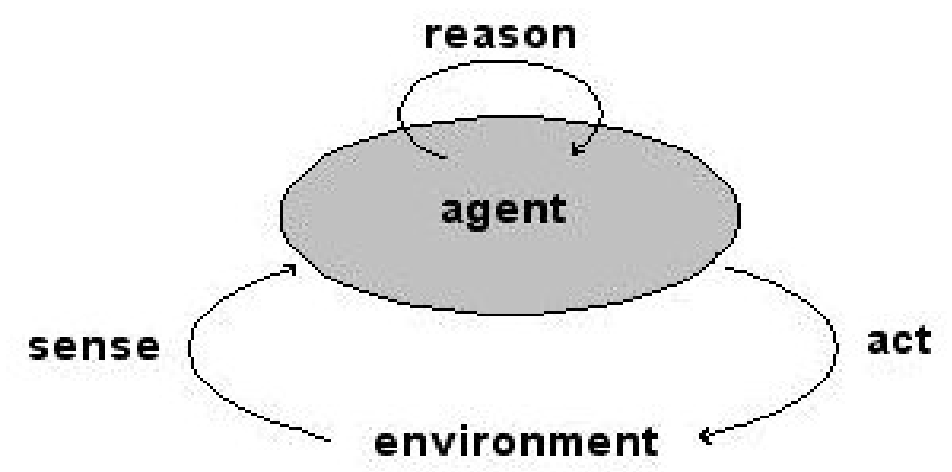

Figura 6.7 - Loop sense-reason-act

Sense: Observa o ambiente e o modela internamente.

Reason: Atualiza o estado interno e determina uma ação baseada no estado do ambiente e no seu estado interno.

Act: Realiza a ação proposta.

Estes passos são repetidos até que o agente tenha completado a tarefa. Utilizando este mecanismo, o agente pode prevenir-se de alterações nos ambientes e de ambientes desconhecidos e agindo de acordo com as observações.

Um exemplo:

Sense: Eu vejo uma xícara de café.

Reason: Eu não estou completamente acordado. Eu acho que irei tomar algum café! Act: eu agarro o copo com minha mão esquerda. 
Sense: Eu sinto uma sensação quente na minha mão esquerda.

Reason: Se eu segurar o copo mais um pouquinho, eu irei queimar a minha mão! E soltaria o copo.

Act: Recolhe a mão!

Os agentes da Tryllian comunicam com os usuários através de diálogos textuais e telas pорир. Os agentes podem, também, ajudar o usuário a gerenciar objetos na home plataform, como os backpacks utilizados para armazenar informações na aplicação Gossip.

Um agente móvel da Tryllian pode se hospedar em um dos dois lugares: em uma Home Base ou em um Ponto de Encontro. Estes são os ambientes, construídos em Java, onde os agentes são executados de uma forma protegida em um computador. Uma Home Base ou Ponto de Encontro permitido que um agente acesse recursos em um computador de uma maneira segura. O proprietário do computador controla quais recursos são acessíveis pelo agente Na Figura 6.8 é representado o ambiente dos agentes como uma estrutura em camadas.

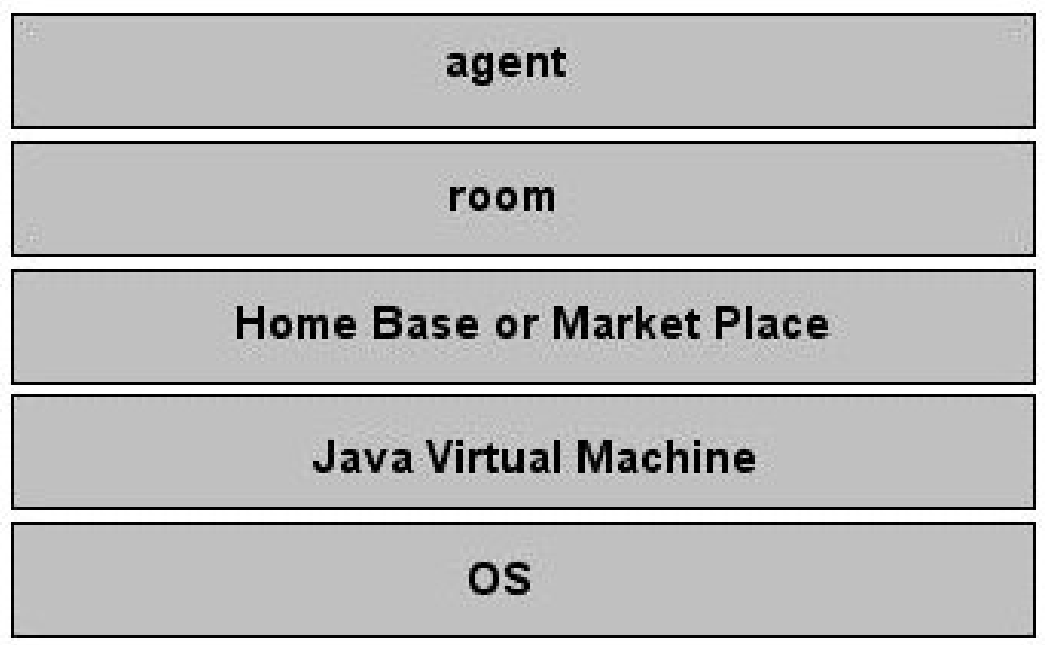

Figura 6.8 - Estrutura em camadas de um ambiente de agentes

Além de oferecer suporte a criação de aplicações agentes, a Tryllian também oferece o ambiente completo para agentes móveis. Este ambiente assegura um nível de segurança que garante que os agentes não possam ser crackeds ou alterados. Gossip (Figura 6.9) é um agente que gerencia e troca informações. O Gossip consiste em uma Home Base com uma interface gráfica bem amigável. O Gossip está disponível para as 
plataformas Windows e no formato Java para as demais plataformas. $\mathrm{O}$ ambiente é bem interativo e animado.

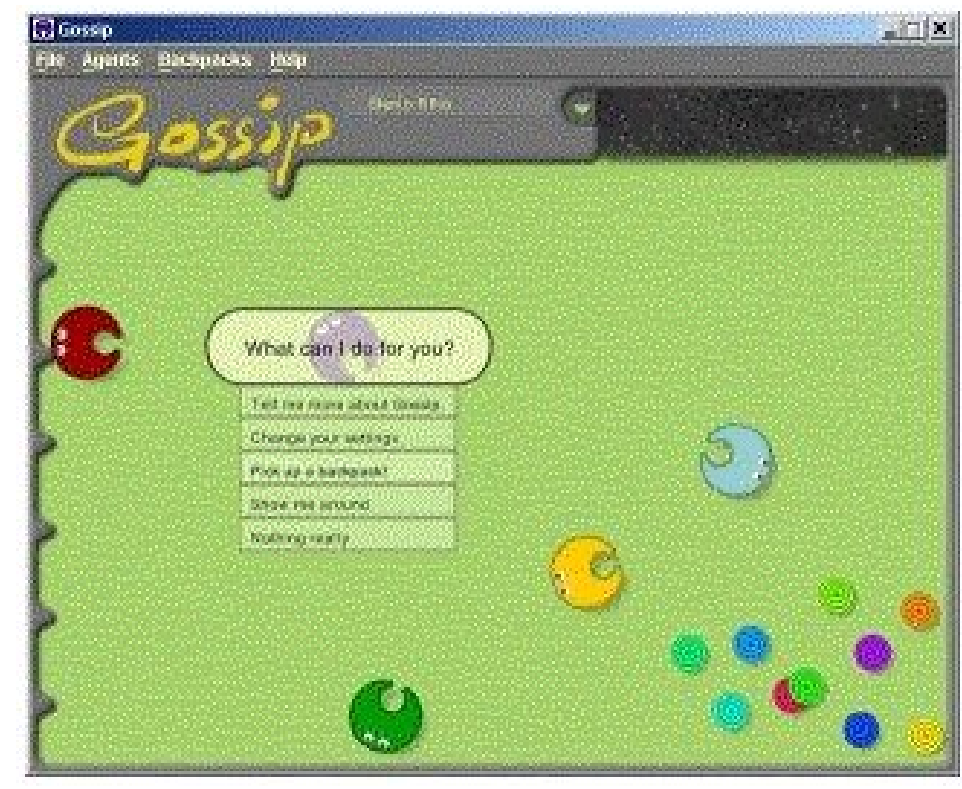

Figura 6.9 - Ambiente Gossip com seus agentes e os backpacks

Toda solicitação de tarefas é feita aos agentes visualmente. $\mathrm{O}$ usuário seleciona um agente e pede a ele que pegue um backpack. Neste backpack estão as informações necessárias para que o agente saiba o que fazer.

\subsection{Considerações Finais}

O objetivo deste capítulo foi apresentar as plataformas selecionadas para avaliação que se encontra no capítulo seguinte. É importante ressaltar que um dos fatores que também influenciou na escolha de tais plataformas foi a documentação e o suporte oferecidos. Diversos outros ambientes, também implementados em Java, não possuíam documentos das API's para desenvolvimento dos agentes e nem do funcionamento do servidor, mesmo sendo solicitado diretamente aos fornecedores. 


\section{Análises de desempenho e segurança}

As análises efetuadas neste capítulo têm a finalidade de demonstrar as características de cada plataforma e seus agentes, para que se tenham parâmetros que influenciem na decisão e na indicação de uma plataforma que mais se adapte ao sistema de detecção de intrusão.

Para efetuar os testes necessários para a captura de informações para análise, foi necessário compreender o desenvolvimento e a criação de agentes, além de aprender o funcionamento de cada plataforma avaliada. Este processo foi o mais demorado e mais complicado de todo o trabalho. O problema maior foi encontrado na documentação, principalmente das plataformas que ainda se encontram na fase "beta". Entre as plataformas avaliadas, Concordia e Gossip foram as mais complicadas, pois suas documentações ainda estão incompletas, em momento algum foi encontrado um material que explicasse como criar um agente básico como o que foi encontrado nas outras plataformas. Já o Grasshoper e ASDK's o processo de aprendizagem e desenvolvimento foi bem menos complicado, mas ainda longe de ser simples. Todas as plataformas apresentaram uma documentação completa das API's de desenvolvimento de seus agentes.

\subsection{Ambiente de testes}

O cuidado maior para a execução dos testes foi criar um ambiente que não influenciasse nos resultados. Como havia comunicação entre servidores, o ideal seria configurar uma rede onde o tráfego fluísse somente entre as máquinas. Um outro cuidado tomado foi em deixar funcionando somente os serviços mínimos necessários ativados para evitar uma grande concorrência com o processador e memória. A disposição e as configurações das máquinas são demonstradas na Figura 7.1. Para testes de desempenho foi utilizada a Maquina 2. A Máquina 1 foi utilizada somente para disparar os agentes para a Máquina 2. 


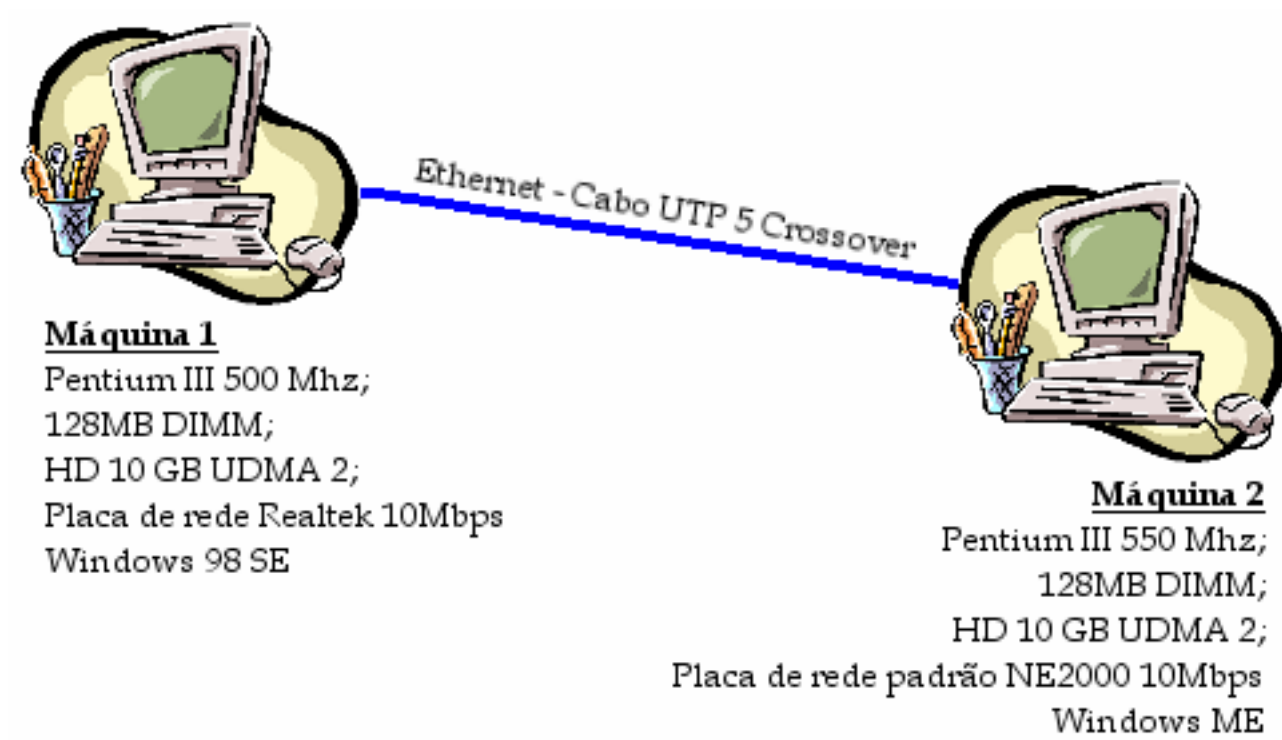

Figura 7.1 - Disposição das máquinas utilizadas nos testes

Para a medir os dados de processamento foi utilizado o Monitor de Sistema oferecido pelo Windows. Os resultados da monitoração eram armazenados em um arquivo de $\log$ com as informações de porcentagem de processamento utilizado a cada 1s (um segundo). A Figura 7.2 mostra a aparência do programa.

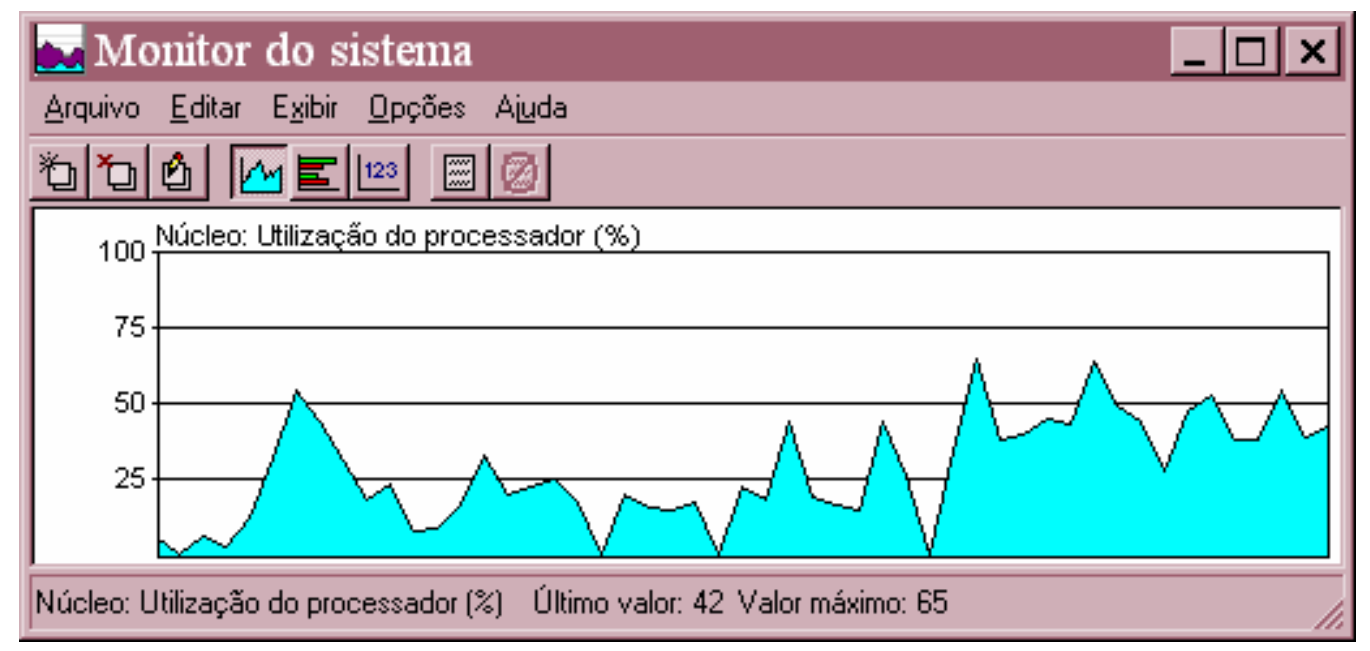

Figura 7.2 - Programa utilizado para capturar informações de processamento

\subsection{Análise de Desempenho}

O objetivo desta análise é demonstrar o desempenho dos agentes de cada plataforma e também comparar os gastos de processamento que os servidores têm quando executam um agente.

A análise de gastos com o processamento é importante para que se possa verificar a carga que a máquina sofrerá quando um sistema baseado na plataforma avaliada for 
utilizado. O interessante é que o sistema se apodere o menos possível do poder de processamento do seu host, possibilitando o compartilhamento do processador com outras aplicações também relevantes. Para o sistema de detecção de intrusão, o importante é que o usuário não sinta que sua máquina está sendo monitorada e que seu processador está sendo utilizado por aplicativos irrelevantes para o seu trabalho.

Já na análise de desempenho dos agentes, o que se verifica, então, é o tempo de resposta do sistema, o tempo gasto pelo agente para a realização de uma tarefa. Para o SDI, a importância do desempenho dos agentes está diretamente relacionada ao tempo de detecção e reação a uma invasão. A lentidão do processo de reação, captura de informações e de análise pode acarretar na ineficiência do sistema e possivelmente na falta de confiabilidade das informações. Em se tratando de segurança, quanto mais rápido puder ser a detecção e a reação, mais confiável e eficiente o sistema será. O processo de invasão pode ser demorado, mas, após o fato ser consumado, a ação do atacante pode ser bem mais rápida e quanto mais demorada for a detecção e a reação, menores serão as chances de evitar danos ao sistema invadido.

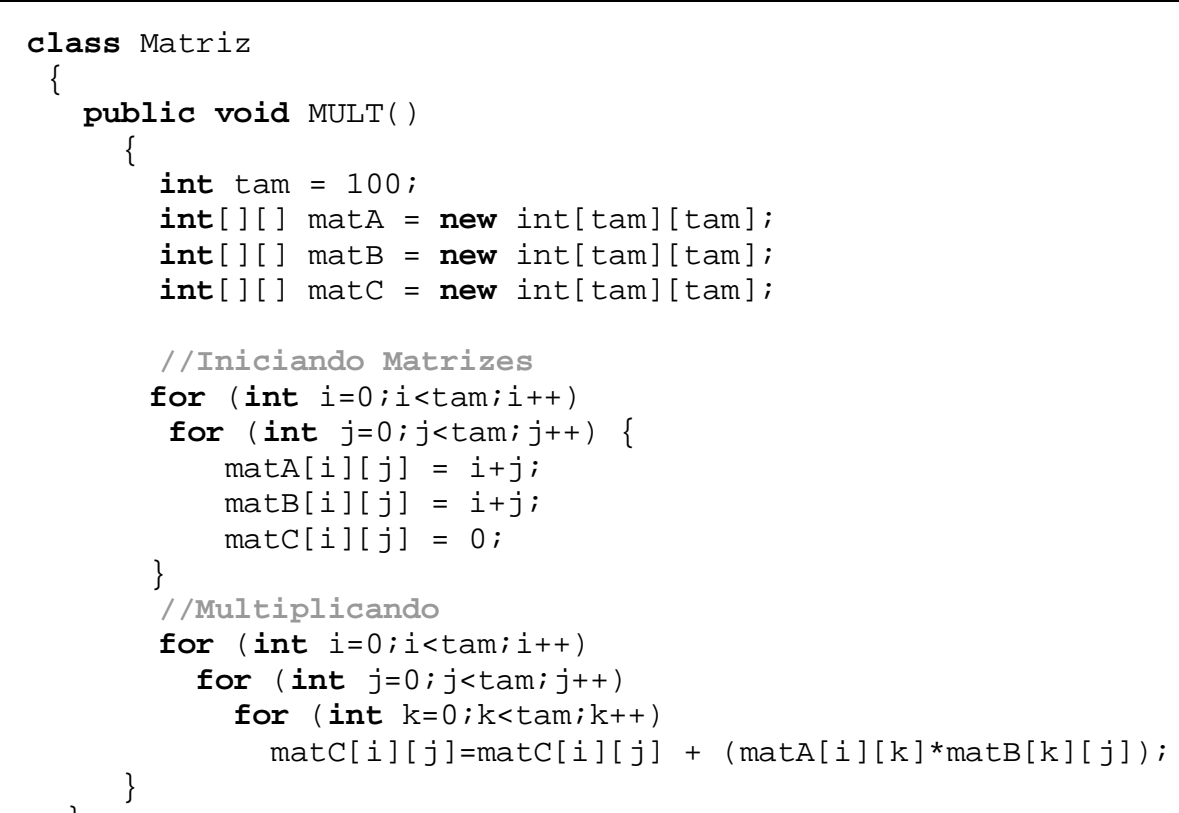

Figura 7.3 - Código fonte da classe de multiplicação de matrizes

O processo de simulação de uma comunicação entre servidores utilizou o esquema apresentado na seção anterior. A Máquina 1 envia um agente que executa uma multiplicação de matrizes 300 x 300, Figura 7.3, na Máquina 2. A multiplicação de 
matrizes foi escolhida, pois possui um código simples e apresenta uma alta demanda de processamento (Figueiredo, 2000).

Para cada plataforma, foi criado um agente que executa o calculo de multiplicação de matrizes. Para a compilação dos agentes foi utilizado o JDK 1.1.8 para manter a compatibilidade entre todas as plataformas, visto que os ASDK's são incompatíveis com Java 2. Na implementação dos agentes, foi seguido o algoritmo apresentado na Figura 7.4. O agente foi executado 100 vezes para obter um resultado médio mais aproximado do real, diminuindo o risco de influências externas como o próprio garbage collect da JVM (Maquia Virtual Java).

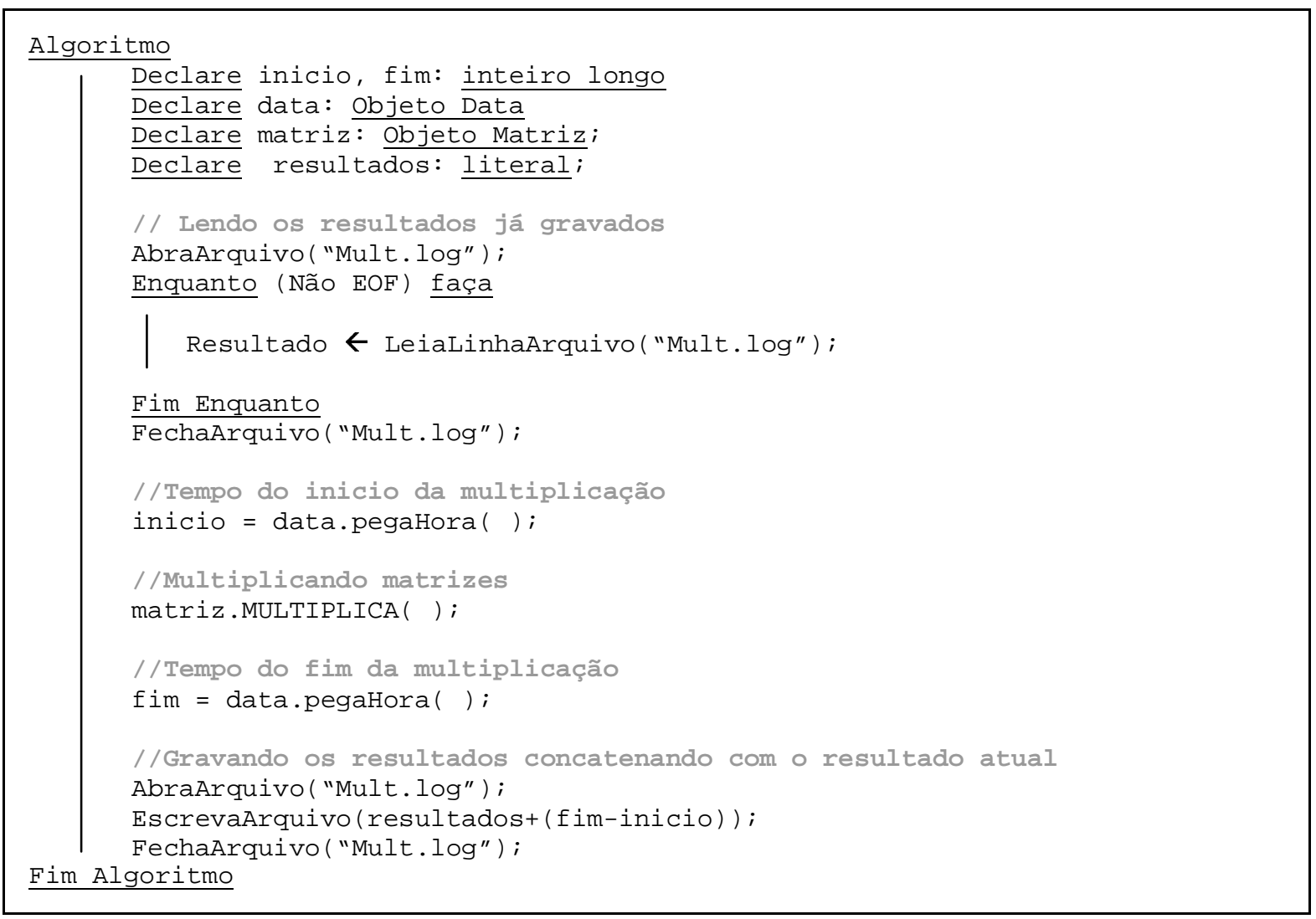

Figura 7.4 - Algoritmo básico do agente multiplicador de matrizes

\subsubsection{Resultados}

Foram executados os testes nas plataformas ASDK 1.0, ASDK 1.1, Concordia, Grasshopper e Gossip. O problema no Gossip é que, até o final da bateria de testes, não havia um ADK (Agent Development Kit) para que o agente matriz fosse criado e testado. Hoje, a Tryllian, desenvolvedora do Gossip, disponibiliza um ADK para desenvolvedores cadastrados e credenciados, não sendo disponível para donwload público. A inclusão da plataforma nos testes de desempenho foi, principalmente, 
para verificar o poder de processamento gasto pelo servidor, pois a interação do usuário com os agentes é feita totalmente gráfica e animada. $\mathrm{O}$ objetivo então era verificar se o fato de possuir uma interface tão amigável, não seria prejudicial ao desempenho de sistemas baseados na sua tecnologia.

As informações capturadas foram divididas em 5 etapas:

1) Carregamento do servidor: Processamento gasto para carregar e ativar o servidor de agentes;

2) Recebimento e instanciamento do agente: Processamento gasto para receber o agente e instanciá-lo na memória;

3) Inicio do agente para execução: Processamento gasto para iniciar a execução do agente (carregamento de todas as classes e reativação do estado prétransmissão)

4) Execução do calculo: Processamento gasto para efetuar o cálculo;

5) Encerramento da execução e encerramento do servidor: Processamento gasto para encerrar e destruir (dispose) o agente e parar a execução do servidor.

As cinco etapas são indicadas nos gráficos de porcentagem de processamento dos servidores para que se tenha uma melhor visualização dos resultados.

Foram gerados dois gráficos para cada plataforma avaliada. $\mathrm{O}$ primeiro apresenta a porcentagem de utilização do processador e o tempo gasto em cada etapa. O segundo apresenta o tempo de cada uma das 100 (cem) execuções do agente matriz.

A primeira versão do ASDK da IBM obteve um bom resultado nos testes, Figura 7.5 e Figura 7.6. A porcentagem média de utilização do processador, $21.63 \%$, foi a segunda mais baixa, perdendo somente para o seu sucessor ASDK 1.1. Já o seu agente se portou de uma maneira instável alterando altos e baixos com a variação de aproximadamente 400 milisegundos e obteve a média de 380.2 milisegundos. Mesmo assim, obteve também a segunda melhor marca quanto ao desempenho do agente, perdendo novamente para o seu sucessor. 


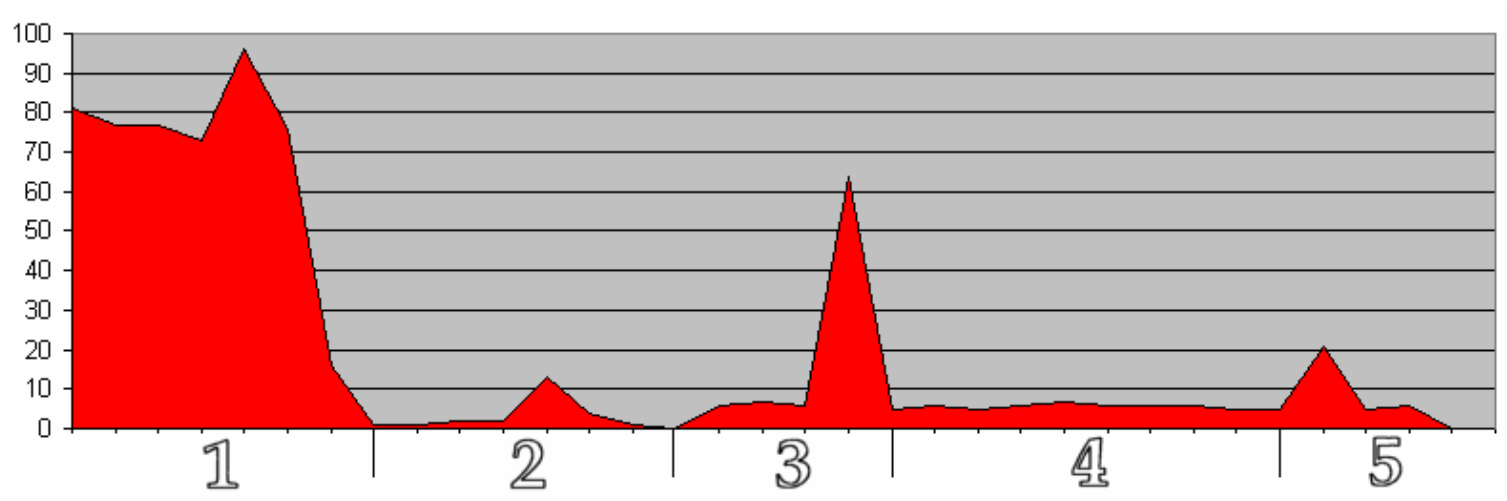

Figura 7.5 - Gráfico de utilização do processador do servidor Tahiti (ASDK 1.0)

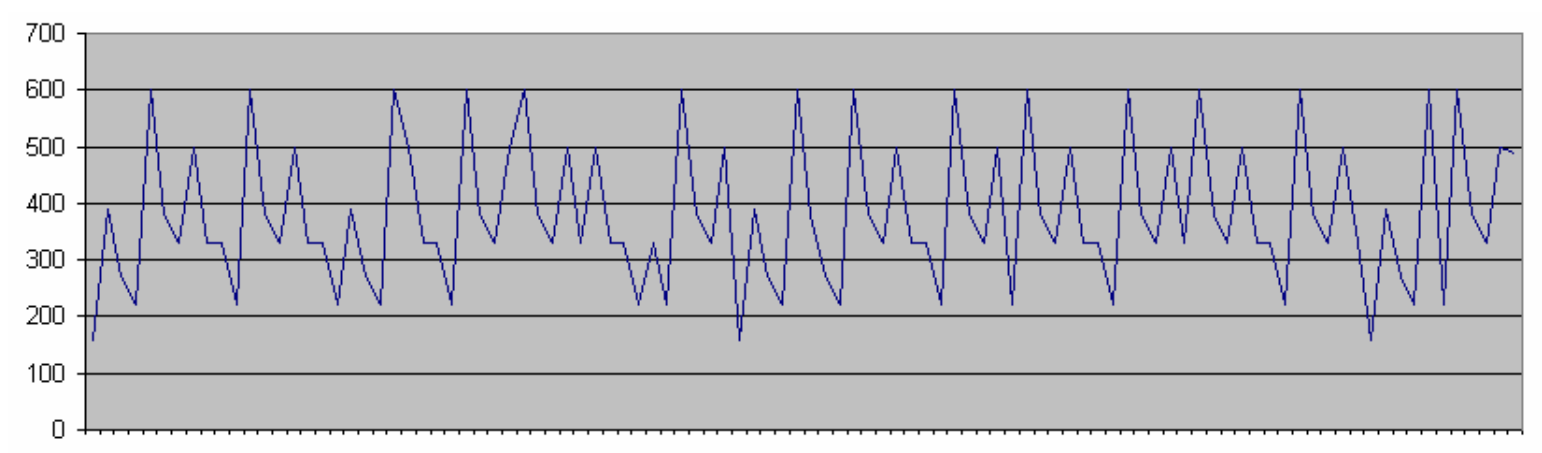

Figura 7.6 - Tempo, em milisegundos, de 100 execuções do agente em ASDK 1.0

O Tahiti (ASDK 1.1) e seu agente, juntos conseguiram os melhores resultados, Figura 7.7 e Figura 7.8. A porcentagem média de utilização do processador do servidor foi de $21 \%$, a menor de todas as plataformas. Já o agente se portou de uma maneira mais estável onde os melhores resultados se diferenciavam do pior em no máximo aproximadamente 150 milisegundos. Sua média de execução foi de 328 milisegundos. O mais rápido e o que exige menos poder de processamento da máquina.

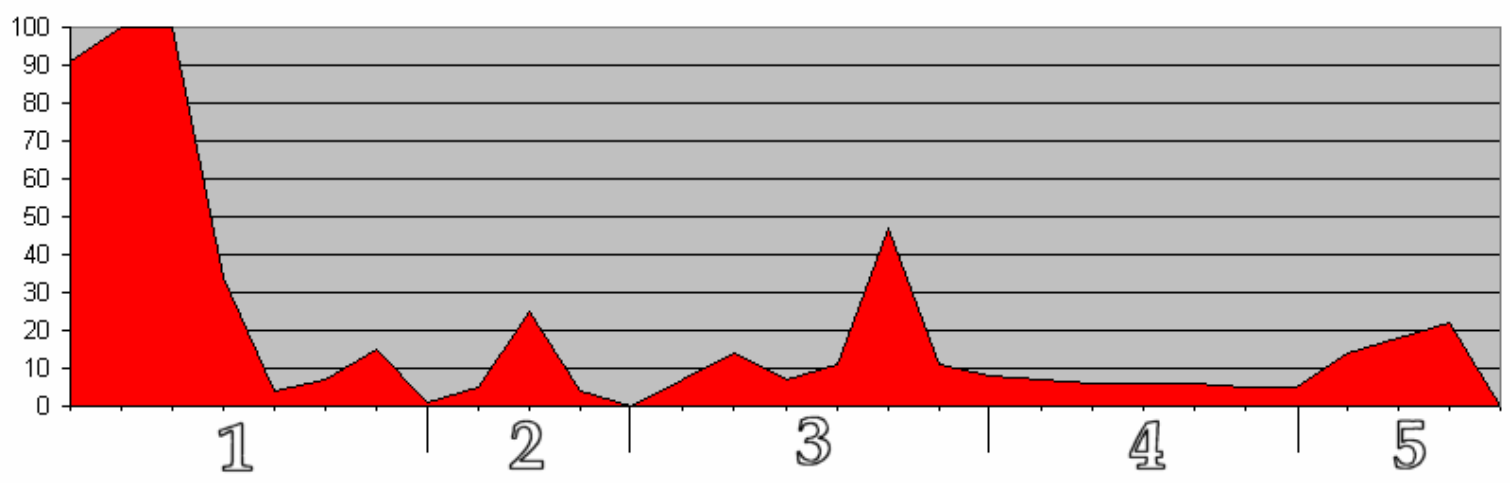

Figura 7.7 - Gráfico de utilização do processador do servidor Tahiti (ASDK 1.1) 


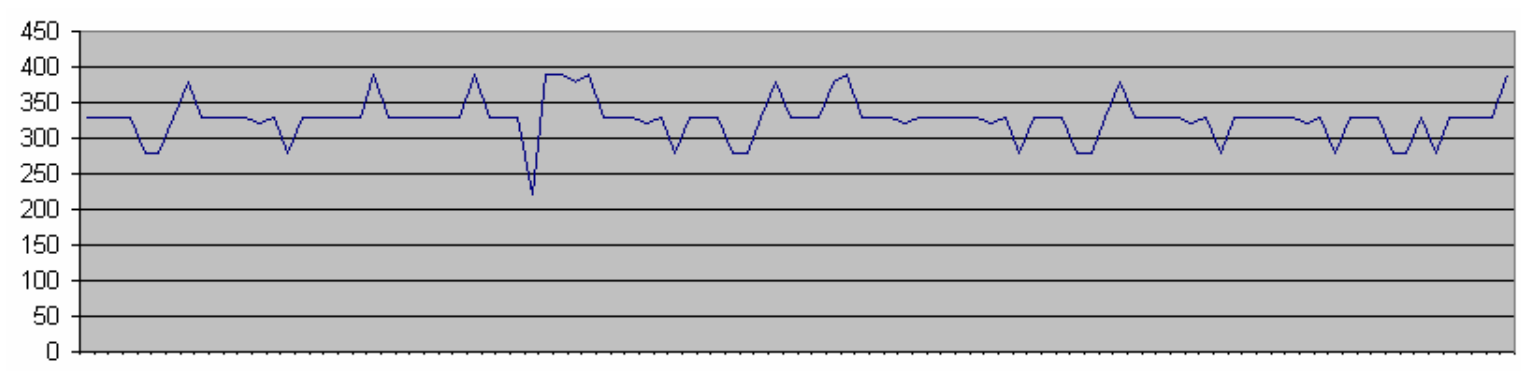

Figura 7.8 -Tempo, em milisegundos, de 100 execuções do agente em ASDK 1.1

Já o Concordia Server obteve resultados menos impressionantes, Figura 7.9 e Figura 7.10. A porcentagem de utilização do processador foi a mais alta, ultrapassando a barreira dos 50\%. Em comparação com o Tahiti do ASDK 1.1, o Concordia Server precisou de três vezes $(3 \mathrm{x})$ mais poder de processamento para realizar a mesma tarefa e ainda consegui ultrapassar o servidor Gossip que possui uma interface mais rica, gráfica e animada. O agente não teve um desempenho tão bom quanto os da IBM, mas ele obteve um bom resultado, próximo dos 1400 milisegundos em média, também se comportando de uma maneira instável com variações máximas de 400 milisegundos.

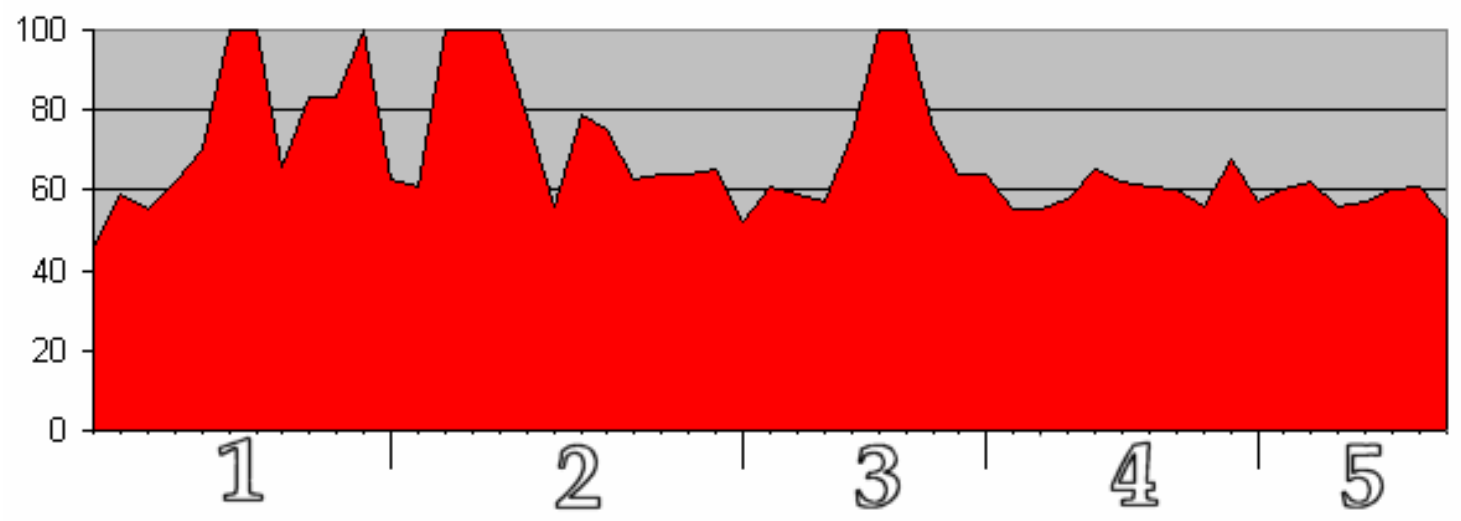

Figura 7.9 - Gráfico de utilização do processador do Concordia Server

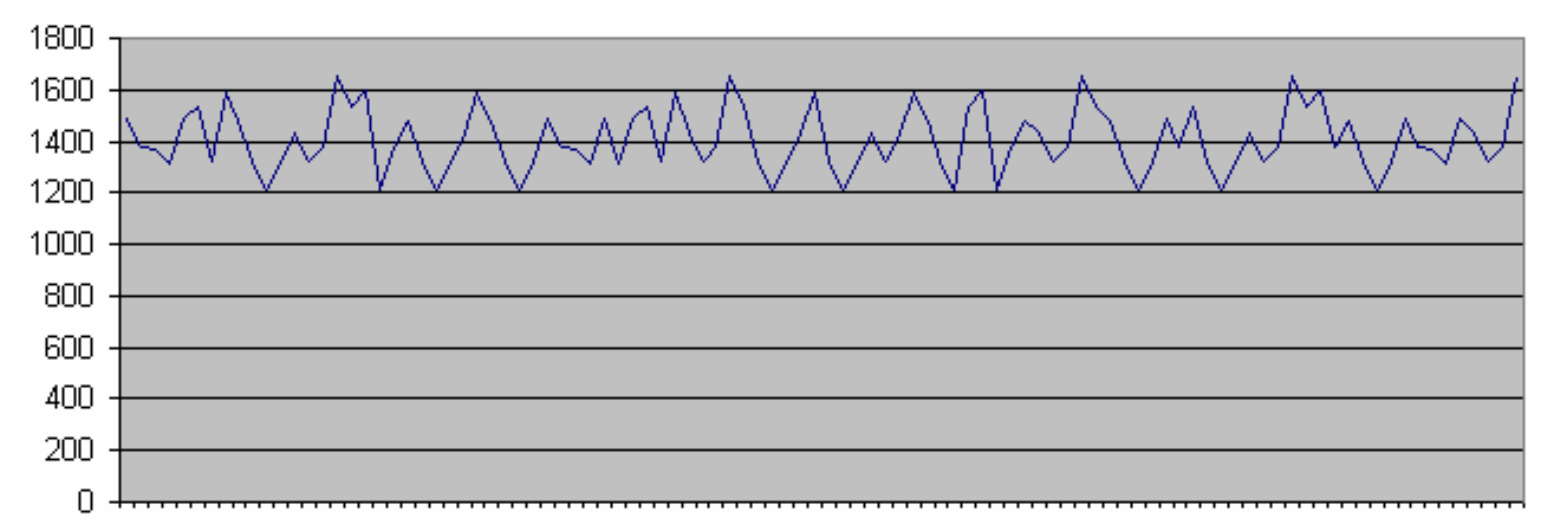

Figura 7.10 -Tempo, em milisegundos, de 100 execuções do agente em Concordia

Eram esperados bons resultados da plataforma Grasshopper, Figura 7.11. De início, o resultado de desempenho do servidor foi bom obtendo $30.21 \%$ de taxa média de 
utilização de processador. Por ser um ambiente onde o gerenciamento e administração são feitos graficamente e por utilizar Java 2, a taxa obtida pode ser considera muito boa. Comparado aos ASDK's, Grasshopper Server precisou apenas de $10 \%$ a mais de poder computacional para realizar a mesma tarefa. A diferença é que gastou bem mais tempo, pois seu agente obteve o pior resultado dos testes, sendo que o tempo médio para realizar a tarefa foi de em média 3600 milisegundos aproximadamente. Isto pode, em partes, ser conseqüência da utilização de Java 2, pois testes mostraram que o desempenho da JVM de Java 2 é pior do que de Java 1 (JOS, 1999).

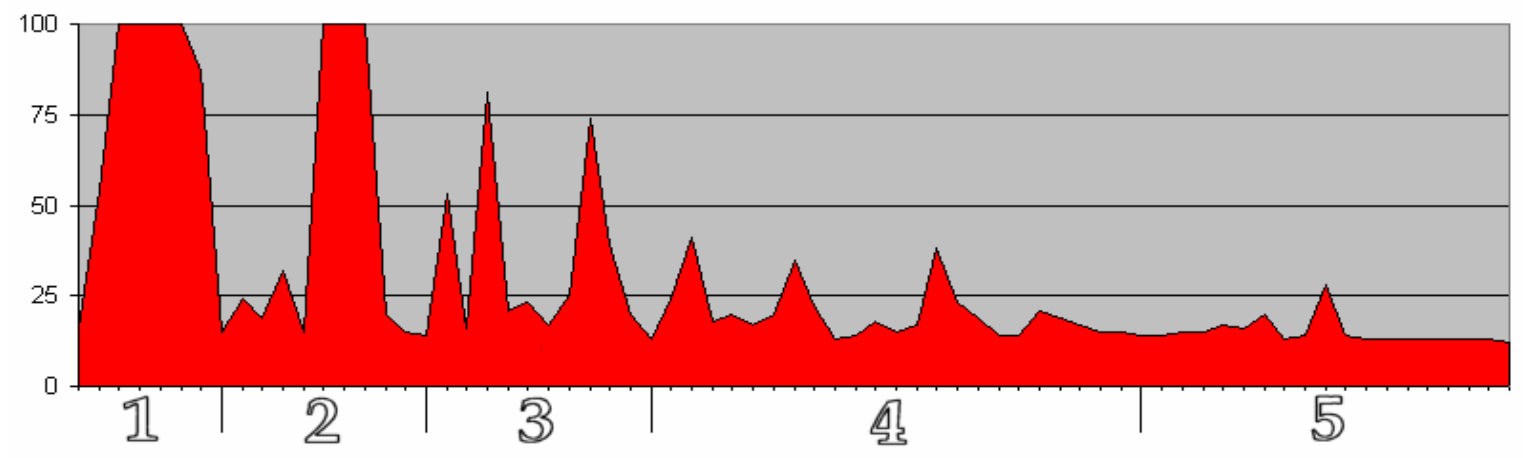

Figura 7.11 - Gráfico de utilização do processador do servidor Grasshopper

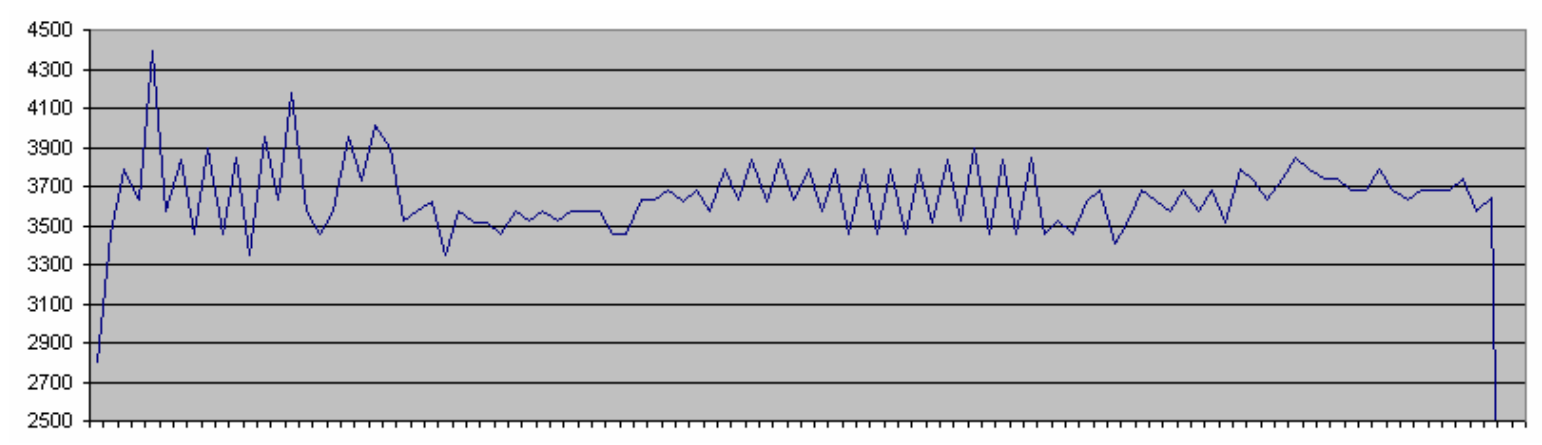

Figura 7.12 - Tempo, em milisegundos, de 100 execuções do agente em Grasshoper

A surpresa foi o resultado do teste de utilização de processador do servidor Gossip, Figura 7.13. Era esperado que os resultados constatassem que o servidor exigiria muito da máquina por tem uma interface pesada. $\mathrm{O}$ resultado mostrou que o ??? não é tão grande. Realmente o que foi esperado foi confirmado. $\mathrm{O}$ agente utilizado para o teste do servidor Gossip foi um agente básico que buscavam informações na web. Por características básicas, o agente Gossip ainda é mais pesado, pois possui uma certa inteligência, conforme apresentado no capítulo 6. Mesmo assim, a tarefa de receber o agente e iniciá-lo para execução, gastou menos processamento do que o 
Concordia. Infelizmente não foi possível apresentar os testes de desempenho do agente, pois a Tryllian não disponibilizou o ADK para download público.

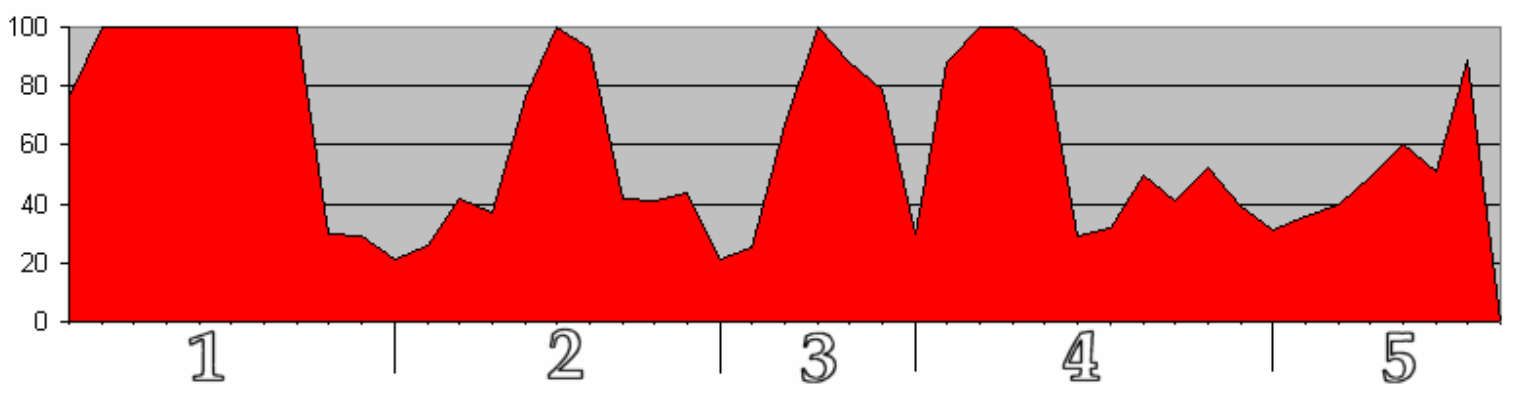

Figura 7.13 - Gráfico de utilização do processador do servidor Gossip

A seguir, tem-se um gráfico geral dos testes de utilização do processador de todas as plataformas. O interessante observar é que o Grasshopper gastou bem mais tempo para realizar as tarefas enquanto o ASDK 1.1 (Tahiti) gastou bem menos, ou seja, quanto maior é o valor de X (tempo em segundos), maior é o tempo gasto para a realização da tarefa. O outro ponto interessante é a área do gráfico do Concordia, área quadriculada, mostrando que foi o servidor que mais gastou poder de processamento, ou seja, quanto maior o Y (Porcentagem de utilização do processador), mais processamento é utilizado.

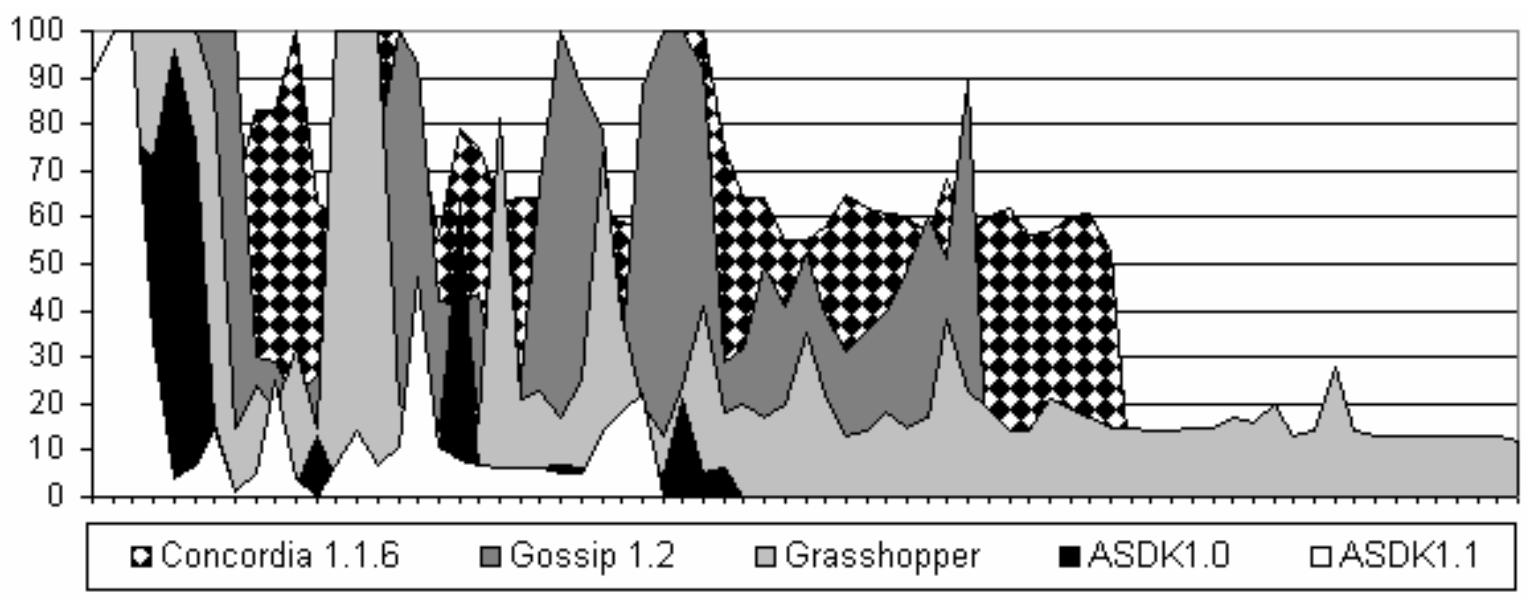

Figura 7.14 - Gráfico geral da taxa de utilização de processamento

Já o próximo gráfico, Figura 7.15, mostra um plano geral dos resultados de testes de desempenho dos agentes de cada plataforma. O ponto interessante é a linha do gráfico do ASDK 1.1, cinza claro, sobreposta pelo gráfico do ASDK 1.0, nota-se a constância dos resultados formando quase uma linha reta, mostrando que a previsão do tempo de resposta do sistema pode ser mais confiável. 


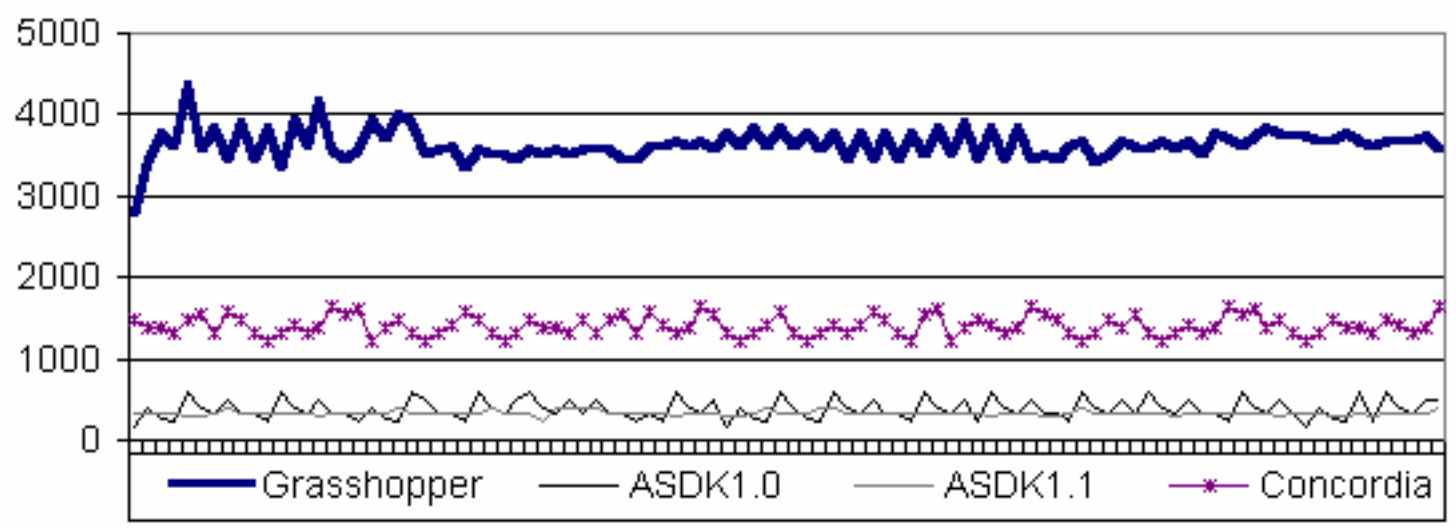

Figura 7.15 - Gráfico geral dos resultados de teste de desempenho dos agentes

\subsection{Análise de Segurança}

Segurança em sistemas baseados em agentes móveis envolve quatro problemas distintos:

1. Segurança na transmissão de agentes;

2. Proteção do servidor contra usuários e agentes maliciosos;

3. Proteção do agente contra o ataque de outros agentes;

4. Proteção de agentes contra ataques de servidores hostis.

A utilização da tecnologia de agentes móveis sem levar em consideração aspectos de segurança pode acarretar em grandes catástrofes, ao mesmo tempo que poderia desmotivar sua utilização.

A finalidade desta seção é apresentar aspectos de segurança que envolve as plataformas apresentadas no Capítulo 6. Testes foram executados com a finalidade de detectar falhas de segurança e também apresentar os serviços que são oferecidos para a proteção dos agentes e servidores. Os serviços analisados são os que foram apresentados no capítulo 2 e que contribuem para a segurança do SDI apresentado no capítulo 5. Na Figura 7.16 tem-se os ambientes e os seus respectivos serviços. 


\begin{tabular}{|l|l|l|l|l|l|}
\hline & ASDK 1.0 & ASDK 1.1 & Concordia & Grasshopper & Gossip \\
\hline $\begin{array}{l}\text { Autenticação de } \\
\text { usuário }\end{array}$ & & & & & \\
\hline $\begin{array}{l}\text { Autenticação de } \\
\text { servidor }\end{array}$ & & & & & \\
\hline $\begin{array}{l}\text { Autenticação de } \\
\text { código }\end{array}$ & & & & & \\
\hline $\begin{array}{l}\text { Autenticaçäo de } \\
\text { agente }\end{array}$ & & & & & \\
\hline $\begin{array}{l}\text { Garantia de } \\
\text { integridade }\end{array}$ & & & & & \\
\hline $\begin{array}{l}\text { Confidencialidade } \\
\text { de informaçöes }\end{array}$ & & & & & \\
\hline Autorizaçäo & & & & & \\
\hline Auditoria & & & & & \\
\hline
\end{tabular}

Figura 7.16 - Figura demonstrativa dos serviços de segurança oferecidos pelas plataformas

Com os resultados apresentados nesta seção, pode-se então apontar quais são os servidores mais seguros para a sua utilização na implementação de sistemas baseados nesta tecnologia.

\subsubsection{ASDK 1.0}

A versão 1.0 do ASDK da IBM oferece poucos serviços e apresenta diversos problemas de segurança. Os problemas são:

- Não há autenticação de usuário. Risco: O problema é que um usuário mal intencionado pode criar e enviar agentes maléficos ao sistema podendo apossar-se de informações sigilosas e até mesmo "derrubar" o sistema. Ataques possíveis: Alteração, Acesso Ilegal, DoS, Retransmissão.

- Não há autenticação de servidor. Risco: O kit oferece bibliotecas para desenvolvimento de servidores, sendo assim, uma pessoa pode criar o seu servidor fazendo-o acessar informações confidenciais dos agentes, altera os dados e enganá-lo. Além disso, o servidor poderá servir de suporte para o usuário atacar outros servidores. Como não há a autenticação a proteção do sistema pode ser difícil. Ataques possíveis: Alteração, Acesso Ilegal, DoS, Retransmissão.

- Não há controle de integridade. Risco: O estado ou as informações do agente pode ser alterado sem que o usuário ou o servidor perceba. Assim, um usuário 
mal intencionado pode alterar resultados a ponto de lhe favorecer. Ataques possíveis: Alteração, Cavalo de Tróia, Disfarce.

- Não garante a confidencialidade das informações. Risco: Os agentes com informações sigilosas podem ser atacados e seus dados capturados. Dependendo das informações contidas nele, o sistema poderá ser comprometido. $\mathrm{O}$ sistema tem que proteger o agente tanto na transmissão quanto no seu armazenamento e em nenhuma das duas situações isto é feito. Ataques possíveis: Alteração, Acesso Ilegal.

- Não oferece recursos para auditoria. Risco: Este serviço é importante para que o administrador possa fazer uma análise do comportamento do sistema para tentar identificar algum problema e até mesmo obter informações necessárias para recuperação do sistema após um crash ou um ataque.

Por outro lado, a versão 1.0 da plataforma da IBM, oferece alguns serviços de segurança na tentativa de minimizar situações de risco. Os serviços são:

- Autenticação de código: Com este serviço, a tentativa é de evitar ataques de agentes que funcionam como cavalo de tróia. Quando o código não é aceito o agente é descartado. O identificador do código é gerado quando o agente é compilado e esta informação é inserida pelo compilador Java.

- Autenticação do agente: Quando um agente é compilado com o kit, além do ID que Java gera para os seus objetos, é também criado um número serial que identifica unicamente o agente. Com isto, a possibilidade que um agente malicioso ataque o sistema é diminuída. Como parte da identificação é considerado o servidor de origem. Os agentes originados do próprio servidor são classificados como confiáveis e os que vêm de fora (de outros servidores) são classificados como não-confiáveis, facilitando a atribuição de permissões e autorização de serviços.

- Serviço de Autorização: Mesmo um agente sendo autêntico, ele pode executar tarefas e acessar informações proibidas. Este serviço pode evitar também que agentes não confiáveis abram portas das máquinas para que uma pessoa possa tentar invadir o sistema. A configuração das permissões é feita no servidor Tahiti. As permissões são atribuídas para um grupo de agentes. 


\subsubsection{ASDK 1.1 Beta 3}

Devido aos diversos problemas de seguranças existentes na versão anteriores, a IBM criou o ASDK 1.1 que possui mais serviços, oferecendo menos riscos aos agentes. Mesmo assim, ainda persistem alguns problemas:

- Confidencialidade das Informações. Risco: Como na versão anterior, ASDK 1.1 não oferece nenhum serviço que sirva para garantir a confidencialidade das informações, tanto nas transmissões quanto no armazenamento dos agentes. Ataques possíveis: Alteração, Acesso Ilegal.

- Não oferece recursos para auditoria. Risco: Também não há suporte a serviço de auditoria na plataforma 1.1 do ASDK. Assim, torna-se necessário uma implementação de servidores e agentes que gerem e capture informações para geração de arquivos de logs ou algo parecido, minimizando o problema.

Isolando-se estes problemas, a plataforma oferece uma variedade de serviços que auxiliam na criação de sistemas mais seguros:

- Autenticação do usuário: O serviço de autenticação de usuário esta presente no servidor e é feito sempre quando o servidor é iniciado. Não há um gerenciamento de usuários, sendo somente um para cada servidor, ou seja, não há possibilidade de configurar profiles para usuários diferentes.

- Autenticação do servidor: Neste Tahiti pode-se configurar quais servidores podem enviar e receber agentes. A identificação do servidor é feita pelo endereço IP e pelo nome do seu usuário (administrador). As informações são armazenadas em um arquivo e toda vez que há uma transmissão de agentes, elas são verificadas. É uma alteração no protocolo de transmissão de agentes (ATP) que não existia na versão anterior. É a única plataforma testada que oferece este serviço.

- Autenticação do código: Da mesma maneira do ASDK 1.0, o código é identificado pelo ID que lhe é atribuído quando é utilizado o compilador Java.

- Autenticação do agente: A classificação de confiável e não-confiável segue a mesma regra. A identificação é pela origem do agente e pelo numero serial gerado quando compilado pelo kit. A autenticação de código e agente é 
importante, pois podem ocorrer casos em que o agente é autêntico, mas pode possuir algum objeto que não é permitido no sistema.

- Garantia de integridade: Sempre antes de iniciar a transmissão, um hash do agente é gerado. Assim, sempre que houver alguma alteração, durante a sua transmissão ou armazenamento, será detectada. O hash é enviado junto com o agente.

- Autorização: Seguindo a linha do antecessor, o servidor Tahiti também permite atribuir permissões para os grupos de agentes. A diferença é que a possibilidade de atribuir permissões a agentes específicos, aumentando a segurança.

\subsubsection{Concordia 1.1.6 Beta}

A plataforma Concordia se comportou bem nos testes e apresentou apenas dois riscos de segurança. Das plataformas avaliadas, o servidor ficou classificado como o terceiro mais seguro das plataformas avaliadas. O que pesou na sua classificação foi a falta de autenticação de código. Os problemas são apresentados a seguir:

- Não há autenticação do servidor. Risco: Diferente do ASKD 1.1 apresentado anteriormente, o servidor Concordia não se autentica ao estabelecer uma conexão com outros servidores. Portanto, a possibilidade de encontrar servidores Concordia maliciosos é grande. Ataques possíveis: Alteração, Acesso Ilegal, DoS, Retransmissão.

- Não há autenticação de códigos. Risco: É a única plataforma onde o código não é assinado e nem autenticado. Isto apresenta um risco de segurança muito alto para sistemas que a utiliza. A possibilidade e a facilidade de criar e executar objetos com a finalidade destrutiva é muito grande, mesmo sendo minimizada pelo serviço de autorização. Ataques possíveis: Acesso Ilegal, Cavalo de Tróia, Disfarce.

Apesar do grande risco apresentado, Concordia apresentou um bom conjunto de serviços que auxiliam na criação de sistemas confiáveis:

- Autenticação do usuário: O ASDK 1.1 é o Concordia são os únicos ambientes que oferecem este serviço. Controlado pelo Security Manager, as informações 
dos usuários são armazenadas em uma base de dados e são cifradas utilizando o algoritmo IDEA (chave simétrica), evitando que sejam descobertas.

- Autenticação do agente: Ao ser compilado, o agente Concordia recebe uma identificação única, contendo um numero serial, versão, mais a identificação do seu usuário. Também gerenciado pelo Security Manager, sempre que ao iniciar a transmissão ou quando um agente acessar um recurso, as informações são comparadas. Agentes não autenticados são descartados imediatamente.

- Garantia de integridade: Também através de hashes os servidores Concordia verificam se as informações ou até o próprio agente foi alterado, assim como no ASDK 1.1 e no Grasshopper. Os hashes são armazenados em arquivos e cifrados com algoritmos de chave simétrica (IDEA, DES).

- Confidencialidade das informações: A transmissão dos agentes é protegida pelo protocolo SSL v3.0, sendo toda a ela cifrada, protegendo as informações e os agentes.

- Autorização: O serviço de autorização é feito pelo Security Manager e sendo ele o responsável em autorizar ou não o acesso a recursos do sistema pelos agentes. Utilizando-se uma base de dados de permissões, a autorização é feita baseada na identificação do agente que é a mesma utilizada para usa autenticação. As informações são utilizadas para a configuração do SecurityManager da máquina virtual Java que executa todo o ambiente. Para ativar o Security Manager do Concordia, deve-se antes da inicialização do servidor, passar sua classe como parâmetro. Toda a configuração das autorizações é feita graficamente ou através do console.

- Auditoria: Concordia possui dois managers responsáveis em monitorar o funcionamento dos agentes e do ambiente, o Event Manager e Persistence Manager. As informações por eles capturadas servem para reativar o sistema quando acontece algum problema e também para se fazer uma auditoria de segurança. Infelizmente estas informações não são cifradas, mas o acesso a elas através dos agentes é protegido pelo serviço de autorização. 


\subsubsection{Grasshopper 2.0}

O projeto do Grasshopper é o mais maduro entre os das plataformas avaliadas. Excluindo as plataformas "betas", Grasshopper é a que oferece maior suporte a segurança, sendo seu servidor classificado como o segundo mais seguro. $\mathrm{O}$ gerenciamento de segurança é gráfico. $\mathrm{O}$ ponto forte desta plataforma é o código aberto. Desenvolvedores podem adaptar e incluir os serviços que lhe interessam na tentativa de aumentar a segurança e confiabilidade do sistema, mas por ser aberto, alguns detalhes importantes de implementação dos serviços de segurança podem ser descobertos. Alguns problemas existentes:

- Não há autenticação do usuário. Risco: Os desenvolvedores do Grasshopper partiram para o principio de que em um sistema, a autenticação do usuário já e feita quando ele se loga na rede. Se ele tem permissão de utilizar o Grasshopper é porque o sistema permite. Mesmo assim, diversos desenvolvedores de sistemas baseados na plataforma reclamaram pedindo a inclusão do serviço de autenticação de usuários, pois há sistemas em que diversos usuários administram suas "agências" e necessariamente as "agências" vizinhas têm que estar protegidas. Assim, há a promessa de que na próxima versão o serviço será incluído. Ataques possíveis: Alteração, Acesso Ilegal, DoS, Retransmissão.

- Não há autenticação do servidor. Risco: Os servidores Grasshopper não se autenticam quando se inicia a transmissão do agente permitindo a criação de sistemas que ataques os agentes quando os recebem. Grasshoper facilita ainda mais este tipo de ataque, pois seu código é aberto e qualquer um pode alteralo de acordo com as suas necessidades. Ataques possíveis: Alteração, Acesso Ilegal, DoS, Retransmissão.

A plataforma Grasshopper prioriza a proteção do servidor contra agentes. Os serviços apresentados confirmam isto:

- Autenticação de código: Utilizando a identificação gerada pelo compilador Java, a camada Segurança presente no Grasshopper, verifica se o código do agente é um código confiável. Além disso, é verificado também, se o código pode ser executado pelo presente agente. 
- Autenticação do agente: Seguindo as implementações das plataformas apresentadas anteriormente, a identificação do agente é feita através de um número serial gerado a partir do ID do código principal do agente, mais as informações do seu criador. Com este número, além de autenticar, é feito também o serviço de autorização.

- Garantia de integridade: Grasshopper utiliza-se de MACs (Message Authentication Codes) para conseguir garantir a integridade do agente e/ou informações. Esses MACs são calculados, sempre quando se inicializa uma transmissão, através de hashes MD5 em conjunto com senhas.

- Confidencialidade das informações: Toda comunicação entre servidores é feita protegida pelo protocolo SSL v3.0, assim como em Concordia. A comunicação entre agentes, mas de servidores diferentes, não possui este suporte, devendo o desenvolvedor implementa-lo. A camada Segurança é responsável pela criptografia do agente.

- Autorização: Baseado no ID do agente, a camada Registro configura o SecurityManager da máquina virtual Java para determinar quais recursos o agente e seus códigos podem acessar. Diferente do Concordia, a camada Registro já vem como padrão no Grasshopper, não necessitando a sua instalação.

- Auditoria: O suporte a auditoria está presente no servidor e é feito por duas camadas, Registro e Persistência. A camada de Registro é responsável pelo monitoramento da interação interagentes. Já a camada de Persistência, monitora as interações dos agentes com o servidor.

\subsubsection{Gossip}

Gossip possui o DataGuard que protege os agentes e tenta garantir uma execução segura e operações confiáveis. Com o DataGuard ativado, nenhum agente consegue obter informações privadas de outros agentes sem uma permissão devida. É o único que não oferece um serviço de autorização e como o ASDK 1.0, também não possui garantia de integridade. Problemas encontrados:

- Não autentica usuário. Risco: Na verdade o usuário é identificado através de uma assinatura digital, mas ela é utilizada somente para acessar as informações do agente. Para utilizar o servidor e o sistema, nenhum tipo de 
verificação é feito. Além disso, a assinatura digital é gerada sempre que um usuário inicia um agente e lhe delega tarefas. Assim, somente é garantido que as informações do agente serão acessadas somente pelo usuário que o ativou. Ataques possíveis: Alteração, Acesso Ilegal, DoS, Retransmissão.

- Não autentica servidor. Risco: Os servidores não possuem nenhum tipo de identificação que determina se ele é confiável ou não. Assim, as informações dos agentes estão sofrendo o risco de serem capturadas. Ataques possíveis: Alteração, Acesso Ilegal, DoS, Retransmissão.

- Não garante a integridade. Risco: Qualquer alteração feita durante a transmissão ou durante a execução ou quando armazenado, não é detectada. Pelo menos, durante a transmissão, o agente poderá estar protegido devido à utilização de SSL nas comunicações. Ataques possíveis: Alteração, Cavalo de Tróia, Disfarce.

- Não possui serviço de autorização. Risco: Qualquer agente pode acessar qualquer recurso oferecido pelo servidor. Não são feitos nenhum controle e gerenciamento de permissões de acesso. Para isto, o administrador tem que manualmente configurar o SecurityManager sempre que um agente for executado. Ataques possíveis: Alteração, Cavalo de Tróia, Acesso ilegal.

- Não oferece suporte para auditoria. Risco: Por não oferecer nenhum suporte para auditoria, o sistema poderá sofre um ataque e reverter o processo será uma tarefa mais demorada e complicada, além de dificultar bastante a identificação da falha utilizada para o ataque e até mesmo o próprio atacante.

Gossip possui serviços de proteção para os agentes e para as informações neles contidas. Aliás, se não oferecesse autenticação de código, os servidores Gossip não teriam nenhum tipo de proteção:

- Autenticação de código: Os códigos dos agentes Gossip são assinados utilizando o algoritmo de chave assimétrica DSA (Digital Signature Algorithm). Os servidores rejeitam qualquer agente que não possuir uma assinatura digital válida.

- Autenticação de agente: Assim como na autenticação dos códigos do agente, a autenticação dos agentes também é feita pela assinatura digital geral através do algoritmo DSA. Qualquer agente que não tiver uma assinatura compatível 
com a base de dados, ele será automaticamente considerado falso e descartado.

- Confidencialidade de informações: A transmissão dos agentes é feita através de conexões SSL v3.0, evitando que o agente e suas informações sejam capturadas durante a sua migração.

\subsection{Escolha da plataforma}

O objetivo deste trabalho é avaliar plataformas de desenvolvimento e hospedagem de agentes móveis também indicar qual delas se encaixa melhor nos requisitos de segurança e desempenho do sistema de deteç̧ão de intrusão em desenvolvimento no ICMC.

Analisando os resultados pode-se observar o seguinte:

- Agentes utilizando ASDK 1.1 são mais rápidos;

- Tahiti do ASDK 1.1 exige menos do processador;

- Sistemas implementados utilizando o ASDK 1.1 podem ficar menos vulneráveis aos ataques.

Durante os testes, quando foi necessário compreender o funcionamento de cada plataforma, foram observados alguns pontos:

- A plataforma Grasshopper possui uma documentação mais completa;

- O agente Grasshopper é mais fácil para programar e entender, portanto melhor para desenvolvimento;

- O servidor Concordia foi o mais complicado para trabalhar;

- O projeto da IKV++, Grasshopper, está num estágio bem mais avançado do que os concorrentes apresentados. A tarefa de administração e gerenciamento é mais fácil e sua interface é bem intuitiva. O suporte oferecido no site é muito bom.

- A lista de discussão do ASDK 1.0 foi decisiva na implementação do SDI.

- O ASDK 1.1 é o mais seguro e o mais rápido.

- Por ser aberto, o Grasshopper pode ser adaptado para as necessidades tornando-se um servidor mais flexível. 
Para o SDI, o importante para a escolha de uma plataforma é verificar se ela apresenta soluções para os problemas de segurança apresentados no Capítulo 5. Em seguida o desempenho do servidor e do agente influencia bastante na decisão. Com isto a conclusão tirada é que a plataforma ASDK 1.1 foi a que mais se encaixou nos moldes do sistema. Ela possui a maioria dos serviços necessários para um SDI seguro e não exige muito da maquina no qual ela está instalada. Além disso, seus agentes apresentaram um desempenho superior aos das outras plataformas avaliadas.

Por outro lado, para um sistema mais complexo como Comércio Eletrônico, onde as tarefas de gerenciamento e administração são importantes, o ASDK não é muito útil. A plataforma que mais se encaixou nestes aspectos foi a Grasshopper. Não só no gerenciamento e administração, como no suporte e na documentação também.

A seguir, um tabela comparativa com as características de cada plataforma:

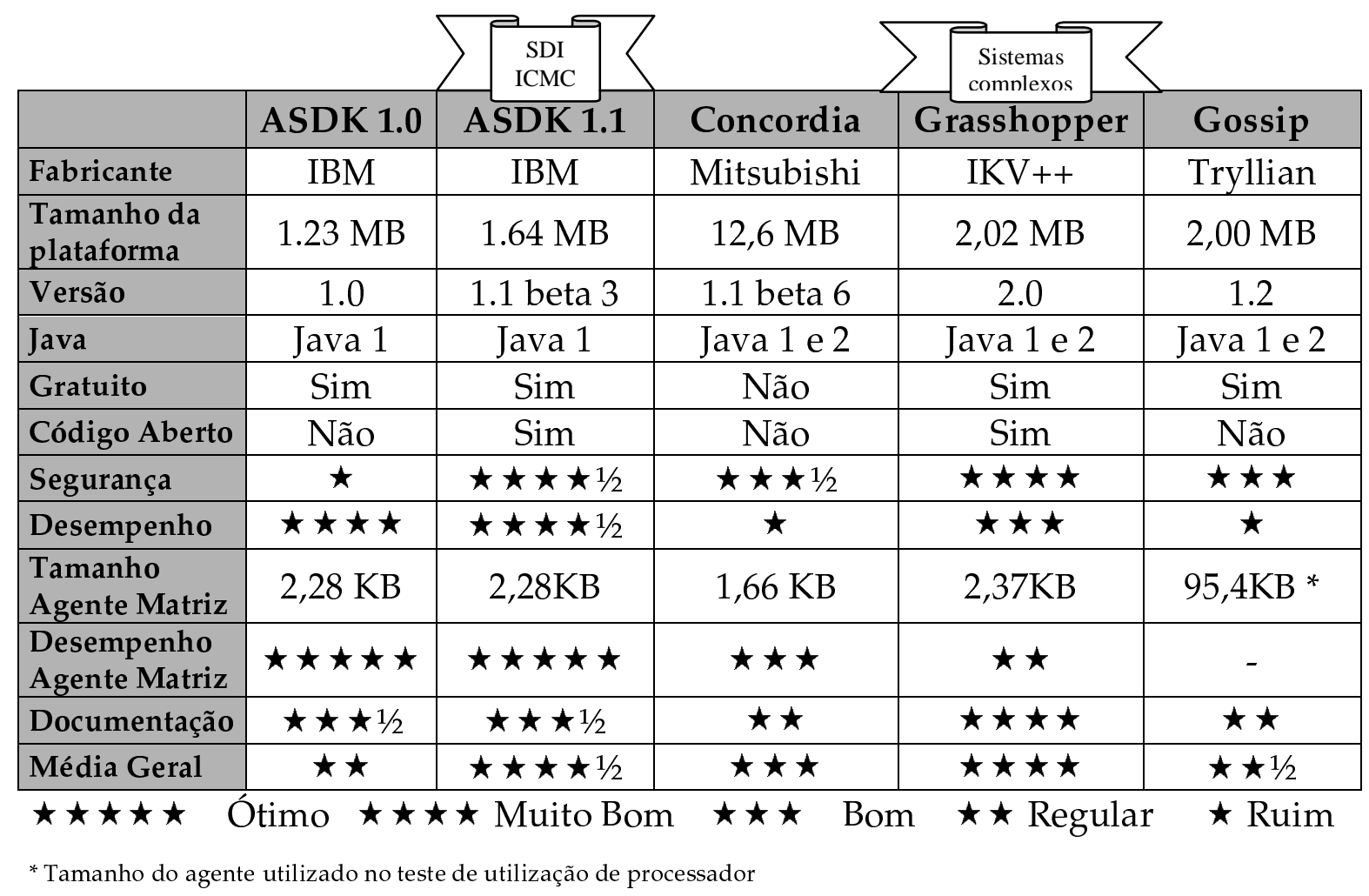

A tabela acima indica as duas plataformas que foram escolhidas, ASDK 1.1 (para o SDI do ICMC) e Grasshopper (para aplicações complexas), como as mais indicadas para implementação de sistemas baseados em agentes móveis. Na classificação, ASDK 1.1 foi considerado o melhor em segurança, desempenho, seguido pelo 
Grasshopper e Concodia. Em documentação o destaque foi para o Grasshopper, seguido pelas plataformas da IBM. Na média geral, o melhor foi o ASDK 1.1. 


\section{Conclusões}

O objetivo desta dissertação foi avaliar plataformas de agentes móveis, onde testes de segurança e desempenho foram executados para obter informações que foram utilizadas para fazer uma análise comparativa para encontrar um ambiente que mais se encaixa nas necessidades do Sistema de Deteç̧ão de Intrusão do ICMC. As informações obtidas nos testes serviram para classificar os ambientes quanto à segurança e quando ao desempenho.

O ASDK 1.1 foi a escolha final. O importante agora é utilizá-lo para a implementação do SDI e dos trabalhos a ele relacionados. Não se pode, também, esquecer de observar a plataforma Grasshopper. Seu projeto é maduro e seu desenvolvimento está sendo contínuo. Outra que pode melhorar seus resultados é a plataforma Concordia. Somente durante a pesquisa de plataformas existentes (fevereiro, março, abril), foram lançadas 3 versões, mas quando foram iniciados os testes deste trabalho, nenhuma outra versão havia sido apresentada, diferente do Grasshopper, cuja versão para Windows CE (Pocket PC) já foi lançada e espera-se uma versão para PalmOS (Palm, Visor, Handsprind) ainda no ano de 2001.

Outros trabalhos em andamento como Especificação e Implementação de Agentes Móveis em um Sistema de Detecção de Intrusão (Milagres, 2001) e Agentes Móveis e Sistemas de Gerenciamento SNMP (Brandão, 2001) utilizarão a plataforma definida no desenvolvimento dos seus agentes.

O que se pode observar no momento atual é que a tecnologia de agentes móveis ainda não é muito utilizada no contexto comercial. Isto se deve ao fator segurança, pois, mesmo havendo algumas plataformas oferecendo algum tipo de suporte, não foi despertada a confiança das empresas para que elas utilizem a tecnologia na implementação dos seus sistemas. $\mathrm{O}$ interesse de grandes empresas vem crescendo e está permitindo que a tecnologia evolua de uma maneira mais rápida, podendo em breve tornar-se mais um padrão para desenvolvimento de sistemas distribuídos. 


\subsection{Trabalhos Futuros}

Definido a plataforma, o próximo passo agora será portar a implementação existente em ASDK 1.0 para a plataforma ASDK 1.1. A codificação dos agentes não deverá ser muito alterada. O que também deverá ser feito durante o porting é configuração dos serviços de segurança dos servidores tornando o sistema menos susceptível a ataques.

Um ponto que também pode ser discutido em outros trabalhos é a adaptação da plataforma ASDK 1.1 ou da plataforma Grasshopper, na tentativa de torná-las, mais rápidas e seguras. Isto é possível, pois, atualmente, ambas possuem código fonte aberto e livre para alterações. Desta maneira, a possibilidade de se conseguir um ambiente que siga com exatidão as especificações encontradas nos trabalhos de Reami (Reami, 1998) e Bernardes (Bernardes, 1999) é maior, podendo tornar o SDI mais eficiente. 


\section{Referências Bibliográficas}

(Ambrósio et al, 2000)

(Bernardes \& Moreira, 2000a)
AMBRÓSIO, D.R., PEREIRA FILHO, S.F.P., MOREIRA, E.S. \& BERNARDES, M.C. Algoritmos Inteligentes Para Busca de Padrões na Detecção de Intrusão. Anais do II Simpósio de Segurança em Informática. ITA/CTA. São José dos Campos, outubro de 2000.

BERNARDES, M.C \& MOREIRA, E. S. A Proposal for Intrusion Detection System Based on Mobile Agents. Proceedings of Fifth Int Symposium on Parallel and Distributed Engineering, eds Nixon and Ritchie, pub IEEE CS Press, june/2000.

(Bernardes \& Moreira, 2000b)

BERNARDES, M.C.\& MOREIRA, E. S. An Architecture for an Intrusion Detection System Based on Mobile Agents. I Simposion Internacional de Sistemas Distribuidos Avanzados - SISDA'2000, Guadalajara, Jalisco, México, março 2000. Trabalho apresentado e publicado nos anais do evento. ISBN: 970.692.045-5.

(Bernardes, 1999)

(Brandão, 2001)

BRANDAO, A.J. Agentes Móveis e Sistemas de Gerenciamento SNMP. Relatório (FAPESP). Instituto de Ciências Matemáticas e de Computação, Universidade de São Paulo, São Carlos, janeiro 2001.

BUENO, F.S. Minidicionário da Lingua Portuguesa Silveira Bueno. $2^{a}$ edição. Editora Lisa, 1987.

CANSIAN, A. M. Desenvolvimento de um sistema adaptativo de detecção de intrusos em redes de computadores. São Carlos, 1997. 153p. Tese (Doutorado) - Instituto de Física de São Carlos, Universidade de São Paulo.

(Cornell \& Hostmann, 1997) CORNELL, G \& HOSTMANN, C. S. Core Java. Makron Books, São Paulo, 1997. 
(CROSBIE \& SPAFFORD 1995a) CROSBIE, M.; SPAFFORD, E.H. Defending a Computer System using Autonomous Agents. Department of Computer Sciences, Purdue University, 1995. (Relatório Técnico CSD-TR-95-022; Coast TR 95-02). Disponível on-line em: http:/ / www.cs.purdue.edu/ homes/spaf/tech-reps/9522.ps. Visitado em 15/01/1999.

(CROSBIE \& SPAFFORD 1995b) CROSBIE, M; SPAFFORD, E.H. Active Defense of a Computer System using Autonomous Agents. Department of Computer Sciences, Purdue University, 1995. (Relatório Técnico CSD-TR-95008). Disponível on-line em: http://www.cs. purdue.edu/homes/spaf/tech-reps/9508.ps. Visitado em 15/01/1999.

(Chess et all, 1995)

CHESS, David; HARRISON, Colin; KERSHENBAUM, Aaron. Mobile Agents: Are They a Good Idea? IBM Research Report. Disponível on-line em: http:/ / www.research.ibm.com/iagentes/paps/mobi le-idea.ps. Visitado em 15/01/1999.

(Figueiredo, 2000)

FIGUEIREDO, T.C \& SANTANA, M.J. Interface AMIGOMPI: uma abordagem flexível e dinâmica para escalonamento de processos. Dissertação (Mestrado). Instituto de Ciências Matemáticas e de Computação, Universidade de São Paulo, São Carlos, outubro 2000.

(Franklin \& Graesser, 1996)

FRANKLIN, S.; GRAESSER, A. Is It An Agent, or Just a Program? A Taxonomy for Autonomous Agents. In: Proceedings of the Third International Workshop on Agent Theories, Architectures, and Languages. Springer-Verlag. 1996. Disponível on-line em: http:/ / www.msci.memphis.edu/ $\sim$ franklin/AgentProg.html. Visitado em 05/12/1998.

(IBM, 1998)

IBM. Aglets Software Development Kit. Disponível on-line em http://www.trl.ibm.co.jp/aglets. Visitado em 10/11/1999.

(IKS, 1999)

IKS. Agentx Site. Disponível on-line em: http://www.iks.com. Visitado em 12/02/2000.

(IKV, 1999a)

IKV++, Grasshopper Site. Disponível on-line em http://www.ikv.de/products/grasshopper. Visitado em $13 / 02 / 2000$ 
(IKV, 1999b)

(Jamsa et al, 1999)

(JOS, 1999)

(Linden, 1997)

(Milagres, 2001)

(Mitsubishi, 1997)

(Oyamada \& Ito, 1998)

(Radtke et al, 1999)

(Reami, 1998)

(Rodriguez, 1998)
IKV++, Grasshopper The Agent Platform (Technical Overview). Disponível on-line em http: / / www.ikv.de/ products/grasshopper. 1999. Visitado em 29/11/1999.

JAMSA, K.; LALANI, S.; WEAKLEU, S. Programando para World Wide Web, Makron Books, São Paulo, 1999.

JAVA OPERATING SYSTEMS. A Free Java Based Operating System. Disponível on-line em: http:/ / www.jos.org. Visitado em 29/03/2001.

LINDEN, P. Just Java. Makron Books, São Paulo, 1997.

MILAGRES, F.G. Especificação e Implementação de Agentes Móveis em um Sistema de Detecção de Intrusão. Relatório (FAPESP). Instituto de Ciências Matemáticas e de Computação, Universidade de São Paulo, São Carlos, janeiro 2001.

MITSUBISHI Eletric Information Center. Concordia - Java mobile Agent Technology. Disponível on-line em http:/ / www.meitca.com/HSL/Projects / condordia, visitado em 11/11/1999.

OYAMADA, M.S. \& ITO, S.A. Aglets: Agentes Móveis em Java. Universidade do Rio Grande do Sul. Disponível on-line em www.inf.ufrgs.br/procpar/disc/cmp134/ trabs/T2/981/Aglets/aglets.html. 1998.

RADTKE, P.V.W., KAESTNERC.A.A., SCALABRIN, E.E. Uma Proposta para a Interação entre Agentes Móveis na Internet. Pontifícia Universidade Católica do Paraná, 1999.

REAMI, E. R \& MOREIRA, E. S. Especificação $e$ Prototipagem de um Ambiente de Gerenciamento de Segurança Apoiado por Agentes Móveis. São Carlos, 1998, Dissertação (Mestrado) - Instituto de Ciências Matemáticas de Computação de São Carlos, Universidade de São Paulo.

RODRIGUEZ, E. J. Uma Modelagem para Comércio Eletrônico usando Corba e Agentes Móveis. Dissertação (Mestrado). Instituto de Computação. Universidade Estadual de Campinas. Campinas, 1998. 
(Rubinstein \& Duarte, 1999) RUBISTEIN, M.G. \& DUARTE, O.C.M.B. Análise da Eficiência de Agentes Móveis no Genrenciamento de Redes. Universidade Fereral do Rio de Janeiro. 1999.

(Sun, 1996)

SUN Networks. The Java ${ }^{\mathrm{TM}}$ Language. http://java.sun.com/docs/overviews/java/javaoverview-1.html. 1993. Visitada em 19/02/2000.

(Tryllian, 1999)

TRYLLIAN, B.V. Tryllian White Paper. http:/ / www.tryllian.com/tryllian-white-paper.pdf, 1999. Visitada em 12/11/1999

(Zamboni et al, 1998)

ZAMBONI, Diego; BALASUBRAMANIYAN, Jai; GARCIA-FERNANDES, Jose Omar and SPAFFORD, E. H.; Department of Computer Sciences, Purdue University; Coast TR 98-05; 1998. Disponível on-line em:http://www.cerias.purdue.edu/coast/projects/a afid.html, visitado em13/01/1999. 